\title{
MÉTODOS GEOESTATÍSTICOS NO ESTUDO DA VARIABILIDADE ESPACIAL DE PARÂMETROS DO SOLO
}

\author{
PAULO JUSTINIANO RIBEIRO JUNIOR \\ Engenheiro Agrônomo
}

Orientador: Prof. Dr. Klaus Reichardt

Dissertação apresentada à Escola Superior de Agricultura "Luiz de Queiroz", da Universidade de São Paulo, para a obtenção do título de Mestre em Agronomia, Área de Concentração: Estatística e Experimentação Agronômica.

P IR A C I C A B A

Estado de São Paulo - Brasil

Janeiro- 1995 
Ficha catalografica preparada pela Seçă de Livros da

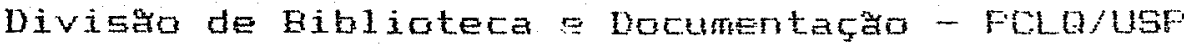

Ribeiro Junior, Faulo Juetiniano

F484m Métodos geoestatisticos no estudo da variabilidade espacial de parametros do 5010 . Firacicaba, 1975. 99p. ilus.

Diss- (Mestre) - ESALQ

Eibliografia.

1. Geoestatistica 2. Golo - Fisica J. Solo-Varia bilidade Espacial - Fetodo estatistico 1 . Escala Stpe rior de Agricultura Luiz de Mueiroz, Firacicaba

CDD 631.43 


\section{MÉTODOS GEOESTATÍSTICOS NO ESTUDO DA VARIABILIDADE ESPACIAL DE PARÂMETROS DO SOLO}

Paulo Justiniano Ribeiro Junior

Aprovada em: 03.03.1995

Comissão Julgadora:

Prof. Dr. Klaus Reichardt ESALQ/USP

Prof. Dr. Sérgio Oliveira Moraes

ESALQ/USP

Prof. Dr. Cássio Roberto de Melo Godoi

ESALQ/USP

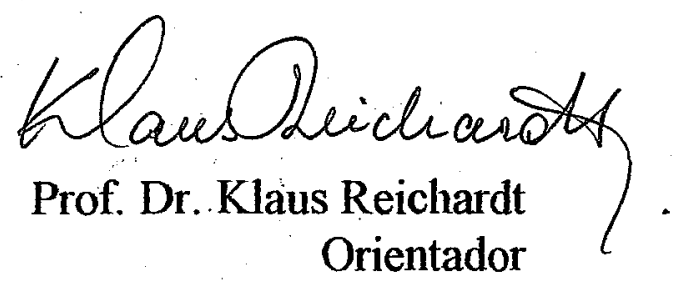

Orientador 
ii.

A meus pais,

Cláudia e Paulo,

Dedico 
iii.

\section{AGRADECIMENTOS}

Ao Prof. Dr. Klaus Reichardt pelo despertar para o tema e pela confiança depositada;

À Prof . Ms. Maria Izalina Ferreira Alves pelo incentivo e amizade;

Ao Prof. Dr. Sérgio Oliveira Moraes pelas proveitosas discussões;

À Rosa Maria Alves pelo constante apoio;

Ao mestre, Prof. Dr. Luiz Henrique Aquino, pelos exemplos de dedicação e motivação;

Ao Prof. Ms. Marcelo Oliveira por mostrar os caminhos nos primeiros passos do estudo do tema;

A Prof. Jorge Festa pelo auxílio no uso dos recursos de informática;

Ao Prof. Dr. Luiz Gonzaga Caleffe pelas valiosas sugestões;

Ao Prof. Dr. Anselmo Chaves Neto pelos ensinamentos;

Ao colega de turma, Prof. Paulo Afonso Bracarense Costa, pelas estimulantes conversas ao longo do curso de mestrado;

A Izabela, Tiago, Tatiana e Liliana pela acolhida em Piracicaba;

Ao Departamento de Matemática e Estatística da ESALQ/USP pela formação que proporcionou;

Ao CNPq pela bolsa concedida;

Ao Departamento de Estatística da UFPR pelas oportunidades;

A todos que, de alguma forma, contribuiram com este trabalho. 


\section{SUMÁRIO}

Página

RESUMO ............................................................................... vi

SUMMARY ............................................................................. viii

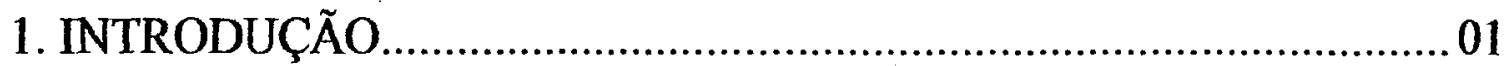

2. REVISÃO DE LITERATURA .................................................. 04

2.1. Geoestatística: Origens e áreas de aplicação..............................04

2.2. O papel da Estatística.............................................................. 05

2.3. Variabilidade espacial ........................................................... 08

2.4. Abordagem probabilística ................................................. 09

2.5. Análise exploratória de dados .......................................... 13

2.6. Análise estrutural: considerações sobre variogramas ................... 15

2.7. Modelagem e ajuste de semivariogramas............................... 21

2.8. Krigagem ........................................................................ 30

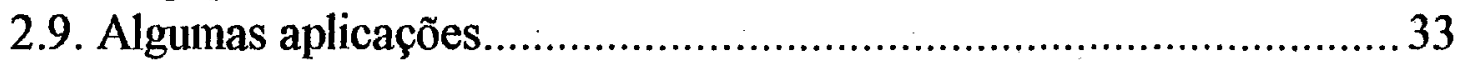

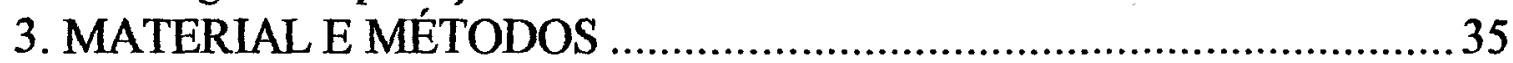

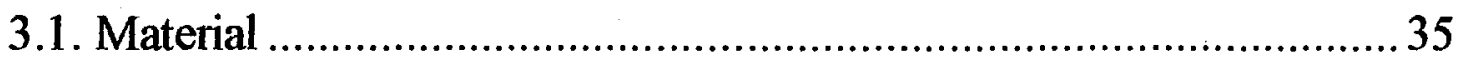

3.1.1. Dados de Densidade do Solo......................................... 35

3.1.2. Dados de Umidade do Solo ........................................... 36

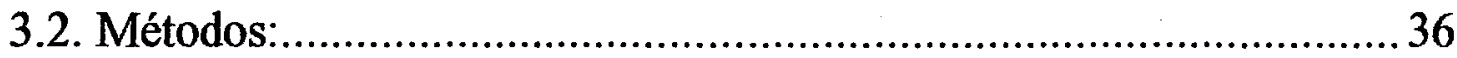

3.2.1. O tipo de problema abordado e a natureza dos dados ......... 37

3.2.2. Modelagem probabilística e estacionaridade....................... 38

3.2.3. Técnicas descritivas e exploratórias................................ 41

3.2.3.1. Análise descritiva geral...................................4 42

3.2.3.2. Análise descritiva espacial ................................. 43

3.2.3.3. Dados atípicos gerais e espaciais ........................... 44

3.2.4. A falta de estacionaridade ........................................... 45

3.2.5. Estrutura de variabilidade: a opção pelos variogramas ......... 47

3.2.6. Análise exploratória para diferentes "lags" ......................... 49

3.2.7. Modelagem da estrutura de variabilidade............................ 49

3.2.8. Isotropia e Anisotropia ................................................52

3.2.9. Validação Cruzada ......................................................... 53

3.2.10. Interpolação: o Preditor de Krigagem .............................. 54 
3.2.11. Mapas e superficies que descrevem o fenômeno...................62

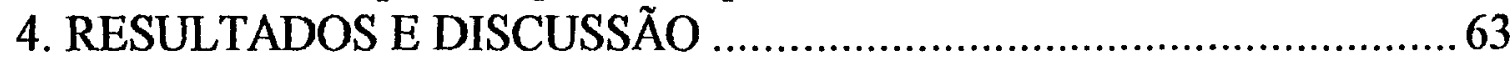

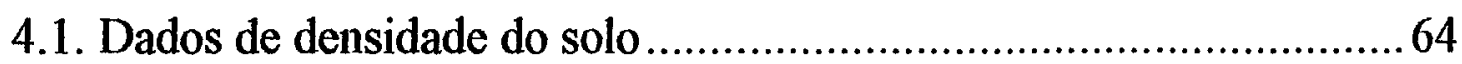

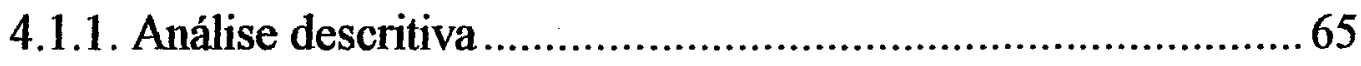

4.1.2. Variograma .................................................................. 70

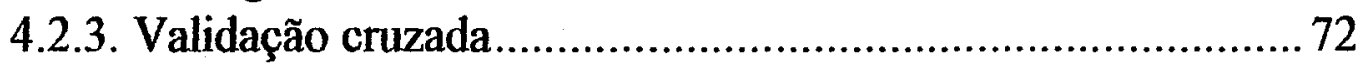

4.2.4. Krigagem e mapa de isolinhas .............................................. 75

4.2. Dados de umidade do solo ........................................................ 76

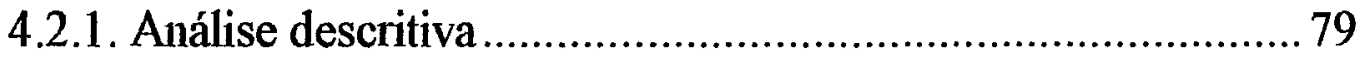

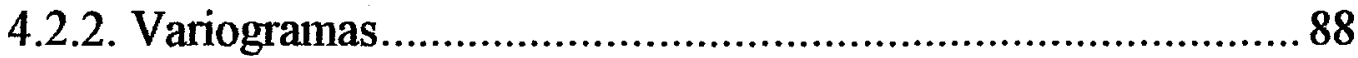

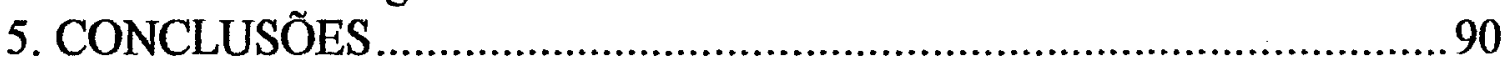

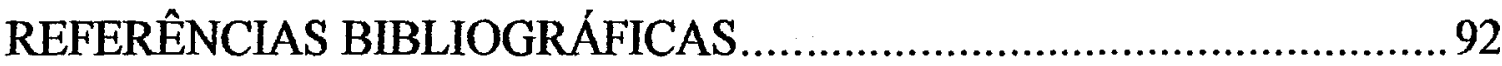


vi.

\section{MÉTODOS GEOESTATÍSTICOS NO ESTUDO DA VARIABILIDADE ESPACIAL DE PARÂMETROS DO SOLO}

Autor: Paulo Justiniano Ribeiro Junior Orientador: Prof. Dr. Klaus Reichardt

\section{RESUMO}

A variabilidade espacial é característica de muitos fenômenos naturais e, entre eles, incluem-se os atributos físicos do solo. Embora o conhecimento da existência deste tipo de variabilidade não seja recente, o seu tratamento estatístico mais criterioso vem sendo desenvolvido e utilizado com maior freqüência e abrangência apenas nos últimos anos. Isto pode ser atribuído à crescente necessidade de conhecimento mais detalhado da estrutura de dependência espacial em situações onde a suposição de independência, comum a vários procedimentos estatísticos, não explica satisfatoriamente a manifestação do atributo em estudo. $O$ desenvolvimento $\mathrm{e}$ disponibilidade de literatura sobre o tema, bem como de recursos computacionais capazes de tratar de forma ágil tais informações, ampliou as possibilidades de tratamento de dados. Além disto, o desenvolvimento de técnicas e instrumentos para medida de atributos diversos, seja no ambiente natural ou em laboratório, permite obter a quantidade de dados exigida por estudos desta natureza.

Dentro da modelagem estocástica para tais problemas, situase um conjunto de técnicas ao qual convencionou-se chamar de Geoestatística. Inicialmente organizada, desenvolvida e voltada para problemas de mineração, foi no decorrer dos últimos anos reconhecida por profissionais das mais diversas áreas como um valioso instrumento para análise de dados espacialmente distribuídos. As ciências do solo passaram então a se valer com frequiência dos recursos da Geoestatística. Porém, a 
compreensão e divulgação destas idéias ainda não se fazem presentes de forma satisfatória nos estudos da área.

O desenvolvimento das técnicas não chegou ainda a termo, nem tampouco há consenso definitivo quanto às estratégias mais adequadas de análise. Portanto, muito há ainda a ser desenvolvido, mas é importante que se dê a devida atenção à aplicação e divulgação destas idéias, tornandoas acessíveis aos profissionais que podem utilizá-la.

O presente trabalho apresenta e discute alguns dos conceitos e recursos da Geoestatística. Para isto, mostra o uso das técnicas na análise de dois conjuntos de dados reais, referentes a densidade e umidade de solos. É dada especial atenção à análise descritiva, considerada passo fundamental de um estudo. Além disto, resenha e comenta algumas estratégias de análise que vêm sendo utilizadas por diversos autores.

Os resultados mostram a capacidade da Geoestatística em ajudar na compreensão dos fenômenos e de sua estrutura de dependência espacial. As técnicas de análise estatística usuais podem passar a absorver informações da variabilidade espacial a fim de aprimorar suas estimativas. Porém não se pode perder de vista as restrições impostas e as hipóteses assumidas, sob o risco de modelagem incompatível com a realidade dos fatos. 
viii.

\title{
GEOSTATISTICAL METHODS IN THE STUDY OF SPATIAL VARIABILITY OF SOIL PARAMETERS
}

\author{
Author: Paulo Justiniano Ribeiro Junior \\ Adviser: Prof. Dr. Klaus Reichardt
}

\section{SUMMARY}

Spatial variability is a characteristic of many natural phenomena which include physical attributes of the soil. Although the existence of this type of variability has been aknowledged for some time, only recently a more accurate statistical handling of this variability has been developed and used. This can be attributed to the increasing need for a more detailed knowledge of the structure of spatial dependency in situations where the assumption of independence, common to various statistical procedures, does not satisfactorily explain the manifestation of the attribute under study. The production and availability of literature about this matter, as well as of computer resources that are able to deal wich such information in a speedy way have broadened the possibilities of data handling. Furthermore, the development of techniques and tools to measure the various attributes, both in the natural environment and in laboratories, makes it possible the gathering of the amount of data that is required by these kinds of study.

Within the stochastic modeling of such problems, there exist a set of techniques wich have been conventionally called Geostatistics, which has initially organized, developed, and aimed at mining problems. In the past few years, Geostatitics has been acknowledge by professionals from all walks of life as an invaluable instrument for the analysis of spatially distributed data. Soil sciences have frequently learned upon Geostatistics for analytical support. However, understanding and dissemination of these concepts by studies from these fields are nevertheless incipient. 
The development of techniques is still under way and there is no general agreement as to the most adequate analytical strategies to use. Therefore, there are still much to developed, but it is important that due attention be given to the applicability and dissemination of these strategies by make them accessible to professionals who might be able to use them.

This study presents and discusses the concepts and resources of Geostatistics. For this purpouse, the use of techniques in the analysis of two sets of actual data, relative to soil density and humidity is presented. Spatial attention is paied to the descriptive analysis in face of its fundamental role in research studies. Furthermore, the study also reviews and comments on some analytical strategies that have been used by various scholars.

The results indicate the capacity of Geostatistics to help understand phenomena and their spatial dependence structure. Currently used techniques of statistical analysis can take into account information on spatial variabilityin order to improve estimates. However, restrictive assumptions and assumed hypotheses should be taken into consideration to avoid the risk of designing a model which is not compatible with actual data. 


\section{INTRODUÇÃo}

Problemas relacionados à mineração motivaram o desenvolvimento e uso de ferramental estatístico que fosse capaz de traduzir a estrutura de variabilidade espacial de um determinado atributo, como por exemplo o teor de um minério dentro de uma região, bem como permitir interpolações que levassem a boas estimativas do teor do minério em pontos não amostrados. Desta forma seria possível construir mapas que exibissem a distribuição do minério na região estudada, fazer estimativas de reservas, ter parâmetros para verificar viabilidade e orientar estratégias de prospecção.

-Inicialmente tais estudos foram desenvolvidos notadamente na África do Sul. Mais tarde na França, em Fountainebleau, o corpo teórico dos métodos estatísticos foi organizado sob a direção de G. Matheron, dando origem à teoria das variáveis regionalizadas, ou, de forma mais sucinta, geoestatística. Foi definida por este autor como "a aplicação do formalismo de funções aleatórias ao reconhecimento e estimação de fenômenos naturais".

Como informações que possuem referencial de posição no espaço não são exclusividade dos problemas de mineração, diversos campos do conhecimento passaram a utilizar tais procedimentos em seus estudos. Hidrologia, ciências do solo, ciências florestais, estudos de poluição, entre outros temas ambientais, são apenas algumas das áreas que viram na geoestatística uma ferramenta adequada para análise de dados. Basicamente, trata-se do entendimento de que informações desta natureza apresentam uma parte estruturada e uma parte aleatória.

É importante assinalar que geoestatística não se refere a um tipo especial, diferente ou alternativo de estatística. $O$ fato é que cada observação é descrita não apenas pelo seu valor, mas também por 
informações de sua posição, expressa por um sistema de coordenadas. Considerando que observações mais próximas geograficamente tendem a ter valores mais similares e que tal fato pode ser avaliado por medidas de associação, fica claro que em geoestatística não se pode trabalhar com a suposição de independência. $\mathrm{O}$ valor da variável em uma localidade pode ser, ao menos parcialmente, predito pelos valores em pontos vizinhos que não são estocasticamente independentes. Portanto, os métodos geoestatísticos consideram a dependência espacial das observações, lançando mão de medidas estatísticas que expressem esta estrutura de dependência tais como covariâncias, correlações e semivariâncias. Por geoestatística, entende-se o uso de um grupo de procedimentos estatísticos aplicáveis a alguns problemas onde os dados são espacialmente referenciados.

Deixar de considerar a correlação espacial não apenas viola pressupostos mas também significa deixar de observar importantes aspectos que determinam a ocorrência do fenômeno estudado.

A análise geoestatística, levando em conta a estrutura de variabilidade espacial, contribui para ampliar a fração explicada da variabilidade dos dados. Além disto, propõe um interpolador com qualidades estatísticas de não-tendenciosidade e variância mínima.

A preocupação com a variabilidade espacial de atributos do solo é expressa em diversos trabalhos de pesquisadores da área. $\mathrm{O}$ conhecimento desta é fundamental para que se possa descrever e compreender o comportamento de determinado atributo do solo. $\mathrm{O}$ mapeamento de tal atributo em uma região e a compreensão de sua estrutura de variabilidade pode auxiliar na definição de estratégias de manejo deste solo.

Este trabalho tem ênfase na aplicação desta teoria em estudos de física de solos, uma vez que os dados que ilustram o uso da metodologia referem-se a valores de umidade e densidade de amostras de solo. Porém, os conceitos são apresentados e discutidos de forma geral, não se restringindo a este tema.

De maneira geral, três objetivos ficam delineados. $O$ primeiro é apresentar alguns fundamentos da teoria geoestatística através da 
descrição de uma estratégia de análise, apresentada de forma a acompanhar os passos de um estudo, o que é feito no ítem métodos (3.2.). O segundo é mostrar a aplicação desta teoria aplicada a um conjunto de dados reais, descritos no item material (3.1.) e discutidos em resultados (item 4.). O terceiro é discutir os diversos tópicos da geoestatística e mostrar abordagens, convergências e divergências de opiniões, além de comentar algumas aplicações que constituem referência sobre o tema, o que é feito na revisão de literatura (item 2.).

As apresentações originais da teoria são bastante complexas e os textos não são de fácil leitura para um leitor sem um embasamento sólido da teoria estatística. Isto gerou uma falsa imagem de dificuldade e inacessibilidade da técnica. Mesmo envolvendo conceitos e se apoiando em formulações que não são triviais para alguém menos familiarizado com o formalismo estatístico, a geoestatística não pode, nem precisa se mostrar como um universo inatingível. Apresentada de forma acessível e cuidadosa, pode de fato cumprir seu papel de instrumento que auxilia a compreensão da realidade. 


\section{REVISÃO DE LITERATURA}

\subsection{Geoestatística: Origens e áreas de aplicação}

A necessidade de obter estimativas quantitativas de propriedades do solo e planejar pesquisas de forma mais econômica tem levado cientistas do solo a buscar métodos cada vez mais racionais e quantitativos (WEBSTER, 1985). A preocupação com a variabilidade espacial de atributos do solo pode ser encontrada já em trabalhos da primeira metade do século (VIEIRA, 1981), porém, apenas recentemente, incorporando a teoria e prática da geoestatística, foi possível descrever a variabilidade de forma satisfatória (McBRATNEY \& WEBSTER, 1986).

Modelos espaciais constituem recente adição à literatura estatística. Geologia, ciências do solo, ciências florestais, astronomia, ou qualquer outra disciplina que trabalhe com dados coletados em diferentes localizações espaciais, precisam desenvolver modelos (não necessariamente estatísticos), que indiquem quando há dependência entre medidas tomadas em diferentes locais (CRESSIE, 1989).

CRESSIE (1991) apresenta um modelo espacial geral (estocástico), que permite tratar de problemas com indexação espacial contínua, em forma reticulada ("lattice") e padrões pontuais. Desta forma os dados espacialmente distribuídos são classificados por este autor como "geostatistical data", "lattice data" e "point patterns", em função da caracterização dos parâmetros do processo estocástico em questão.

Tem surgido na literatura das mais diversas áreas, entre elas as ciências do solo, diversos trabalhos que utilizam geoestatística, bem como 
que comparam suas propostas com outras técnicas. Ressalte-se ainda que a abordagem geoestatística não é totalmente consensual e vem sendo questionada por diversos autores (LASLETT, 1994).

O desenvolvimento das técnicas geoestatísticas foi motivado por estudos referentes à exploração de minas de ouro na África do Sul. Porém, a formalização da teoria se deu na França sendo atribuída a Matheron através de suas publicações na década de 60. Muitos dos textos disponíveis são direcionados para a área de mineração (JOURNEL \& HUIJBREGTS, 1978; CLARK, 1979; GUERRA, 1988; VALENTE, 1982; entre outros). A adaptação para outras áreas, tais como ciências do solo, deve ser feita com cuidado, verificando se as interpretações dos resultados são apropriadas ao contexto (HOROWITZ \& HILLEL, 1983).

\subsection{O papel da Estatística}

A literatura tem tratado com freqüência da relação da Estatistica e seus profissionais com outras áreas do conhecimento. Um dos aspectos abordados é a importância da prática na orientação do desenvolvimento da teoria estatística. BOX (1984) mostra como a aplicação e consideração do contexto científico no qual a estatística é utilizada motivou importantes avanços tais como mínimos quadrados, estimadores' razão, ANOVA, modelos ARIMA e diversos outros. Portanto, a noção de como a abordagem estatística se insere no contexto geral da pesquisa deve estar sempre em mente no desenvolvimento de qualquer trabalho. Segundo o autor, as teorias e métodos estatísticos sofrem uma espécie de seleção natural, na qual sobrevivem apenas aqueles que respondem a questões levantadas por problemas aplicados.

O desenvolvimento de um programa experimental envolve mais que um específico delineamento estatístico apropriado ou uma técnica de análise de dados. Pesquisadores e estatísticos precisam tirar vantagem da combinação de suas habilidades no desenvolvimento da lógica global da experimentação (BISHOP, 1982). Qualquer estudo geoestatístico, ao menos 
idealmente, envolve diferentes áreas de conhecimentos. Por exemplo, em aplicações em mineração a equipe deve ser composta ao menos por um geólogo, um engenheiro de minas, um metalurgista, um economista e um estatístico (CRESSIE, 1985). A estatística e os estatísticos devem participar de todas as fase do processo e não simplesmente propondo uma matriz de pontos experimentais e analisando os resultados. Em muitas aplicações, a seleção do plano formal de testes representa apenas o topo de um típico iceberg (HAHN, 1984). Representar graficamente e sumarizar dados, detectar e admitir a falta de estacionaridade, estimar relações espaciais (usualmente através de semivariogramas e covariogramas), estimar recursos in situ (geralmente pela krigagem) e avaliar reservas recuperáveis são os estágios nos quais o estatístico deve liderar a equipe anteriormente citada (CRESSIE, 1984).

Muitas vezes o pesquisador por algum motivo desenvolve as análises sem uma orientação estatística. Neste caso ele estará se valendo de seus conhecimentos, estudos e experiências passadas. Mas nem sempre o conteúdo teórico de tais pesquisadores é suficiente para solucionar as particularidades de cada trabalho. Isto pode gerar análises incorretas ou parcialmente corretas, o que compromete ou faz com que se deixe de explorar as informações contidas nos dados. GATES (1991) afirma que em seu ponto de vista a única solução é educação, educação e mais educação do usuário final.

Por outro lado, é necessário que os procedimentos da estatística sejam apresentados de forma compreensivel para os profissionais das diversas áreas e não como um universo impenetrável, exceto para alguns poucos iniciados. Neste sentido BOX (1978) ressalta que mais importante que aprender uma série de técnicas é assimilar o pensamento estatístico.

WILD (1994) afirma que, de fato, os estatísticos têm falhado em comunicar qualquer quadro coerente da natureza e âmbito da disciplina. Citando diversos outros autores, $o$ artigo mostra preocupação com a dificuldade de a estatística se afirmar e a necessidade de ser divulgada de forma eficiente. A comunicação é parte essencial do processo investigativo. $O$ estatístico precisa conhecer também a linguagem do cliente e assumir o 
papel de tradutor. As respostas encontradas devem ser expressas na mesma linguagem do problema original ("english in, english out").

SANSA \& ODDONE (1994) defendem que os resultados das análises estatísticas devem ser apresentados de forma integrada ao contexto da pesquisa em questão. Em seu artigo, os autores dão exemplos de formas "não integrada" e "integrada" de apresentação dos resultados. MOORE (1990) lembra que dados nada mais são que números em um determinado contexto.

Segundo WILD (1994), não se pode apresentar um determinado assunto sem que se fale também de suas limitações. As possibilidades geradas pela análise geoestatística trouxeram o interesse, mas também a decepção e/ou a sensação de inacessibilidade a profissionais de diversas áreas.

Todos estes fatos podem ser relacionados com a preocupação em desmistificar a geoestatística, tornando-a mais clara, a exemplo de JOURNEL (1988), que afirma: "Durante muito tempo a geoestatística se apresentou como uma teoria difícil, um pouco esotérica, desenvolvida do outro lado do Atlântico e acessível apenas a pessoas altamente treinadas, ou aqueles afortunados o bastante para ter acesso a algum programa computacional caro e do tipo caixa preta. De fato, a dificuldade é artificial e devida em grande parte à apresentação original da teoria, bastante pesada. Gasta-se tempo, muitas aplicações e alguma humildade para compreender a essência da técnica e aceitá-la em sua simplicidade, ao risco de parecer ordinária. Uma vez que a teoria geoestatística tenha sido desmistificada, pode-se centrar atenção nos verdadeiros problemas que tratam da implementação: como colocar uma idéia simples para funcionar".

O fato de a teoria das variáveis regionalizadas ter sido apresentada com uma notação quase própria e ter sido batizada com um novo nome "geoestatística", acabou por gerar algumas confusões. Muitos autores se referem a "estatística clássica" e a "geoestatística" como se fosse possível fazer tal distinção. Esta divisão carece de fundamentação. A geoestatística é construída a partir de conceitos básicos de estatística, em particular de processos estocásticos (ou funções aleatórias, termo usado na 
literatura francesa e por Matheron). É possível que estes autores estejam se referindo à suposição de que as observações são independentes e igualmente distribuídas, usual de muitos procedimentos, mas que não é feita na geoestatística. Isto faz com que medidas de covariâncias, correlações e semivariâncias assumam papel fundamental na análise. Mas isto definitivamente não separa dois universos distintos. Outra confusão que pode ser provocada pelo termo geoestatística é imaginar que ele se refere a todo o conjunto de métodos estatísticos aplicados a dados geológicos.

Portanto, o que' se entende por geoestatística não é uma nova ou alternativa teoria, mas sim a reunião de conceitos e métodos estatísticos para o estudo da variabilidade espacial de fenômenos, quando as informações coletadas são georeferenciáveis e apresentam dependência espacial.

\subsection{Variabilidade espacial}

Como evidenciado na literatura recente, muitas das propriedades do solo exibem claramente estrutura espacial (HAMLETT et alii, 1986).

Segundo JOURNEL (1988), dados espaciais caracterizamse por:

- Apenas um dado em cada locação.

- Dados em locações diferentes são dependentes. A dependência espacial não é uma inconveniência estatística, mas um verdadeiro beneficio que permite informar sobre locais não amostrados a partir de dados em localizações ao redor do ponto desejado.

CRESSIE (1991) justifica a importância de uma abordagem que leve em consideração a dependência espacial, mostrando os efeitos da autocorrelação espacial em problemas de estimação, predição e delineamentos de experimentos. A deteç̧ão da estrutura de autocorrelação espacial em áreas experimentais pode permitir estimação mais eficiente dos contrastes entre tratamentos. Por outro lado, a não consideração da 
variabilidade espacial pode impedir que diferenças reais sejam levantadas. Preocupações e discussões desta natureza são encontradas em trabalhos como os de GRONDONA e CRESSIE (1991) e Van ES \& Van ES (1993).

LEGENDRE (1993) comenta que quando a autocorrelação se mostra presente nos dados, são possíveis dois enfoques: o primeiro consiste em remover a dependência espacial excluindo amostras ou filtrando a estrutura espacial de alguma forma. A âlternativa é considerar um método de análise estatística que leve em conta a autocorrelação espacial. Esta segunda abordagem é preferível quando tal método é disponível e especialmente em casos em que a estrutura espacial é parte importante do processo em estudo.

A análise estatística deve ser capaz de reconhecer e tratar adequadamente as fontes de variabilidade sob o risco de apresentar resultados dúbios e/ou inconsistentes (LASLETT \& McBRATNEY, 1990). Existe uma forte necessidade da incorporação dos procedimentos geoestatísticos na análise de dados espacialmente distribuídos para produzir inferências e predições espaciais mais poderosas.

\subsection{Abordagem probabilística}

Um estudo de solo envolve três passos essenciais: a configuração da amostragem no campo, o delineamento dos ensaios de laboratório e a seleção de um método apropriado para predizer valores em locais não medidos (LASLETT \& McBRATNEY, 1990). Este trabalho trata de uma abordagem probabilística para as informações geradas pelos dois primeiros passos.

Uma medida é uma quantificação de um atributo de um material sob investigação. $O$ processo de medida produz resultados que servem como parte do embasamento usado pelo experimentador para julgar o atributo investigado (KEMPTÓRNE \& ALLMARAS, 1986).

Para o caso de dados espacialmente distribuídos, a estrutura espacial de propriedades do solo pode ser efetivamente descrita quando vista 
como um processo estocástico espacial tal como descrito por CRESSIE (1991):

$$
\left\{Z(s): s \in D \subset \mathfrak{R}^{d}\right\}
$$

conjunto das variáveis aleatórias $Z$, relacionadas com o atributo em questão, nas localizações $s$ genéricas da região $D$ contida no espaço euclidiano d-dimensional. Para o caso de dados geoestatísticos $D$ é um subconjunto fixo de $\mathfrak{R}^{d}$ e $Z(s)$ é um vetor aleatório nas posições $s \in D$.

Uma descrição estocástica completa dó atributo em estudo seria dada pelo conhecimento da distribuição de probabilidade conjunta de nésima ordem das $n$ variáveis aleatórias medidas nos $n$ pontos do espaço (PAPPOULIS, 1991). Entretanto a estimação desta densidade ou mesmo dos parâmetros associados às distribuições das $n$ variáveis aleatórias não é possível, uma vez que usualmente se dispõe de apenas uma observação de cada uma das variáveis aleatórias.

$O$ entendimento de que o valor em um ponto pode ser ao menos parcialmente predito pelos seus vizinhos implica no fato de que os valores não são estocasticamente independentes uns dos outros (LEGENDRE, 1993). A caracterização da variabilidade espacial pode ser dada por medidas de associação entre as várias variáveis aleatórias que constituem o processo estocástico mencionado anteriormente (JOURNEL \& HUIJBREGTS, 1978).

Uma descrição parcial da estrutura espacial, porém, possível de ser obtida, é dada pela função de covariância que serve como medida da associação espacial entre as observações (ÜNLÜ et alii, 1990). Mas para isto é necessário que certas hipóteses restritivas (no caso, estacionaridade de segunda ordem) sejam assumidas.

Já a krigagem, que muitas vezes é o objetivo principal das análises, pode ser levada a cabo sob pressupostos mais fracos do que a estacionaridade de segunda ordem. De fato, funções aleatórias que possuem incrementos estacionários constituem uma classe útil pois $E\{Z(s)\}$ não precisa ser estimada. Além disto, tal classe contém a dos processos estacionários de segunda ordem (CRESSIE, 1988). Desta forma, uma 
alternativa à covariância é a semivariância. Esta última exige hipóteses menos restritivas (hipótese intrínseca) e portanto aplica-se a um universo maior de situações (ROBINSON, 1990). Sendo válida a hipótese intrínseca, o semivariograma, se conhecido, contém toda a informação sobre a variabilidade espacial do atributo em estudo (McBRATNEY \& WEBSTER, 1986).

É importante notar que a decisão sobre a estacionaridade não é particularidade da geoestatística (ou de séries temporais). Ela se faz presente nas abordagens probabilísticas. Não existe procedimento estatístico que não adote algum tipo de estacionaridade, seja na dimensão espacial, seja na dimensão do tempo (JOURNEL, 1988).

Quando a função aleatória é gaussiana a estacionaridade de segunda ordem e estrita coincidem pois tal processo fica caracterizado pelas suas funções média e covariância (CRESSIE, 1988).

A interpretação básica feita pela estatística é que una observação tem uma parte determinística que pode ser descrita por um modelo e o restante é dito resíduo (ou erro), considerado aleatório. Segundo KEMPTORNE \& ALLMARAS (1986), o resíduo pode ser compreendido como o efeito total de diversas componentes independentes. Quando estas componentes se manifestam de forma aditiva, geram uma distribuição normal. No caso lognormal, se comportam de forma multiplicativa. Os autores discutem os diferentes tipos de erros que ocorrem em um processo de medida, seus efeitos, seu tratamento estatístico e seu uso na avaliação de processos.

Muitos fenômenos naturais geram variáveis que possuem distribuições claramente assimétricas à direita, como por exemplo teores de minerais (CLARK, 1979; JOURNEL \& HUIJBREGTS, 1978) e níveis de poluentes (JOURNEL, 1988). Em situações deste tipo a distribuição lognormal tem sido utilizada.

Os dados obtidos $\left\{z\left(s_{i}\right): i=1,2, \ldots, n\right\}$ podem ser modelados como realização de um processo estocástico parcialmente amostrado $\{z(s): s \in D\}$ que, segundo CRESSIE (1988), pode ser decomposto da seguinte forma: 


$$
Z(s)=\mu(s)+\omega(s)+\eta(s)+\varepsilon(s), \text { onde: }
$$

$\mu(.) \equiv E\{Z()$.$\} é a estrutura determinística, que pode ser$ chamada de variação de larga escala;

$\omega($.$) é um processo intrinsicamente estacionário de média$ zero, contínuo em $\mathrm{L}_{2}$ cujo alcance do variograma (se existir) é maior que $\min \left[\left\|s_{i}-s_{j}\right\|: 1 \leq i<j \leq n\right]$; chamado variação de pequena escala;

$\eta($.$) é um processo intrinsicamente estacionário de média$ zero, independente de $\omega$, cujo alcance do variograma é menor que $\min \left[\left\|s_{i}-s_{j}\right\|: 1 \leq i<j \leq n\right]$; chamado variação de micro escala;

$\varepsilon($.$) é um processo ruído branco de média zero,$ independente de $\omega$ e $\eta$, chamado erro de medida ou ruído. Denota-se $\operatorname{var}[e(s)]=C_{M E}$.

A decomposição apresentada não é obtida de forma única, uma vez que a quantidade de variação atuibuida a cada um dos termos pode variar. Isto significa que diferentes pesquisadores estudando os mesmos dados podem modelar e decompor a variabilidade de forna diferente e até mesmo chegar a diferentes conclusões.

CRESSIE (1986) propõe o refinamento pela mediana para estimar $\mu(s)$. No caso $\mu(.) \equiv c^{t e}$ o processo é dito intrinsecamente estacionário. A variabilidade pode ser decomposta da forma:

$$
\gamma_{z}(h)=\gamma_{\omega}(h)+\gamma_{\eta}(h)+C_{M E}
$$

Onde $C_{M E}$, a variância do erro de medida, não pode ser estimada dado o fato de que apenas uma observação é tomada em cada posição. Ela se soma à variação de microescala (aquela que ocorre em distância menores do que a dimensão da malha de amostragem), que também 
não pode ser detectada, compondo o efeito pepita $C_{0}$. Desta forma a decomposição que pode ser estimada é:

$$
\gamma_{z}(h)=\gamma_{\omega}(h)+C_{0}
$$

\subsection{Análise exploratória de dados}

Uma detalhada análise exploratória tem papel fundamental para o entendimento de como processos geradores definiram o conjunto de dados em análise. Indicando a forma da distribuição, os padrões espaciais e contaminações no conjunto de dados, auxilia na decisão das hipóteses que podem ser assumidas e orienta a escollha da análise a ser desenvolvida.

HAMLETT et alii (1986), chamam atenção ao fato de que a literatura sobre variabilidade espacial contém pouca discussão das análises efetuadas antes da modelagem do semivariograma, que se relacionam com o tipo de hipótese de estacionaridade assumida. Esta é uma decisão crítica e precisa ser tomada com extremo cuidado, uma vez que muitos dos resultados da análise geoestatística serão construídos a partir dela.

A decisão de estacionaridade é fundamental na geoestatística. A análise exploratória pode auxiliar na decisão do tipo de estacionaridade que pode ser assumida. Mapas de contorno e tridimensionais, perfis e estatísticas baseadas em janelas móveis, gráficos de médias vs variâncias são alguns dos instrumentos sugeridos por JOURNEL (1988). Também outros autores sugerem técnicas para tal análise (CRESSIE, 1991; ISAAKS \& SRISVASTAVA, 1989; SAMPER \& RAMIREZ, 1990). É interessante notar que as técnicas sugeridas e utilizadas pelos autores não são necessariamente as mesmas.

Diversas técnicas para a análise exploratória dos dados, que levam em conta a robustez e resistência são discutidas em HOAGLIN et alii (1983). Algumas delas são utilizadas nas análises dos dados deste trabalho. 
Um exemplo de aplicação destas técnicas é encontrado em HAMLETT et alii (1986), onde técnicas resistentes e exploratórias são utilizadas para verificar se as condições restritivas relativas à estacionaridade não estão sendo violadas. CAHN et alii (1994) verificam normalidade, assimetria e curtose. São eliminados nos conjuntos asșimétricos valores superiores a quatro desvios acima da média. É utilizado o refinamento pela mediana e, para verificar o efeito da variabilidade de larga escala, são calculadas as somas de quadrados total, dos resíduos e da tendência. Isto dá uma idéia da percentagem da variabilidade devida a tendência.

É comum a ocorrência de dados que têm distribuições com. caudas pesadas, ou seja, que parecem normais exceto pela ocorrência de alguns pontos atípicos (HAWKINS \& CRESSIE, 1984). A análise exploratória pode ajudar na deteç̧ão de tais ocorrências.

Uma vez identificado um dado deste tipo, a primeira recomendação é que seja verificada a consistência da informação, se o dado foi corretamente obtido e anotado. No caso de se tratar de um erro grosseiro o usual é retirar tal informação, caso não seja possível retificá-la.

Diferentes (e não necessariamente excludentes) formas de tratar os dados atípicos são citadas na literatura. Tais dados podem ser simplesmente retirados de análise como em CAHN et alii (1994), estatisticamente corrigidos (editados) conforme proposto por CRESSIE (1991) ou podem ser adotadas técnicas resistentes de análise (HAMLETT et alii, 1986).

Valores atípicos em dados geológicos podem ser: (a) isolados e devidos a erros topográficos, (b) agrupados e devidos ao fato de pertencerem a uma região geologicamente diferente do restante, ou (c) dispersos através da área, indicando alta variabilidade (HAWKINS \& CRESSIE, 1984). Para identificá-los segundo esta classificação, é necessário que as técnicas exploratórias na análise descritiva levem em conta a posição espacial das amostras. ISAAKS \& SRISVASTAVA (1989) apresentam técnicas univariadas e bivariadas usadas na descrição de dados $\mathrm{e}$ acrescentam técnicas próprias para dados espacialmente distribuidos.

A análise exploratória vem sendo de fato utilizada, orientando as decisões a serem tomadas na análise. Em síntese, ela consiste 
no uso de diversas ferramentas e conceitos que auxiliam o conhecimento do fenômeno estudado. Mas não se deve esquecer que elas são ferramentas a extrair fatos a partir de informações disponiveis. Ferramentas não tomam decisões. Uma decisão é necessariamente humana e é tomada a partir de interpretações necessariamente subjetivas dos fatos (ou estatísticas). Não há nada de condenável nestes procedimentos, desde que sejam claramente documentados. A objetividade é geralmente conseqüência de alguma decisão subjetiva ocultada anteriormente (JOURNEL, 1988).

\subsection{Análise estrutural: considerações sobre variogramas}

As funções média e covariância são as medidas estatísticas mais práticas para a caracterização de um processo estocástico espacial. Desta forma, selecionar um modelo para as funções média e covariância, estimar seus parâmetros e validar o modelo assumido são passos necessários na caracterização do processo estocástico espacial (ÜNLÜ et alii, 1990).

$\mathrm{Na}$ análise geoestatística é comum o uso de semivariogramas para descrever a estrutura de dependência espacial. Covariogramas e correlogramas de forma geral são pouco utilizados. ROBINSON (1990) discute os motivos desta preferência e advoga o uso do semivariograma mesmo em problemas de séries temporais, quando não é requerido o conhecimento da variância do processo. Ocorre freqüentemente em ciências do solo que variáveis espacialmente distribuídas parecem não ter variância nem covariância $a$ priori definida. Nestas circunstâncias o semivariograma pode existir sem a covariância correspondente e isto justifica seu uso predominante nas análises (WEBSTER, 1985).

$\mathrm{O}$ uso dos semivariogramas não é particularidade nem criação da geoestatística. Surge em outras áreas como por exemplo em trabalho de probabilidades de Yaglom, (1957)', estudos meteorológicos de

\footnotetext{
1YAGLOM, A.M. Some classe of randon fields in n-dimensional space relatede to stationary random processes. Theory of Probability and its Aplications, 2: 273-320, 1957.
} 
Gandin $(1963)^{2}$ e Komolgorov $(1941)^{3}$, com o nome de função estrutural. Jowett $(1952)^{4}$ usou em séries temporais a terminologia diferença média quadrática, conforme CRESSIE (1989).

Sob estacionaridade de segunda ordem, a semivariância $\gamma(h)$, a covariância $C(h)$ e a autocorrelação $\rho(h)$ podem ser relacionadàs. Enquanto a covariância e a correlação são medidas de similaridade, a semivariância é medida de dissimilaridade (JOURNEL, 1989).

A estimativa de semivariância para uma determinada distância, pode ser vista como o momento de inércia médio do gráfico de dispersão dos pontos $Z(s)$ vs $Z(s+h)$, em torno da linha $x=y$ (ISAAKS \& SRISVASTAVA, 1989). Desta forma, a estimativa é medida de dispersão desta nuvem de pontos. Um menor espalhamento indica maior associação e gera uma medida menor de semivariância, ao contrário do que ocorre com a covariância e a correlação.

É importante se ter em mente que, ao se trabalhar com geoestatística e assumindo a hipótese intrínseca, a variável aleatória considerada é $Y(h)=Z(s+h)-Z(s)$. É a respeito da variabilidade de $Y(h)$ que estará se referindo ao efetuar os cálculos fundamentais como a estimação do semivariograma.

O semivariograma é a pedra fundamental da geoestatística (CRESSIE, 1989). A análise variográfica/covariográfica é uma arte, no melhor senso do termo. A'rtes requerem bons instrumentos, como neste caso, um bom programa interativo; mas também experiência e habilidade para sintetizar e, às vezes, ir além dos dados (JOURNEL, 1988).

Em vista disto, a qualidade da estimação do semivariograma tem sido objeto de preocupação de diversos autores. Diferentes estimadores podem ser encontrados na literatura. Em geral, para todos estimadores a precisão é função do número de dados, do grau de autocorrelação, da variâncias destes dados, do conhecimento de função de densidade envolvida,

\footnotetext{
${ }^{2}$ GANDIN, L.S. Objective Analysis of Meteorologica Fields. Leningrad, Gidrometeorologichescoe Izdatel'stvo, 1963.

${ }^{3}$ KOMOLGOROV, A.N. The local structure os turbulence in an incompressible fluid at very large reynolds numbers. Dokladv Akademii Nauk SSSR, 30:229-303, 1941.

4JOWETT, G.H. The accuracy of sistematic sampling from conveyoors belts. Applied Statistics, 1: 50-9, 1952.
} 
bem como da presença de dados atípicos (LI \& LAKE, 1994). Propriedades como não-tendenciosidade, precisão, resistência e robustez orientam a busca de estimadores para o semivariograma.

O estimador "clássico" do semivariograma, também dito estimador de Matheron, vem sendo largamente utilizado na literatura de geoestatística. Nada mais sendo do que um estimador obtido pelo método dos momentos, tem, sob a hipótese intrínseca, a desejável qualidade de nãoviesado. Sua expressão é:

$$
\hat{\gamma}(h)=\frac{1}{2 N(h)} \sum_{N(h)}[z(s+h)-z(s)]^{2}
$$

onde $N(h)$ é o número de pares de pontos separados pela distância $h$.

Desta forma, para obtenção de tal estimador não é necessário o conhecimento da distribuição de $Z(s)$. Mas este estimador também vem sendo contestado e colocado a prova por diversos autores. Outros estimadores têm sido propostos buscando uma maior qualidade de estimação.

CRESSIE \& HAWKINS (1980), comparando 10 estimadores para 6 conjuntos de dados simulados para uma transeção segundo um processo autoregressivo, concluem que, sob normalidade, o estimador de Matheron é o mais estável. Porém, tal fato não ocorre quando são simuladas distribuições de caudas pesadas. $\mathrm{O}$ artigo mostra ainda que a média aritmética da raiz quarta de $[z(s+h)+z(s)]^{2}$ formece uma estimativa do semivariograma razoavelmente robusta e estável, com distribuição próxima da normal. Surge daí um estimador que vem sendo tratado como "o estimador robusto de Cressie e Hawkins" pela literatura (WEBSTER, 1985; LI \& LAKE; entre outros). CRESSIE (1991) apresenta ainda outros estimadores robustos. A expressão do estimador robusto de Cressie e Hawkins é a seguinte: 


$$
\bar{\gamma}(h)=\frac{1}{2} \frac{\left[\frac{1}{N(h)} \sum_{N(h)}|z(s+h)-z(s)|^{1 / 2}\right]^{4}}{0.457+\frac{0.494}{N(h)}}
$$

Quando os valores da semivariância estão relacionados com a média dos pontos usados em cada distância, pode-se usar os semivariogramas relativos. ISAAKS e SRISVASTAVA (1989) apresentam três tipos citados a seguir. Estes semivariogramas devem ser usados apenas para propósitos descritivos uma vez que modelos ajustados a eles não podem ser utilizados diretamente na interpolação por krigagem.

i) Variograma relativo local:

$$
\hat{\gamma}_{L R}(h)=\frac{\sum_{i=1}^{n} N_{i}(h) \frac{\hat{\gamma}_{i}(h)}{m_{i}^{2}}}{\sum_{i=1}^{n} N_{i}(h)}
$$

Onde em cada região $i$ os variogramas amostrais são estimados (estimador de momentos) e divididos pelas médias $m$ daquela região.

ii) Variograma relativo geral

$$
\hat{\gamma}_{G R}(h)=\frac{\hat{\gamma}(h)}{m^{2}(h)}
$$


iii)Variograma relativo pareado

$$
\hat{\gamma}_{P R}(h)=\frac{1}{2 N(h)} \sum_{(i, j) h_{i j} \approx h} \frac{[z(s+h)-z(s)]^{2}}{\left[\frac{z(s+h)+z(s)}{2}\right]^{2}}
$$

LI \& LAKE (1994) afirmain que todos os estimadores produzem resultados confiáveis apenas para pequenas distâncias. Os resultados são erráticos para distâncias maiores devido ao fato de que o número de pares de pontos $\mathrm{N}(\mathrm{h})$ decresce a medida que h cresce. $\mathrm{O}$ artigo propõe um novo estimador cuja expressão não envolve $N(h)$, apenas n, e desta forma sua precisão não decresce ao longo dos sucessivos "lags". Os autores afirmam que o estimador é robusto, resistente e usa todos os dados em todos os "lags". Exige estacionaridade de segunda ordem e as condições para aplicação do teorema ergódigo.

Os métodos para estimação do semivariograma podem ser agrupados, segundo SAMPER \& RAMIREZ (1990), em cinco grupos: 1) método dos momentos, 2) método dos mínimos quadrados, 3) método "jackknife", 4) método de máxima verossimilhança e 5) método de validação cruzada. Esta classificação não separa com clareza a estimação do semivariograma amostral com o ajuste do modelo variográfico.

Quando vários atributos são estudados e deseja-se verificar se eles têm o mesmo padrão de variabilidade espacial, são utilizados os semivariogramas escalonados. Estes permitem comparar os semivariogramas dos diferentes atributos, uma vez que todos eles assumem valores em uma escala padronizada. GUIMARÃES (1994), adota este procedimento no estudo de propriedades físicas do solo.

A estimação do semivariograma necessita de certas pressuposições, que muitas vezes os dados originais não sustentam. A fim de contornar problemas desta natureza, são utilizadas algumas técnicas tais como: refinamento pela mediana, remoção de extremos, transformações e retirada de tendências usando polinômios. Esta última assume que a tendência é determinística, quando de fato ela pode conter um componente 
aleatório. Por outro lado o refinamento pela mediana remove tendências tanto determinísticas quanto aleatórias. Porém, em se tratando de um método não-paramétrico, não possui procedimento estatístico para testar a significância da tendência ajustada (CAHN et alii, 1994).

$\mathrm{Na}$ tradição geoestatística, as semivariâncias não são testadas quanto à sua significância, embora isto possa ser feito a partir do teste desenvolvido por Geary para seu coeficiente $c$ de autocorrelação, que pode ser relacionado com a semivariância (LEGENDRE, 1993).

A capacidade do semivariograma detectar a estrutura de dependência espacial está diretamente ligada ao desenho do plano amostral. Uma importante consideração é que, no caso de malhas regulares (freqüentemente utilizadas), os pontos mais próximos (e que serão usados na interpolaçạ̃o) muitas vezes estão a uma distância do ponto a ser estimado inferior à dimensão da malha. Portanto, será usado o modelo variográfico extrapolando os valores obtidos, cuja distância mínima (eixo $\mathrm{X}$ do variograma) coincide com o espaçamento da malha. Este fato justifica $o$ cuidado que se deve ter ao ajustar o modelo variográfico para pequenas distâncias. Uma forma de contornar, ou ao menos minimizar, o problema é buscar configurações amostrais capazes de detallar o comportamento do variograma a pequenas distâncias, como por exemplo, o sugerido no artigo de LASLETT \& McBRATNEY (1990). O desenho de planos amostrais no contexto da geoestatística é também tratado por OLIVEIRA (1991). Este trabalho compara malhas quadradas, triangulares e hexagonais quanto a sua eficiência e propõe algorítimos para obtenção de tamanhos de amostra. WEBSTER \& NORTCLIFF (1984) utilizam informações da variabilidade espacial expressa em semivariogramas para determinar o esforço amostral necessário para estimar teores médios de alguns nutrientes. A ressalva é que este procedimento depende de um 'módelo confiável de semivariância. A obtenção de uma configuração amostral adequada para estimar o semivariograma é discutida em WEBSTER \& OLIVER (1992). 


\subsection{Modelagem e ajuste de semivariogramas}

Solos variam continuamente no espaço, ao menos em escalas práticas. Semivariogramas de propriedades do solo são, portanto, funções contínuas. Os semivariogramas amostrais entretanto, são constituídos por um conjunto discreto de valores, que são estimativas sujeitas a erros (WEBSTER, 1985).

O variograma é uma função da distância $h$ que é éstimado apenas em um conjunto discreto de distâncias ("lags"). A partir destas estimativas, ajusta-se um modelo que depende de diversos parâmetros (CRESSIE, 1985).

Porém, existem condições que definem uma classe de modelos válidos. As justificativas destas limitações podem ser encontradas em ISAAKS e SRISVASTAVA (1989), JOURNEL (1988) ou de forma mais aprofundada em CRESSIE (1991), entre outros. Basicamente, estas condições surgem dos fatos seguintes. Os termos do sistema de krigagem são medidas de covariância ou de semivariância de variáveis separadas por uma certa distância que não necessariamente pôde ser estimada a partir dos pontos amostrais. Isto define a necessidade do modelo. Mas além disto, é desejável que tal sistema tenha solução única, o que fica garantido se a matriz dos coeficientes for positiva definida. Portanto o modelo covariográfico ou variográfico deve assegurar tal condição. Uma discussão mais aprofundada sobre sistemas de equações lineares pode ser encontrada em SEARLE (1971). Uma condição necessária para assegurar que a matriz em questão seja positiva definida é que:

$$
\sum_{i=1}^{m} \sum_{j=1}^{m} a_{i} a_{j} C\left[Z\left(s_{i}\right), Z\left(s_{j}\right)\right] \geq 0
$$

onde:

$a_{i}$ e $a_{j}$ são componentes do vetor $\underline{a}$ de pesos não nulo e $C\left[Z\left(s_{i}\right), Z\left(s_{j}\right)\right]$ é a covariância entre $Z\left(s_{i}\right)$ e $Z\left(s_{j}\right)$.

A expressão acima coincide com a variância de uma combinação linear de variáveis aleatórias que é necessariamente não nula. 
Portanto, o modelo de covariância $C(h)$ deve satisfazer a condição de positivo definido. A expressão acima pode ser reescrita com a medida de semivariância em lugar da covariância, a partir da relação $C(h)=C(0)-\gamma(h)$, contanto que à soma dos pesos seja nula. Consequentemente, o modelo variográfico $\gamma(h)$ deve ser negativo definido condicional (NDC).

JOURNEL (1988) lembra que impor a restrição de que os pesos devem somar zero amplia a família de funções estruturais que pode ser usada. Embora todo modelo de covariância tenha um modelo de semivariância correspondente, a recíproca não é verdadeira, como no caso dos modelos potência de variogramas. Mais uma vez fica claro o motivo da preferência pelo uso de variogramas.

Embora aparentemente restritivas, estas condições não têm sido empecilho nas análises geoestatisticas. Também não é necessário que se busque a cada instante modelos que atendam as condições mencionadas. Existem alguns modelos adequados descritos na literatura que têm atendido a contento as necessidades de modelagem de variogramas.

Alguns modelos básicos, usuais em geoestatística são mencionados a seguir:

Modelo esférico:

$$
\begin{aligned}
& \gamma(h)=C_{0}+C_{s}\left[\frac{3}{2} \frac{h}{a}-\frac{1}{2} \frac{h^{3}}{a^{3}}\right], 0<h \leq a \\
& \gamma(h)=C_{0}+C_{s}, h \geq a
\end{aligned}
$$

Modelo exponencial:

$$
\gamma(h)=C_{0}+C_{s}\left[1-e^{-3 h / a}\right], h \geq 0
$$


Modelo gaussiano:

$$
\gamma(h)=C_{0}+C_{s}\left[1-e^{-3 h^{2} / a^{2}}\right], h \geq 0
$$

Nestes modelos o vetor de parâmetros é $\underline{\theta}=\left(C_{0}, C_{s}, a\right)^{\prime}$; cujas componentes são chamadas de efeito pepita, patamar e alcance; respectivamente. Todos os parâmetros devem ser não negativos.

Modelo potência:

$$
\gamma(h)=C_{0}+b h^{\lambda}, h \geq 0
$$

Neste caso de parâmetros é $\underline{\theta}=\left(C_{0}, b, \lambda\right)^{\prime}$, onde $C_{0} \geq 0, b \geq 0$ e $0 \leq \lambda<2$. O modelo linear é um caso particular deste modelo quando $\lambda=1$.

As expressões de outros modelos válidos podem ser encontradas na literatura (BRAGA, 1990; VALENTE, 1982; entre outros).

Além destes modelos básicos, tem-se que qualquer combinação linear destes modelos também atendem as condições de NDC, o que amplia as possibilidades para o ajuste (ISAAKS \& SRISVASTAVA, 1989).

McBRATNEY \& WEBSTER (1986) mostram alguns modelos válidos de semivariograma e as idéias geométricas de suas construções. Por exemplo, a expressão do modelo esférico é obtida considerando o volume comum de duas esferas de diâmetro $a$ (onde $a$ é o alcance e $h$ a distância entre seus centros). Um alerta importante feito pelos autores é que modelos obtidos para maiores dimensões podem ser utilizados em problemas que envolvem dimensões menores (ex. o esférico, que é baseado em três dimensões, pode ser usado para uma ou duas), porém, a recíproca não é verdadeira. Desta forma, o modelo linear com patamar é NDC em apenas uma dimensão e não pode ser usado em estudos de duas ou três dimensões, por melhor que pareça o ajuste. Fica claro aqui o problema de utilizar programas computacionais onde não se tenha possibilidade de 
escolha cuidadosa do modelo variográfico. Um caso que vale ser destacado é o modelo linear com patamar que atende a condição de positivo definido para uma dimensão, mas não em outras dimensões (WEBSTER, 1985).

Escolher um modelo de semivariograma apropriado é algo que ainda guarda certo mistério. Não é um procedimento automático. Requer um bom julgamento baseado na experiência e uma compreensão das limitações matemáticas da função (McBRATNEY \& WEBSTER, 1986).

De fato o que se espera é que o ajuste do semivariograma seja eficiente especialmente para pequenas distâncias. SAMPER \& RAMIREZ (1990) observam que as flutuações do semivariograma amostral para valores grandes de $h$ não constituem um problema sério, dado que os resultados da krigagem são pouco sensíveis aos valores do semivariograma para grandes distâncias.

O método de ajuste de modelos variográficos mais tradicional é o chamado ajuste "a sentimento". Uma vez obtido o variograma amostral, este serve de indicação visual sobre a forma e os parâmetros do modelo a ser adotado. Textos tradicionais de geoestatística como os de JOURNEL e HUIJBREGTS (1978) e CLARK (1979) adotam este procedimento e ainda fazem ressalvas a respeito do uso de métodos automáticos de ajuste. Literatura mais recente como ISAAKS \& SRISVASTAVA (1989), SAMPER \& RAMIREZ (1990) e CRESSIE (1991) discute outras formas de ajuste mas ainda considera a utilização daquele método. Com a apresentação e discussão de métodos de ajuste mais fundamentados e na medida em que recursos computacionais se tomam mais disponíveis, a tendência é que o método de ajuste a sentimento seja cada vez menos utilizado.

O método de ajuste de modelos de semivariograma por mínimos quadrados ordinários é insensível ao que se pretende no ajuste; porém, é o de implementação mais fácil. Por outro lado, um criterioso procedimento é o uso de mínimos quadrados generalizados, que exige um processo iterativo, de implantação mais dificil. Uma alternativa intermediária é o uso de mínimos quadrados ponderados que podem ajustar bem modelos de variogramas ou ao menos servir de valor inicial para estimação por mínimos quadrados generalizados. CRESSIE (1985) mostra o uso de uma 
aproximação ao método de mínimos quadrados ponderados, discutindo o ajuste de modelos esféricos, exponenciais e lineares a semivariogramas obtidos através do uso dos estimadores de Matheron e robusto de Cressie e Hawkins.

McBRATNEY \& WEBSTER (1986), comentando ajuste de semivariogramas, abordam os métodos de mínimos quadrados (ordinários, generalizados e ponderados) e de máxima verossimilhança. Segundo os autores, o método de mínimos quadrados ponderados tem provado ser realístico e computacionalmente eficiente.

SAMPER \& RAMIREZ (1990) comentam ainda outros métodos de ajuste: método "jackknife", validação cruzada e validação cruzada de máxima verossimilhança.

WEBSTER (1985) afirma obter bons resultados utilizando mínimos quadrados. Para modelos não-lineares, são obtidas inicialmente estimativas para os parâmetros não lineares iterativamente (notadamente para o alcance) e então ajustam-se os demais. As semivariâncias são ponderadas pelo número de pares que as geraram.

A validação cruzada é freqüentemente utilizada na análise geoestatística. VIEIRA (1981, 1993), TABOR et alii (1984) e McBRATNEY (1991) são alguns exemplos de aplicação desta técnica. A despeito do termo validação, JOURNEL (1988) afirma que, de fato, a técnica não valida modelos e sim "toca sinos de alerta" em casos de modelagem inapropriada ou erros grosseiros.

De maneira geral, pode-se dizer que é uma forma de avaliar o erro no processo de interpolação. Este erro deve-se ao fato de que geralmente a variável a ser estimada é um pouco diferente do valor estimado (JOURNEL e HUIJBREGTS, 1978). A interpolação por krigagem está fortemente associada ao modelo de variograma escolhido. Decorre daí ser mencionada como forma de diagnosticar problemas com o ajuste do modelo do semivariograma (VIEIRA, 1981; CRESSIE, 1991). Delfiner (1976), citado por DAVIS (1987), apresentou a validação cruzada como forma de escollher a função de covariância entre diversas candidatas. Após validação

${ }^{5}$ DELFINER, P. Linear Estimation of non-stationary spatial phenomena. In: Advanced Geostatistic in The Mining Industry. Guarascio, et alii ed. D. Ridel Pub. Co. Dordretch, Holanda. 1976. 
cruzada bem sucedida do modelo do semivariograma, pode-se ter confiança em que a predição baseada no modelo variográfico é não-viciada e o erro quadrático médio de predição é mais ou menos correto (CRESSIE, 1991). Entretanto, a validação cruzada tem sido utilizada com outras finalidades além de avaliar o modelo adotado para o semivariograma. VIEIRA (1983) utiliza seus resultados para estudar o tamanho da vizinhança de krigagem, ISAAKS e SRISVASTAVA (1989) para comparar métodos de interpolação (krigagem e método dos polígonos); ÜNLÜ et alii (1990) na comparação de métodos para estimar os parâmetros do variograma.

A forma mais comum de levar a cabo a validação cruzada é retirar um dado de cada vez do conjunto e estimá-lo usando a krigagem. Desta forma, com a diferença entre o valor estimado e o observado obtém-se uma medida de erro de predição para cada observação. Esta é a descrição encontrada em ISAAKS e SRISVASTAVA (1989) e SAMPER \& RAMIREZ (1990). CRESSIE (1991) afirma que o desejável seria obter novas amostras ou deixar um conjunto à parte na análise para serem utilizados na validação cruzada (tais dados não seriam utilizados para estimar o semivariograma), mas ressalta que em geral este enfoque não é possível na prática. JOURNEL (1988) descreve a técnica separando uma parte dos dados, que será estimada e usada na avaliação logo no início da análise e que não contribue, portanto, na estimação do semivariograma. BREGT et alii (1991) adotam este procedimento. JOURNEL (1988) afirma ainda que, caso não seja possivel prescindir destes dados na análise variográfica, deve-se na validação cruzada retirar de uma só vez todos os dados a serem utilizados na validação e não um a um. A despeito destas observações não é esta a prática encontrada na literatura. Usualmente os dados são retirados e estimados um a um (procedimento tratado por "leaving-one-out " segundo DAVIS, 1987).

$\mathrm{Na}$ avaliação, durante a validação cruzada, são utilizadas estatísticas dos erros, verificação se os erros padronizados (uma vez que se dispõe da variância de krigagem) têm média nula e variância unitária, gráficos de valores estimados $v s$ observados, mapas de erros, etc. Diversos autores tais como JOURNEL (1988), SAMPER \& RAMIREZ (1990), 
ISAAKS e SRISVASTAVA (1989) entre outros, comentam como avaliar os resultados.

VIEIRA $(1981,1983)$ chega a utilizar o teste "t" para verificar igualdade da média dos erros a zero, constata se $95 \%$ deles estão na faixa de dois desvios padrões como indicação de normalidade e testa se o coeficiente de correlação entre valores estimados e observados difere da unidade. Já CRESSIE (1991) afirma que não advoga a validação cruzada para análise confirmatória de dados devido ao fato de a correlação entre os dados dar origem a uma complicada teoria de distribuição que precisa de mais estudos. JOURNEL (1988) afirma que o verdadeiro compromisso com a realidade não é executar testes mas sim documentar claramente as decisões a priori e os fatos que determinaram a escolha do modelo $\mathrm{e}$ as conseqüências do modelo escolhido e dos preteridos nos passos subseqüentes da análise.

Alguns autores não fazem distinção entre os termos validação cruzada e "jackknife" (VIEIRA, 1983 e TABOR et alii 1984), enquanto outros (DAVIS, 1987; CRESSIE, 1991; JOURNEL, 1988) afirmam que se tratam de métodos diferentes com diferentes objetivos. Neste sentido, SAMPER \& RAMIREZ (1990) tratam por "jackknife" o método para estimar estatísticas de uma variável baseado na divisão dos dados em grupos, enquanto validação cruzada refere-se a um método para avaliar erros de estimação.

DAVIS (1987) aponta usos e abusos na utilização da validação cruzada em geoestatística e conclui que a técnica deve ser encarada como um. instrumento exploratório, que permite melhor conhecimento do fenômeno em estudo. A interdependência introduzida no problema onde os dados são de fato correlacionados espacialmente torna técnicas confirmatórias questionáveis. Segundo CRESSIE (1991), é um dificil problema adaptar as técnicas para observações independentes igualmente distribuídas como a validação cruzada, o "jackknife" e o "bootstrap" no contexto da geoestatística.

Assumindo a normalidade dos erros foi proposto o método da validação cruzada de máxima verossimilhança. O objetivo é estimar os parâmetros do semivariograma de forma a maximizar a verossimilhança dos 
erros de validação. SAMPER \& RAMIREZ (1990) comentam este enfoque. Esta abordagem deve ser vista com cuidado uma vez que parâmetros desconhecidos são utilizados para definir os "dados" (que são os erros de estimação) o que torna insensato pensar na função a ser maximizada como sendo uma verossimilhança (CRESSIE, 1991).

Outros métodos de estimação paramétrica do semivariograma podem ser encontrados como ÜNLÜ et alii (1990), que utilizam máxima verossimilhança e máxima verossimilhança restrita para èstimação dos parâmetros. Os mesmos autores usam na avaliação dos modelos além da validação cruzada o método dos resíduos nãocorrelacionados.

$\mathrm{Na}$ escolha do modelo a ser ajustado para o semivariograma, um compromisso satisfatório entre a parcimônia e a qualidade do ajuste pode ser encontrado pela aplicação do Critério de Informação de Akaike (AIC) através do qual, em um conjunto de modelos, aquele que apresentar menor valor de $\mathrm{AIC}$, pode ser selecionado (WEBSTER \& McBRATNEY, 1989). O critério foi apresentado no contexto de séries temporais por AKAIKE (1974) e utilizado por HIPEL (1981) na discriminação de modelos geofisicos. Este não é o único critério para comparação de modelos existente na literatura. SAMPER \& RAMIREZ (1990) apresentam também os critérios de Akaike modificado, de Hannan e de Kashyap. Todos eles se baseiam no valor da verossimilhança e no número de parâmetros do modelo.

Um ajuste que proporcione menor soma de quadrados de resíduos pode ser obtido aumentando o número de parâmetros do modelo. $\mathrm{O}$ que é feito pelo critério é estabelecer uma penalidade para o acréscimo de parâmetros. Se todos os modelos a serem comparados possuírem o mesmo número de parâmetros, buscar aquele com menor AIC não traz vantagens sobre minimizar a soma de quadrados de resíduos. O critério é especialmente útil quando se pensa em ajustar modelos com mais de uma estrutura ("nested models") e para a decisão de modelar a anisotropia. WEBSTER \& McBRATNEY (1989) mostram que o critério está relacionado com o teste $F$. para a contribuição da adição de parâmetros para a qualidade do ajuste do modelo. 
O semivariograma reflete a estrutura espacial do fenômeno estudado desde que as hipóteses assumidas sejam verdadeiras. A hipótese intrínseca, muitas vezes assumida, considera que $L\{Z(s)\}=m$ é constante em toda a região. Mas na realidade muitos dos fenômenos naturais não exibem tal comportamento, pois é comum a ocorrência de tendências, ou seja, uma esperança não estacionária $E\{Z(s)\}=m(s)$ onde $m(s)$ depende de $s$, dentro da região. A tendência acaba por provocar un viés na estimação do semivariograma, sendo que este pode assumir formas totalmente diferentes das verdadeiras. STARKS \& FANG (1982) concluem que geoestatísticos precisam considerar a presença da tendência como um fator que pode provocar distorções na análise variográfica. HAMLETT et alii (1986) vão mais além afirmando que a falta de estacionaridade é muito mais regra do que exceção em problemas reais. A existência da tendência pode ser detectada da seguinte forma:

1) Verificar se a tendência é evidente no fenômeno em estudo (como, por exemplo, o que comumente ocorre com amostras tomadas em diferentes profundidades).

2) Verificar se o efeito pepita pode ser explicado em termos de descontinuidades, enros de medida ou combinação destes.

3) Verificar se a isotropia é uma suposição plausivel.

4) Verificar se a validação cruzada produz resíduos padronizados $N(0,1)$.

Esta última é dúbia pois o modelo pode ser inadequado ou podem ocorrer tendências, mas de qualquer forma, é un alerta de que algo não parece adequado (STARKS \& FANG, 1982).

Quanto ao comportamento no infinito, pode ser mostrado que o variograma $\gamma(h)$ necessariamente cresce mais lentamente quando $h$ tende a infinito do que $h^{2}$. Variogramas que não mostram tal comportamento são incompatíveis com a hipótese intrínseca e, em geral, indicam presença de tendências (LASLETT \& McBRATNEY, 1990).

Portanto, se a função aleatória satisfaz a hipótese intrínseca, segundo CRESSIE (1991), deve-se ter que: 


$$
\lim _{\|h\| \rightarrow \infty} \frac{\gamma(h)}{\|h\|^{2}}=0
$$

Se o semivariograma cresce mais rápido que $h^{2}$ pode-se pensar que a variável não é intrínseca (SAMPER \& RAMIREZ, 1990).

$O$ efeito da tendência sobre o variograma experimental, consiste essencialmente em um nítido crescimento parabólico devido ao termo $\frac{1}{2}[m(s+h)-m(s)]^{2}$ (JOURNEL \& HUIJBREGTS, 1978).

Um ponto que tem causado alguma confusão na literatura é a relação entre a variância da amostra e o patamar do variograma. BARNES (1991) esclarece esta questão deduzindo uma expressão que mostra que o valor esperado da variância amostral é igual ao valor médio do variograma entre todos os $\mathrm{N}^{2}$ pares de valores amostrais. Esta esperança é portanto função da configuração geográfica dos dados e de todo variograma, e não apenas de seu patamar. $O$ autor conclui que, em geral, se o patamar é claramente presente no gráfico do variograma, seu valor pode ser usado como uma estimativa da variância populacional. Porém, a variância amostral não pode ser usada como uma estimativa do patamar do variograma.

\subsection{Krigagem}

Krigagem é um nome genérico adotado pelos geoestatísticos para um grupo de técnicas de estimação baseado em minimização da variância do erro. De fato, todos os tipos de krigagem provêm de um princípio comum de minimização e todas as equações de krigagem são variantes do bem conhecido sistema de equações normais, neste caso, sujeito a restrições. Este passo da análise (estimação) é absolutamente clássico, a despeito da confusão trazida pelo novo nome "Kriging". A essência da geoestatística não reside na krigagem, mas sim em: documentar a decisão de estacionaridade, escolher certos dados (transformados ou não) a serem utilizados e inferir modelos de covariância (JOURNEL, 1988). 
A necessidade e importância da interpolação pode ser ilustrada por uma situação referente ao controle de poluentes atmosféricos. Pessoas que vivem em cidades e distritos rurais onde não há estações de monitoramento dos niveis de poluição também têm direito de saber se sua água ou ar estão poluídos (CRESSIE, 1989). Isto é possível a partir de métodos de interpolação capazes de detectar e prever o comportamento do fenômeno em estudo.

A popularidade da krigagem em ciência do solo é, ao menos em parte, devida ao fato de a técnica produzir, juntamente com a malha interpolada, uma medida da precisão do preditor (estimativas da variância de krigagem) para cada ponto da malha (BREGT et alii, 1991).

O estimador de krigagem não é ótimo em sentido absoluto, pois o critério de optimalidade não é único (JOURNEL, 1988). Desta forma podem ser feitas comparações com outros métodos de interpolação como ocorre em ISAAKS e SRISVASTAVA (1989), LASLETT (1994) dentre outros.

O preditor de krigagem assume que o erro de medida é idêntico a zero. É portanto esta versão de $Z\left(s_{0}\right)$, livre de qualquer erro de medida, que pode ser predita. Nesta circunstância o interpolador é exato (CRESSIE, 1986).

A principal objeção à krigagem é o fato de se basear em processos estocásticos, particularmente à invocação de estacionaridade e ao comumente repetido alerta de que tendências raramente precisam ser modeladas explicitamente (LASLETT, 1994).

ISAAKS \& SRISVASTAVA (1989) consideram um conjunto de 78.000 dados como sendo uma população e retiram deste conjunto uma amostra de 470 . As análise são feitas em ambas as situações, o que permite avaliar os métodos, pressupostos e decisões utilizados e comparar diferentes interpoladores.

LANDIM (1988) chama atenção ao fato de que na solução do sistema de krigagem, se a configuração da vizinhança permanece a mesma em dois pontos distintos, a matriz que multiplica os pesos para ponderação não se altera. Isto reduz o número de inversões de matrizes, diminuindo o tempo computacional (VIEIRA et alii, 1981). 
O fato de o sistema de krigagem ser montado a partir de medidas de semivariância (ou covariância) não significa que o método deixa de considerar a distância dos vizinhos na ponderação, como diversos dos demais métodos de interpolação. Ao menos implicitamente, as distâncias são consideradas (CLARK, 1979). As matrizes do sistema de krigagem contêm "distâncias estatísticas" em lugar de distâncias simplesmente geométricas (ISAAKS \& SRISVASTAVA, 1989).

OLIVER \& WEBSTER (1990) comentam o uso da krigagem em sistemas de informações geográficas, chamando atenção ao fato de que ao contrário de métodos matemáticos a krigagem permite estimativas dos erros de predição.

Quando os dados seguem distribuição normal, os estimadores de krigagem linear são geral e condicionalmente não-viciados. Caso contrário são apenas não-viciados de forma geral e geralmente são condicionalmente viciados (HAWKINS \& CRESSIE, 1984). Isto é um incentivo para que se esforce em trabalhar com dados gaussianos, lançado mão de transformações quando necessário.

A proposta de estimação robusta engloba estimação do semivariograma pelo estimador robusto e edição de dados atípicos antes de efetuar a krigagem (CRESSIE \& HAWKINS, 1984).

$\mathrm{Na}$ krigagem, o modelo variográfico precisa ser aproximadamente correto, ao menos até a distância considerada na interpolação $\mathrm{e} o$ uso de funções aleatórias de ordem $\mathrm{k}$ deve ser considerado a fim de se obter modelos menos influenciados por tendências (STARKS \& FANG, 1982).

Alguns trabalhos têm indicado a robustez da krigagem ordinária a certos graus de não-estacionaridade e assimetria da distribuição (YOST et alii, 1982 e BREGT et alii, 1991). Há poucos trabalhos que tratam do efeito da mudança do modelo de semivariograma e seus parâmetros, bem como da configuração dos pontos sobre os resultados do sistema de krigagem. BARDOSSY (1988), estudando estas questões, mostra que estes efeitos existem e propõe formas de medi-los. 


\subsection{Algumas aplicações}

LANDIM (1988) ilustra o uso de diversas técnicas estatísticas como regressão, análise de variância, superficies de respostas e geoestatística na análise de dados de um depósito de carvão.

"A necessidade de compreensão das várias escalas de variabilidade se traduz em um novo paradigma para os ecologistas: a estrutura espacial é um importante componente dos ecossistemas" (LEGENDRE, 1993). O autor discute técnicas que levam em conta a posição da amostra aplicadas à estudos ecológicos.

OLIVER \& WEBSTER (1990) assinalam que as principais contribuições da geoestatística para os Sistemas de Informação Geográfica são: a krigagem, desenhos de planos amostrais ótimos, simulação de reservas e considerações espaciais nas classificações multivariadas. Estes temas são discutidos neste artigo.

CRESSIE (1991) dedica um capítulo para exemplos que ilustram aplicações da geoestatística a estudos de diversas naturezas que mostram o uso de técnicas altemativas às tradicionais tais como uso do estimador robusto de semivariograma, refinamento pela mediana, krigagem robusta e residual.

Um exemplo interessante de composição de modelos no ajuste do semivariograma pode ser visto em McBRATNEY \& WEBSTER (1986); em que o semivariograma para condutividade elétrica é obtido pela combinação de quatro estruturas: efeito pepita, linear, esférico e periódico.

BREGT et alii (1991) corrigem as variâncias de krigagem justificando que estas não consideram o grau de incerteza na estimação do semivariograma. Mapas de isolinhas de déficit hídrico são apresentados com limites de confiança.

VIEIRA et alii (1992) ajustam modelos de variogramas e variogramas cruzados para parâmetros que descrevem a curva de retenção de água, densidade, teores de argila, silt e areias, discutindo a variabilidade espacial destes atributos coletados em transeções.

O estudo da variabilidade espacial de atributos físicos do solo realizado por SILVA (1988) não extrai resultados satisfatórios da 
análise geoestatística. Segundo o autor o fato pode ser atribuído a pequena dimensão do campo experimental e espaçamento largo demais entre as amostras para que fosse detectada estrutura de depêndencia. Já DOURADO NETO (1989) estudando precipitação, lâmina de irrigação e potenciais de solução do solo ajusta variogramas em uma região onde foi verificada anisotropia. Medidas feitas diretamente na planta são utilizadas por HAMAKAWA (1991) que chega a recomendação de tamanho de parcela de 60 a 70 metros para experimentos com feijão.

CAHN et alii (1994) promovem análises geoestatísticas de atributos químicos do solo. Levando em conta os dois lados da aplicação de nutrientes, que por um lado o excesso pode provocar contaminação da água e, por outro, a falta pode causar quebras de produção, os autores lembram que os equipamentos já disponíveis para aplicação diferenciada necessitam de mapas para efetuar tal aplicação. Em adição às inovações nos equipamentos, métodos estatísticos que possam resumir de forma acurada os padrões espaciais dos dados do solo são necessários para determinar taxas de aplicação localmente específicas. A análise de parâmetros de fertilidade levam à conclusão que, dadas as presentes limitações da acurácia dos sistemas de navegação e aplicação associadas aos custos da análise amostral, os beneficios das aplicações espaciais podem ser maiores para nutrientes que exibem longos alcances na autocorrelação espacial, variação de larga escala bem definidas e padrões espaciais que são correlacionados no tempo.

Um experimento foi conduzido com o propósito de isolar as fontes de variação potenciais em um estudo: 1) tendência instrumental ou temporal de laboratório (componente não-aleatória); 2) erro de medida (componente aleatório); 3) variação de microestrutura; 4) correlação espacial e 5) tendência espacial. As componentes podem ser estimadas devido a um esquema amostral adequado, replicações nas análises de laboratório e análises seqüenciais com amostras-controle intercaladas entre as obtidas no campo. Os resultados são encontrados em LASLETT \& McBRATNEY (1990). 


\section{MATERIAL E MÉTODOS}

\subsection{Material}

Análises de dois conjuntos de dados reais são efetuadas com o propósito de ilustrar a aplicação de algumas técnicas geoestatísticas. Porém, este trabalho não tem em momento algum a intenção de discutir os aspectos específicos dos dados, referentes a atributos físicos dos solos, daí os conjuntos não serem descritos de forma mais detalhada.

Com o uso de dados referentes a duas situações em que o comportamento das variáveis é distinto em relação a hipótese de estacionaridade, é possível mostrar de forma mais clara como utilizar as informações fornecidas pela análise, especialmente a exploratória espacial.

Os programas computacionais Geo-EAS ("Geostatistical Enviromental Assessment Software") e Statgraphics foram utilizados para manipulação dos dados, desenho de gráficos e desenvolvimento das análises.

\subsubsection{Dados de Densidade do Solo}

Este conjunto é detalhadamente descrito em Moraes (1991). Foram tomadas as leituras de densidade do solo de 250 pontos dispostos em uma malha regular $(10 \times 25)$, separados por 5 metros, totalizando uma área de $6250 \mathrm{~m}^{2}$. 


\subsubsection{Dados de Umidade do Solo}

Em 25 pontos de uma transeção, separados por 25 metros, foram feitas leituras da umidade do solo, utilizando sonda de neutrôns, em seis profundidades: 0,$25 ; 0,50 ; 0,75 ; 1,00 ; 1,25$ e 1,50 metros. Este trabalho apresenta análises das leitura feitas em 29/05/1990. A área a qual cada ponto da superficie se refere é dita "parcela". Tem-se portanto 25 parcelas e 6 profundidades totalizando 150 leituras de umidade do solo.

\subsection{Métodos:}

Antes de se iniciar uma análise geoestatística é preciso que o analista esteja ciente de algumas de suas particularidades e, disposto a considerá-las.

1) Não se trata de um procedimento de "mão única". A análise é um contínuo ir, voltar, refazer e comparar antes de qualquer decisão definitiva.

2) Uma série de decisões subjetivas são tomadas ao longo do trabalho. Isto faz com que o roteiro a ser seguido, bem como os resultados intermediários e finais não sejam obtidos de forma única.

3) A técnicas descritivas e exploratórias devem permear todas as diversas fases das análises, e não ser utilizadas apenas inicialmente.

4) É necessário o conhecimento do problema em questão e das potencialidades e limitações da técnica de análise. Unir estas características em um único profissional não é uma tarefa simples. Uma solução pode ser dada então pela associação de diferentes profissionais.

A seguir são descritos passos de uma análise. Em muitas situações são feitas opções, muitas vezes a partir de decisões subjetivas e até mesmo questionáveis. Inicia-se com a proposta de modelagem probabilística, 
segue-se com os diversos procedimentos até a confecção de um mapa que detalha o comportamento do atributo do solo na região estudada.

Não se abordam todas as alternativas e potencialidades da análise geoestatística. Também não se esgota a discussão de pontos específicos de cada passo. $O$ que se pretende é dar uma visão geral da proposta geoestatística de tratamento da informação e os resultados que ela pode produzir.

\subsubsection{O tipo de problema abordado e a natureza dos dados}

As técnicas apresentadas neste trabalho aplicam-se à análise de dados provenientes de uma amostra tomada em uma determinada região onde, em pontos que podem ser identificados por coordenadas, realiza-se a medida de algum atributo, expresso por uma variável aleatória que é aqui considerada contínua. Os procedimentos a serem descritos utilizam a informação da posição da amostra. Não é suficiente, como em diversos casos de análise estatística, apenas o valor que a variável assume em cada ponto amostrado. Desta forma, de cada amostra deve-se ter o valor da variável e coordenadas do ponto onde foi coletada a amostra. As coordenadas devem ser expressas em um sistema de unidades que permita o cálculo de distância (euclidiana) entre as amostras.

A análise de dados espacialmente distribuídos, ao contrário de diversos procedimentos estatísticos que entendem os elementos de una amostra como diversas "repetições" ou realizações de uma única variável aleatória, considera, ao menos inicialmente, que em cada ponto da região tem-se uma variável aleatória distinta. Desta forma, para toda região o que se tem é um conjunto de variáveis aleatórias, ou seja, um processo estocástico (também chamado de processo aleatório ou função aleatória) denotado por:

$$
\left\{Z(s): s \in D \subset \mathfrak{R}^{d}\right\}
$$

onde:

$Z$ é a variável em questão; 
$\boldsymbol{S}$ indica a posição no espaço;

$D$ é a região em estudo e

$\mathfrak{P}^{d}$ o espaço d-dimensional no qual está contida a região.

Nos dois conjuntos estudados, $d=2$. Os dados são localizados por duas coordenadas. As técnicas a seguir serão descritas segundo esta dimensão. No caso de outras dimensões, adaptações devem ser feitas.

\subsubsection{Modelagem probabilística e estacionaridade}

Quando se pretende conhecer 'o comportamento de uma variável aleatória, tomam-se várias amostras desta variável, ou seja, diversas realizações dessa variável. A partir destas realizações é possível fazer conjecturas sobre a distribuição da variável e estimar seus parâmetros e/ou momentos; enfim, é possível fazer inferências de interesse. Desejando-se estudar mais de uma variável aleatória, deve-se obter diversas realizações de cada uma delas, conhecendo os comportamentos individuais e conjuntos das variáveis aleatórias.

O conhecimento completo de um processo é dado pela distribuição conjunta:

$$
F_{z_{1}, z_{2}, \ldots, z_{n}}\left(z_{1}, z_{2}, \ldots, z_{n} ; s_{1}, s_{2}, \ldots, s_{n}\right)
$$

Ao amostrar a região, a informação obtida usualmente é um único valor em cada ponto de amostragem, ou seja, uma única realização de cada variável aleatória. Com tal informação não é possível qualquer tipo de inferência, uma vez que não se pode fazer estimação a partir de uma única observação. Desta forma, o processo estocástico mencionado não pode ser conhecido de forma a permitir conclusões sobre o fenômeno em estudo.

A fim de contornar tal impedimento de ordem prática, a análise pode prosseguir caso seja adotado algum tipo de estacionaridade. 
Será assumido que o processo tenha um determinado comportamento sem que isto possa ser objetivamente comprovado. A necessidade de adotar um pressuposto, um tanto quanto subjetivo, é o "preço que se paga" por possuir apenas uma realização de cada variável aleatória. A estacionaridade permite obter dos dados diversas realizações de alguma variável aleatória, de forma que pelo menos os dois primeiros momentos da distribuição desta variável possam ser estimados. Na abordagem aqui apresentada, assumindo certo tipo de estacionaridade, é possível obter diversas realizações da variável dada pela diferença entre os valores em pontos separados por uma certa distância.

Este é um passo crítico uma vez que toda a análise considera que tal decisão é válida para o fenômeno estudado e nela se baseia cada procedimento subsequente.

Um processo estocástico possui distribuições de várias ordens. Desta forma a distribuição de primeira ordem fica caracterizada por $F_{z}(z, s)$, a de segunda ordem por $F_{z_{1}, z_{2}}\left(z_{1}, z_{2} ; s_{1}, s_{2}\right)$ e assim por diante. $\mathrm{O}$ interesse aqui retringe-se às distribuições de segunda ordem. As propriedades de interesse do processo estocástico até esta ordem são as funções de média, de covariância, de correlação e de semivariância.

Uma vez que não se pode estimar as funções de primeira e segunda ordem, o que se pretende é estimar ao menos as propriedades do processo anteriormente mencionadas. Tal estimação feita a partir de uma única realização de cada variável aleatória depende da adoção de algum tipo de hipótese de estacionaridade.

O tipo de estacionaridade mais forte e também mais restritivo é a estacionaridade em senso estrito que implica em que as leis da função sejam invariantes para toda translação efetuadas sobre os pontos de amostragem:

$$
F\left(z_{1}, z_{2}, \ldots, z_{n} ; s_{1}, s_{2}, \ldots, s_{n}\right)=F\left(z_{1}, z_{2}, \ldots, z_{n} ; s_{1+h}, s_{2+h}, \ldots, s_{n+h}\right)
$$

Neste tipo de estacionaridade o que está se afirmando é que as leis da função de distribuição dependem apenas da configuração dos pontos (de sua geometria relativa) e não deles individualmente. Isto fica mais 
claro verificando como ficam as distribuições de primeira e segunda ordem sob tal tipo de estacionaridade. Para primeira ordem tem-se:

$$
F_{z}(z, s)=F_{z}(z, s+h),
$$

que significa que a distribuição de primeira ordem independe de $s$, ou seja, em cada ponto da região a distribuição da variável aleatória é a mesma. Para segunda ordem:

$$
F_{z_{1}, z_{2}}\left(z_{1}, z_{2} ; s_{1}, s_{2}\right)=F_{z_{1}, z_{2}}\left(z_{1}, z_{2} ; s_{1}+h, s_{2}+h\right)
$$

e portanto,

$$
F_{z_{1}, z_{2}}\left(z_{1}, z_{2} ; s_{1}, s_{2}\right)=F_{z_{1}, z_{2}}\left(z_{1}, z_{2} ; s_{1}-s_{2}\right)=F_{z_{1}, z_{2}}\left(z_{1}, z_{2} ; h\right)
$$

Nesta última, afirma-se que a distribuição conjunta de segunda ordem depende apenas da distâncias entre os dois pontos. Portanto diversos pontos separados pela mesma distância forneceriam as repetições necessárias para estimações.

Caso esta forma de estacionaridade seja aplicável apenas até uma determinada ordem $k<\mathrm{n}$, tem-se uma estacionaridade de ordem $k$. Mesmo assumindo $k=2$ (estacionaridade de segunda ordem), a hipótese ainda é muito restritiva pois exige o conhecimento da forma da distribuição.

A estacionaridade em sentido amplo é definida apenas a partir das propriedades da distribuição de segunda ordem. Um processo estacionário em sentido amplo deve obedecer às condições:
i) $E\{Z(s)\}=\mu, c^{t e} \forall s$
ii) $C\left[Z_{1}\left(s_{1}\right), Z_{2}\left(s_{1}+h\right)\right]=C(h)=E\left[Z_{1}\left(s_{1}\right) Z_{2}\left(s_{1}+h\right)\right]$

Note-se que todo processo estacionário em sentido estrito é também em sentido amplo, porém a recíproca não é verdadeira.

Outro tipo de estacionaridade que pode ser assumida fica definida não mais a partir das distribuições das variáveis aleatórias de cada 
ponto e sim da diferença entre elas. É a chamada estacionaridade dos incrementos. Pode-se então assumir algum dos tipos mencionados de estacionaridade para uma "nova" variável $[Z(s+h)-Z(s)]$.

A hipótese assumida neste trabalho é um tipo de estacionaridade dos incrementos, chamada hipótese intrínseca, definida pelas condições:

$$
\begin{aligned}
& \text { i) } E\left\{\left[Z\left(s_{1}\right)-Z\left(s_{2}\right)\right]\right\}=0 \\
& \text { ii) } E\left\{\left[Z\left(s_{1}\right)-Z\left(s_{2}\right)\right]^{2}\right\}=2 \gamma(h)
\end{aligned}
$$

A partir deste ponto, é este tipo de estacionaridade que estará sendo discutida e verificada. Esta hipótese abrange um conjunto mais amplo de processos do que a estacionaridade de segunda ordem. Todo processo estacionário de segunda ordem é também intrinsicamente estacionário, mas a recíproca não é verdadeira. Portanto, no enfoque dado neste trabalho, espera-se que os dados sejam uma realização de um processo estocástico ao menos intrinsecamente estacionário.

A semelhança com séries temporais é nítida, mas não o é a adaptação de seus procedimentos, uma vez que dados espaciais não são referenciados por apenas em uma dimensão (como no caso do tempo), mas até em quatro dimensões (três do espaço e uma do tempo).

\subsubsection{Técnicas descritivas e exploratórias}

A estacionaridade é uma afirmação ou suposição a respeito do comportamento das variáveis aleatórias. A decisão de adotá-la ou não pode ser facilitada pelo conhecimento do fenômeno em estudo. A experiência do pesquisador tem papel fundamental neste passo. Embora não seja algo que possa ser posto à prova de forma objetiva, ou seja, não é uma hipótese que possa ser testada, a decisão de assumir algum tipo de 
estacionaridade pode ser orientada por uma análise exploratória adequada dos dados.

Este é, portanto, o ponto de partida na manipulação dos dados. Para dados espacialmente distribuídos essas técnicas podem ser "divididas" em duas etapas: 1) descrição geral, que não considera a posição das amostras e 2) descrição espacial que, de alguma forma, considera a posição das amostras. Estas serão tratadas daqui em diante como análise descritiva geral e análise descritiva espacial,

\subsubsection{Análise descritiva geral}

Esta análise só leva em conta os valores obtidos na amostra, sem considerar sua posição. São tratados como realizações de uma mesma variável aleatória, o que poderia sugerir que se está assumindo estacionaridade em senso estrito, o que não é feito usualmente dada a rigidez desta suposição. $O$ objetivo é pura e simplesmente a identificação inicial do comportamento dos dados, sem nenhuma pretenção de inferência. Desta forma, a análise descritiva não deve ser de modo algum descartada nem tampouco utilizada para afirmações conclusivas.

$\mathrm{O}$ uso de histogramas, " $\mathrm{q}-\mathrm{q}$ plots", das diversas medidas descritivas, "box-plot", ramo-e-folhas permite uma primeira visão dos aspectos gerais dos dados. Padrões, informações sobre locação e escala e indicações sobre forma de distribuição são sugeridos nesta fase. Além disto, estas análises assinalam dados atípicos no conjunto que devem ser verificados de forma cuidadosa.

São portanto utilizados aqui instrumentos comuns a diversas análises estatísticas, já bem conhecidos (embora talvez não tão utilizados quanto seria desejável). 


\subsubsection{Análise descritiva espacial}

Embora mais detalhada que a anterior, uma vez que leva em consideração de alguma forma a posição das amostras, também esta análise pode parecer pressupor algum tipo de estacionaridade em cada um dos seus procedimentos. Mas novamente a intenção é tão somente ter-se um indicativo do comportamento dos dados agora associando-os às suas posições na região amostrada. Em troca de um maior detalhamento, a análise descritiva espacial requer um maior número de dados.

Quando os dados são coletados em uma malha regular, os recursos descritivos são em maior número e mais claros. Para malhas irregulares muitas vezes são necessárias adaptações, quando estas são possíveis. Este trabalhó considera a amostragem feita em malhas regulares.

As técnicas mencionadas a seguir são aquelas utilizadas na análise dos dados no presente trabalho.

O "postplot" é um gráfico gerado pelo Geo-EAS em que as amostras são representadas no ponto onde foram tomadas, localizado pelas suas coordenadas. O programa tem opções para assinalar o valor da variável obtido em cada ponto e pode ainda marcar os pontos com cores/símbolos identificando os quartis da distribuição dos dados. Este gráfico mostra o comportamento espacial das realizações obtidas do atributo em questão na região estudada. Pode-se ter a partir dele uma idéia inicial sobre a continuidade do fenômeno, verificar se há regiões com concentração de amostras de altos ou baixos valores que podem sugerir a partição da área em subregiões. Aqui é indiferente se a malha é ou não regular.

Uma outra opção de representação dos dados é um gráfico tridimensional que mostra a superficie definida pela amostra. Esta superficie é grosseira e dá apenas uma idéia visual inicial do comportamento do atributo em estudo na região. Uma superfície definitiva e detalhada é obtida ao final, após a construção por interpolação de uma malha mais fina do que a amostrada.

Médias e variâncias de cada linha e coluna do conjunto de dados podem mostrar o comportamento da variável ao longo dos eixos da malha de amostragem. Gráficos construídos a partir destas informações 
podem mostrar rápida e nitidamente padrões existentes nestas direções. Medidas resistentes como medianas e amplitudes interquartílicas, bem como gráficos "box-plot" podem ser usadas de forma alternativa e/ou complementar.

O mesmo tratamento pode ser dado às informações das chamadas janelas móveis. Aqui, ao invés de se tomar todos os dados de uma linha ou coluna, montam-se "janelas" que cobrem apenas algumas linhas e colunas. Estas são deslocadas ao longo da região podendo ou não haver uma sobreposição parcial. A cada deslocamento calculam-se as estatísticas das informações contidas na janela. Estas janelas devem conter um número de dados que permita confiança nas estimativas obtidas. JOURNEL (1988) sugere pelo menos 10 dados.

A partir das medidas estatísticas calculadas em linhas, colunas e/ou janelas móveis deve-se desenhar gráficos de médias $v S$ variâncias, ou de medianas $v s$ amplitudes interquartílicas. O objetivo é verificar a existência do chamado efeito proporcional. Este efeito está presente quando existe uma relação entre média e variância. É desejável que ele não ocorra uma vez que indica heterocedasticidade. Transformações de variáveis podem anular tal efeito. É comum a ocorrência na natureza de fenômenos que têm distribuição assimética do tipo log-normal. Nestes casos tal efeito está presente e pode ser evitado utilizando-se a transformação logarítmica dos dados.

As técnicas citadas não abrangem todas as possíveis opções de descrição espacial. Também não são excludentes. É a reunião das informações trazidas por todas elas que explicitará a forma de manifestação do fenômeno estudado.

\subsubsection{Dados atípicos gerais e espaciais}

Dados atípicos podem ser identificados nas análises descritivas. Neste tipo de estudo podem surgir dados localmente atípicos. 
São situações em que um valor pode ser apontado como atípico na análise descritiva espacial, mesmo que isto não ocorra na análise geral.

Uma vez identificado, deve-se buscar a origem de tal valor, tentando justificar sua ocorrência. Em se tratando de um erro grosseiro (erro de anotação, leitura, etc) deve ser corrigido, se isto for possível e caso contrário, eliminado. Quando é atípico, mas que não por estas causas, devese procurar explicações para seu comportamento. Tal situação ocorre com as leituras de umidade da parcela 24 do segundo conjunto de dados. A decisão pode ser eliminá-los, editá-los (ou seja, corrigi-los usando algum critério estatístico) ou preservá-los. No caso desta última deve se avaliar seu impacto nos resultados da análise. Uma forma de fazer isto é obter alguns resultados com estes dados e sem eles. A decisão a ser tomada pode ser orientada pelo conhecimento do problema em questão e pode variar de acordo com a própria opinião do pesquisador.

É importante que se leve em considerąão a localização dos dados atípicos na região. Quando ocorrem de forma concentrada, indicam subregiões com comportamento diferenciado do geral da área. Quando ocorrem de maneira dispersa, podem estar indicando que o fenômeno tem alta variabilidade.

\subsubsection{A falta de estacionaridade}

O conhecimento do fenômeno estudado já pode indicar a falta de estacionaridade, que será posteriormente evidenciada pela análise descritiva espacial. Este é o caso dos dados de umidade do solo aqui tratados. O comportamento da umidade não é o mesmo ao longo das profundidades. A falta de estacionaridade pode ser tanto na média (valores médios diferentes nas diferentes profundidades), quanto na variância. Isto justifica a elaboração dos gráficos anteriormente citados por trazerem informações não só de medidas de posição mas também de dispersão.

A não estacionaridade do fenômeno pode ser devida a diferentes fatores. A região pode ser um agregado de subregiões distintas 
quanto à manifestação do atributo em questão. Nesta situação, o ideal é delimitar tais subregiões e estudá-las individualmente. Uma outra situação é a ocorrência de una tendência na manifestação da variável. Neste caso, temse que a esperança depende da posição $s$ na região:

$$
E\{Z(s)\}=m(s) .
$$

Diferentes alternativas de análise podem ser seguidas. Podese estimar e retirar tal tendência pelo uso do refinamento pela mediana usando os resíduos (que devem ser estacionários) nos passos subsequentes. Outra alternativa é modelar esta tendência com o uso de polinômios, seguindo os passos da Krigagem universal. Pode-se ainda considerar o uso de funções aleatórias de ordem $k$.

O presente trabalho adota o refinamento pela mediana. Este enfoque consiste em considerar que os dados podem ser decompostos da forma:

$$
z\left(s_{i j}\right)=\mu+r_{i}+c_{j}+\varepsilon_{i j}
$$

onde:

$z\left(s_{i j}\right)$ é o valor observado nas coordenadas i e $\mathrm{j}$;

$\mu$ é um valor típico;

$r_{i}$ é o efeito da i-ésima linha.

$c_{j}$ é o efeito da j-ésima coluna e

$\varepsilon_{i j}$ é o resíduo do refinamento na posição $s_{\mathrm{ij}}$.

A decomposição acima é facilmente obtida. Inicialmente os dados originais são dispostos em uma tabela de acordo com sua posição na malha de amostragem. Calcula-se a mediana de cada linha e subtraem-se os dados da linha da respectiva mediana. Procedimento análogo é feito com as colunas. Os valores remanescentes na tabela são os resíduos. Desta forma é obtida a primeira decomposição. Pode-se continuar iterativamente até algum critério de convergência ser obedecido. Ao contrário de um ajuste por mínimos quadrados, o refinamento pela mediana não tem solução única. Por 
outro lado, é um procedimento resistente. A decomposição proposta é análoga ao modelo paramétrico de blocos ao acaso.

Os resíduos passam a ser encarados como novos dados. No caso do uso do refinamento, é deles que se estará se falando daqui em diante. Uma vez que devem ser estacionários, toda a análise descritiva deve ser novamente efetuada para verificar se seu comportamento está de acordo com tal suposição.

\subsubsection{Estrutura de variabilidade: a opção pelos variogramas}

Uma vez assumido algum tipo de estacionaridade, o passo seguinte é conhecer a estrutura de variabilidade do processo. A suposição básica é a de que valores não são independentes e estão mais associados na medida em que estão mais próximos uns dos outros. Medidas de associação indicam a forma de manifestação do atributo estudado. É usual em geoestatística que tal estrutura seja estimada através de semivariogramas. Isto pode gerar um questionamento: por que não adotar medidas usuais tais como funções de covariância (covariogramas) ou correlação (correlogramas)? A preferência pelos semivariogramas pode ser explicada pelo fato de que eles exigem hipóteses de estacionaridade menos restritivas e portanto abrangem um maior universo de situações. Se o problema em questão não exige o conhecimento da variância do processo para sua solução, pode-se dizer que, de forma geral, a abordagem pelos semivariogramas é mais simples e genérica.

Como medida de dissimilaridade, valores menores de semivariância indicam uma maior associação. A definição do semivariograma é dada pela própria hipótese intrínseca:

$$
\gamma(h)=\frac{1}{2} E\left\{\left[Z\left(s_{1}\right)-Z\left(s_{2}\right)\right]^{2}\right\}, \text { em que }
$$


$s_{1}$ e $s_{2}$ indicam a localização de dois pontos na região separados por uma distância $h$.

Para melhor compreender e interpretar os semivariogramas é preciso que se atente ao fato de que, para sua construção, não se utilizam os valores observados das variáveis aleatórias e sim as diferenças entre tais valores separados por uma determinada distância.

O semivariograma é uma função que descreve o valor da variância de $\{Z(s+h)-Z(s)\}$ em função de $h$. Desta forma, conhecendo a distância que separa dois pontos estima-se o valor da variância da diferença das variáveis aleatórias em estudo nos pontos. Isto só faz sentido admitindose a hipótese intrínseca de que tal variância não depende da localização dos pontos mas apenas da distância entre eles. Isto é o mesmo que dizer que, sendo a distância que separa dois pontos a mesma, não importando a localização destes pontos na área, as diferenças entre os valores observados nos pontos constituem diversas reakizações de uma mesma variável aleatória.

Existem diversos estimadores para a semivariância, conforme discutido na revisão de literatura. Neste trabalho será utilizado o conhecido por estimador "clássico", de Matheron, ou do método dos momentos. Esta terceira designação parece mais adequada uma vez que indica sua real natureza. A expressão do estimador é dada por:

$$
\hat{\gamma}(h)=\frac{1}{2 N(h)} \sum_{N(h)}[z(s+h)-z(s)]^{2}
$$

Para malhas regulares, o semivariograma amostral é obtido da seguinte forma: 1) Fixa-se uma distância $h$ ("lag"); 2) Formam-se todos os pares de pontos separados por tal distância; 3) Aplica-se a expressão do estimador adotado obtendo a semivariância estimada e 4) Toma-se uma outra distância e repete-se os passos 1 a 3 . Isto é feito até uma distância máxima de interesse. 5) Os pares de pontos formados pelas distâncias (eixo $\mathrm{X}$ ) e semivariâncias (eixo Y) são assinalados em um gráfico.

No caso de malhas irregulares, tolerâncias angulares e de distâncias definem faixas com as quais são construídos os pares. 


\subsubsection{Análise exploratória para diferentes "lags"}

O estimador da semivariância aqui utilizado nada mais é do que a média da metade do quadrado da diferença observada entre pontos separados pela distância $h$. A média, como se sabe, não é uma medida resistente e portanto as informações que a geram devem ser avaliadas com cautela.

Ao formar todos os pares de pontos separados por uma certa distância $h$, pode-se representá-los em um gráfico de dispersão $Z(s)$ vs $Z(s+h)$ chamado de "h-scatterplot". A semivariância é uma medida de espalhamento da nuvem de pontos formada. Esta medida é o momento de inércia médio dos pontos em relação à bissetriz do gráfico.

Para cada distância $h$ do semivariograma há um gráfico correspondente deste tipo. Estes gráficos devem ser analizados cuidadosamente para indentificar possíveis problemas. Os eventuais pontos discrepantes são aqueles que notadamente se afastam da bissetriz $x=y$.

Enfim, uma análise exploratória para os diferentes "lags" pode ajudar na obtenção de um semivariograma amostral mais próximo da realidade dos dados e menos sensível a distorções.

\subsubsection{Modelagem da estrutura de variabilidade}

O semivariograma amostral pode não ser suficiente para descrever o padrão de variabilidade espacial do fenômeno, uma vez que contém estimativas de semivariâncias apenas para alguma distâncias que a malha amostral permite calcular. A interpolação por Krigagem exige medidas de semivariâncias para outras distâncias.

Um modelo que descreva a semivariância em função da distância é então ajustado a partir de um conjunto discreto de pontos, estimativas da semivariância para os diferentes "lags". A função deve satisfazer certas condições, discutidas no ítem 2.7. da revisão de literatura deste trabalho. 
Sendo que o variograma amostral é uma nuvem de pontos à qual deseja-se ajustar um modelo, pensa-se logo em um ajuste de mínimos quadrados ordinários como em um problema de simples de regressão. Porém tal ajuste não é adequado pois os pontos da nuvem correspondem a estimativas obtidas através de diferentes números de pares de pontos e portanto não possuem a mesma precisão, além de não serem independentes. Outro ponto é que, em geral, a informação da função que vai ser utilizada é aquela referente às menores distâncias, o que faz com que o interesse seja em que o modelo se ajuste bem principalmente para os pontos iniciais do semivariograma. A estimativa de mínimos quadrados ordinários não leva em conta tais aspectos.

Alternativamente, utiliza-se o ajuste dito "a sentimento". Neste caso, escolhe-se um modelo e seus parâmetros e este é sobreposto aos pontos estimados verificando-se visualmente a sua adequação. $O$ processo se repete até que se encontre um "bom" modelo. Tal procedimento deixa a desejar em termos de rigor, mas é sensível aos aspectos acima mencionados. $\mathrm{O}$ modelo escolhido pode ser posto a prova através da validação cruzada e desta forma é possível selecionar não apenas um único modelo, mas um conjunto deles e a escolha final entre os candidatos pode ser definida a partir dos resultados da validação.

A opção no presente trabalho foi comparar alguns modelos obtidos "a sentimento" e uma vez escolhida a forma da função, um ajuste mais "fino" de seus parâmetros foi obtido por mínimos quadrados ponderados, para o qual o ajuste a sentimento forneceu o "chute" inicial. Este procedimento é um compromisso entre o rigor, a simplicidade e exeqüibilidade.

Os modelos avaliados no presente trabalho, foram os disponíveis no programa Geo-EAS: esférico, exponencial, gaussiano e linear.

Supõe-se que o comportamento dos fenômenos estudados seja tal que valores separados por menores distâncias apresentem uma associação maior do que aqueles separados por distância maiores. Admite-se ainda que em certos casos, não há mais associação a partir de certa distância. 
Desta forma, o modelo que descreve a semivariância em função da distância nunca decresce ${ }^{1}$.

Os semivariogramas deveriam iniciar-se na origem. Porém, os variogramas amostrais nem sempre mostram este comportamento. $\mathrm{O}$ valor de semivariância no qual se inicia o modelo variográfico é chamado efeito pepita e denotado por $C_{0}$.

De acordo com seu aspecto, os modelos podem ser divididos em dois grupos:

\section{1) Modelos com patamar}

São aqueles em que a semivariância estabiliza-se em torno de um valor chamado patamar (notação: $C_{s}$ ), após certa distância, chamada alcance $(a)$. Nestes casos, observações separadas por distâncias maiores que $a$ são consideradas independentes.

Os modelos exponencial, esférico e gaussiano são exemplos de funções com patamar ${ }^{2}$. Neste casos, $C_{0}, C_{s}$ e $a$ são os parâmetros que definem os modelos.

Um outro tipo de modelo com este comportamento é o linear com patamar. Entretanto, estes modelos só são válidos em $\mathfrak{R}^{1}$, situações em que os dados são obtidos em transeções.

\section{2) Modelos sem patamar}

São aqueles em que não há indicação de estabilização da semivariância. Os modelos potência (entre eles o linear) descrevem tal comportamento. Este comportamento do semivariograma pode ser devido ao fato de que não foram obtidas amostras suficientemente afastadas para que $o$ patamar fosse detectado, ou pode ser uma indicação de que a hipótese intrínseca não é válida. Nestes casos a atenção com a análise descritiva deve ser redobrada no sentido de avaliar as condições de estacionaridade.

As expressões dos modelos anteriormente citados encontram-se na revisão de literatura.

\footnotetext{
${ }^{1}$ Existem certos tipos particulares de regionalização em que modelos trigonométricos, portanto com decréscimos de semivariância, são ajustados. Estes casos não são abordados neste trabalho.

${ }^{2}$ No caso do modelo exponencial o patamar é atingido apenas assintoticamente.
} 


\subsubsection{Isotropia e Anisotropia}

Em tudo o que foi apresentado até aqui a respeito de semivariogramas, não se considerou a direção na qual as distâncias eram medidas, ou seja, $h$ foi tratado como um escalar. Isto é válido, desde que o padrão da estrutura de variabilidade espacial seja o mesmo em todas as direçổes. Neste caso o fenômeno é dito isotrópico.

Mas nem sempre isto ocorre. Um exemplo é o caso em que dados são coletados em diferentes profundidades. Muitas vezes nestas situações, a estrutura de variabilidade na superficie é distinta daquela encontrada ao longo do perfil do solo. Em situações como estas ocorre a anisotropia.

Para verificar se um fenômeno é isotrópico, estima-se o variograma geral com informações de todas as direções ("omnidiretional"). Depois, são obtidos semivariogramas para diferentes direções. Quando o fenômeno é isotrópico, os semivariogramas geral e construídos para diferentes direções não .apresentam diferenças relevantes e um mesmo modelo é adequado a todos eles. $O$ fenômeno isotrópico indica que a área de influência de uma amostra é circular.

Não sendo o fenômeno isotrópico, é preciso encontrar os eixos de anisotropia. Desde que o número de dados permita, isto é feito tomando-se direções perpendiculares que possuam o maior e menor alcance no semivariograma. São ajustados modelos para estas duas direções.

Dois tipos de anisotropia podem ocorrer. A primeira, mais simples e talvez mais comum, é a geométrica. No caso de modelos com patamar, variogramas de diferentes direções têm o mesmo patamar e alcances diferentes. Nos lineares sem patamar, os coeficientes angulares são diferentes. Aqui tem-se que a área de influência de cada amostra é elipsoidal. Este tipo de anisotropia pode ser entendido como se diferentes "réguas" tivessem sido utilizadas para medir as distâncias nas diferentes direções, ou seja, um certo número de unidades de distância em uma direção é equivalente a um número diferente de unidades em outra direção. Para a padronização basta estabelecer um fator de correção utilizando os alcances (ou coeficientes angulares no caso de ajuste de modelos lineares). As 
medidas de distâncias ficam então corrigidas pelo grau de continuidade do fenômeno.

Um outro tipo é a anisotropia zonal. Pode ser notada quando os variogramas direcionais possuem diferentes patamares. Neste caso, o fenômeno apresenta diferentes formas de regionalização nas diferentes direções. Uma forma de tratá-la é ajustar um modelo (ou estrutura) para a direção de menor variabilidade. $O$ modelo para a direção perpendicular é então obtido pela soma daquele inicialmente considerado com um outro, de forma que esta soma de modelos se ajuste ao variograma da segunda direção.

Modelar a anisotropia significa considerar um maior número de parâmetros a serem estimados e portanto só deve ser feito quando isto mostrar efetiva colaboração para uma melhor descrição do fenômeno. Além disto, requer um maior número de dados. $\mathrm{O}$ conhecimento do tema $\mathrm{e}$ da região estudada pode ser fundamental na decisão de modelar a anisotropia.

\subsubsection{Validação Cruzada}

Conforme já mencionado, a análise geoestatística exige uma série de decisões que dependem de um certo grau de subjetividade. Através da validação cruzada pode-se avaliar se tais decisões são pertinentes. A idéia é que se o fenômeno foi satisfatoriamente modelado, é possivel reproduzir, com boa aproximação, informações da amostra.

A forma de executar a validação considerada neste trabalho é a seguinte: retira-se um ponto do conjunto original de dados e estima-se o valor da variável para aquele ponto a partir dos restantes, utilizando-se a Krigagem. É também estimada a variância da estimativa. Retorna-se o ponto ao conjunto e retira-se o seguinte, repetindo o processo para todos os pontos amostrados. Para cada ponto é possível então obter o erro de estimação 'e padronizá-lo pelo desvio padrão da estimação. Espera-se que o conjunto dos erros padronizados tenha distribuição normal de média zero e variância unitária. Não são aplicados testes devido às ressalvas apresentadas na 
revisão de literatura. As estatísticas obtidas a partir dos erros, bem como os diversos gráficos que mostram seu comportamento são usados na avaliação.

Uma observação importante é que a validação cruzada não está avaliando simplesmente o modelo escolhido para o semivariograma. Toda a modelagem do processo estocástico em questão está sendo posta a prova. Isto inclui a decisão de estacionaridade, os estimadores utilizados, o tratamento dos dados atípicos, o modelo de semivariograma adotado e a decisão relativa a anisotropia.

Os erros refletem inconsistências, porém nem sempre é uma tarefa simples identificar a causa de possíveis problemas apontados pelos resultados da validação cruzada. Com uma certa experiência e conhecimento do problema em questão, aliados a uma análise cuidadosa através de diversos recursos descritivos, especialmente gráficos, pode-se conseguir identificar a(s) origem(ens) do problema(s) entre as mencionadas no parágrafo anterior.

Os resultados da validação cruzada podem ser usados em comparações de modelos, estratégias de análise, etc.

\subsubsection{Interpolação: o Preditor de Krigagem}

Muitas vezes o interesse da análise não se esgota em modelar a estrutura de variabilidade. Em diversas situações o interesse está na estimação de valores em pontos não amostrados, seja por um interesse local ou pela intenção de obter um detalhamento da área que vai além do permitido pela amostra. Nestes casos é preciso lançar mão de algum interpolador (preditor) dentre os existentes na literatura.

A proposta de predição geoestatística é a Krigagem. Uma vez que as observações são dependentes, ao menos a certas distâncias, utilizam-se os vizinhos do ponto a ser predito para obter a estimativa. A idéia é atribuir pesos a estes vizinlos, de forma que o preditor é, simplesmente, uma média ponderada dos valores observados na vizinhança: 


$$
\hat{Z}\left(s_{0}\right)=\sum_{i=1}^{k} \lambda_{i} z\left(s_{i}\right),
$$

onde:

$\hat{Z}\left(s_{0}\right)$ é o preditor para um ponto $s_{0}$ da região;

$k$ é o número de vizinhos utilizados na predição;

$\lambda_{i}$ é o peso atribuído a cada vizinho e $z\left(s_{i}\right)$ é o valor observado em cada vizinho.

Entretanto esta expressão não é exclusiva deste preditor. $\mathrm{O}$ que diferencia a Krigagem de outros preditores é o critério utilizado para obtenção dos pesos $\lambda_{i}$.

Existem diversos tipos de Krigagem: simples, ordinária, universal, indicadora e probabilística. Neste trabalho será abordada a Krigagem ordinária, na qual não é necessário o conhecimento da média do atributo na região e os dados são realização de um processo ao menos intrinsicamente estacionário.

A compreensão de que pontos mais próximos são mais associados de que os mais distantes faz com que seja razoável que qualquer critério para atribuir pesos seja baseado em distâncias. Desta forma, vizinhos mais próximos devem ter maior peso do que aqueles mais distantes. Um exemplo de aplicação imediata desta idéia é o uso do método do inverso do quadrado das distâncias.

A questão que se levanta é: como se mede uma distância? A noção usual é a medida de distância euclidiana. Porém ela pode não ser a mais adequada. Um caso em isto ocorre é quando o grau de continuidade do fenômeno é diferente em diferentes direções (ou seja, ocorre anisotropia). Dois pontos separados pela mesma distância euclidiana do ponto a ser estimado podem ter influências diferentes na estimação dependendo da direção onde estão situados, uma vez què a variabilidade é distinta nas diferentes direções. Portanto, para compreender o preditor de Krigagem é fundamental que se liberte da noção euclidiana de distância e se pense em uma distância "estatística" que incorpore tainbém a estrutura de variabilidade. 
Mas não apenas a distância dos vizinhos ao ponto a ser estimado deve ser considerada. Também as distâncias entre os vizinhos devem influir na atribuição dos pesos. Vizinhos agrupados devem ter importância individual relativamente menor do que aqueles isolados. O preditor de krigagem, ao contrário de outros, considera este aspecto, possuindo então uma característica chamada de "declustering".

A figura 1 ilustra este aspecto. $O$ objetivo é estimar o valor no ponto A usando as informações dos vizinhos v1, v2, v3 e v4. Supondo o fenômeno isotrópico, na configuração da esquerda todos os vizinhos receberiam pesos iguais a 0,25 . Já na configuração da direita, v2, v3 e v4 trazem informações da mesma região e são quase redundantes. É razoável que a distribuição dos pesos neste caso seja diferente, com v1 recebendo peso superior a 0,25 .

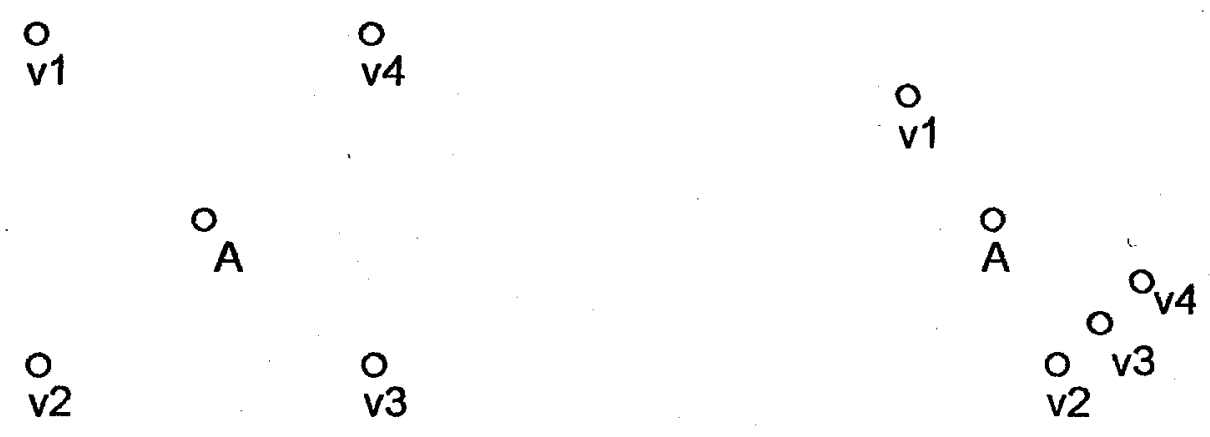

Figura 1 - Diferentes configurações de vizinhanças.

O preditor de krigagem leva em conta os aspectos acima relacionados através de alguma medida de associação entre os pontos. Esta medida pode ser a covariância (no caso de a estacionaridade de segunda ordem ser assumida) ou a semivariância (sob hipótese intrínseca), que será aqui utilizada. Fica claro aqui a necessidade do semivariograma. Uma vez que se tenha o modelo variográfico, a semivariância entre dois pontos é obtida substituindo a distância $h$ entre eles na função $\gamma(h)$.

$O$ preditor de krigagem considera que o modelo do variograma é correto e que não há erros de medida. A partir deste 
pressuposto ele é obtido de forma a atender duas qualidades desejáveis em um preditor: não-tendenciosidade e variância mínima. Neste sentido é dito ser BLUP ("best linear unbiased predictor").

A dedução da expressão do preditor ilustra e justifica os procedimentos e preocupações da geoestatística. Será aqui apresentada a obtenção do preditor de krigagem ordinária pontual, assumindo a hipótese intrínseca. A figura 2 ilustra a situação em que o valor da variável em um ponto $s_{0}$ será obtido por uma ponderação dos valores $\left[z\left(s_{1}\right), z\left(s_{2}\right), \ldots, z\left(s_{k}\right)\right]$ observados em $k$ vizinhos. Os pesos serão diretamente obtidos ao se assegurar as condições de qualidade do preditor anteriormente mencionadas.

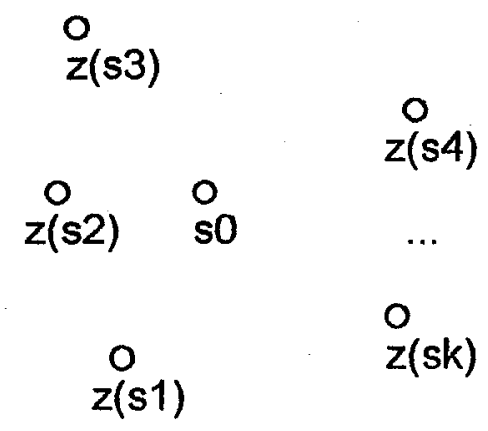

Figura 2 - Ponto a ser estimado e valores observados na vizinhança.

Denotando por $\hat{Z}\left(s_{0}\right)$ o estimador e por $Z\left(s_{0}\right)$ o verdadeiro (e desconhecido) valor da variável no ponto $s_{0}$, a fim de se satisfazer a condição de não-tendencioso, deve-se ter que:

$$
\begin{aligned}
& E\left\{\hat{Z}\left(s_{0}\right)-Z\left(s_{0}\right)\right\}=0 \\
& E\left\{\sum_{i} \lambda_{i} Z\left(s_{i}\right)-Z\left(s_{0}\right)\right\}=0 \\
& \sum_{i} \lambda_{t} E\left\{Z\left(s_{i}\right)\right\}-E\left\{Z\left(s_{0}\right)\right\}=0
\end{aligned}
$$

A condição (i) da hipótese intrínseca permite que se escreva: 


$$
\begin{aligned}
& \mu \sum_{i} \lambda_{i}-\mu=0 \\
& \sum_{i} \lambda_{i}=1
\end{aligned}
$$

Portanto, se a soma dos pesos for um, fica garantida a nãotendenciosidade do preditor.

A variância de estimação decomposta da forma:

$\operatorname{Var}\left\{\hat{Z}\left(s_{0}\right)-Z\left(s_{0}\right)\right\}=E\left\{\left[\hat{Z}\left(s_{0}\right)-Z\left(s_{0}\right)\right]^{2}\right\}-E\left\{\left[\hat{Z}\left(s_{0}\right)-Z\left(s_{0}\right)\right]\right\}^{2}$

Atendida a condição de não-tendenciosidade, o segundo termo do lado direito da equação se anula. Deve-se então minimizar a variância de estimação. Antes porém, é necessário que se desenvolva a expressão desta variância conforme se segue.

$$
\begin{aligned}
& \operatorname{Var}\left\{\hat{Z}\left(s_{0}\right)-Z\left(s_{0}\right)\right\}=E\left\{\left[\hat{Z}\left(s_{0}\right)-Z\left(s_{0}\right)\right]^{2}\right\}= \\
& =E\left\{\left[\hat{Z}\left(s_{0}\right)\right]^{2}\right\}-2 E\left\{\hat{Z}\left(s_{0}\right) Z\left(s_{0}\right)\right\}+E\left\{\left[Z\left(s_{0}\right)\right]^{2}\right\}= \\
& =E\left\{\left[\sum_{i} \lambda_{i} Z\left(s_{i}\right)\right]\left[\sum_{j} \lambda_{j} Z\left(s_{j}\right)\right]\right\}-2 E\left[\sum_{i} \lambda_{i} Z\left(s_{i}\right) Z\left(s_{j}\right)\right]+E\left\{\left[Z\left(s_{0}\right)\right]^{2}\right\}= \\
& =\sum_{i} \sum_{j} \lambda_{i} \lambda_{j} E\left[Z\left(s_{i}\right) Z\left(s_{j}\right)\right]-2 \sum_{i} \lambda_{i} E\left[Z\left(s_{i}\right) Z\left(s_{0}\right)\right]+E\left\{\left[Z\left(s_{0}\right)\right]^{2}\right\}=\ldots
\end{aligned}
$$

Os termos da expressão acima podem ser escritos em função da semivariância definida na condição (ii) da hipótese intrínseca. Antes de prossegir com o desenvolvimento da variância de estimação, considere-se as relações e notações seguintes. 


$$
2 \gamma_{i j}=2 \gamma\left(s_{i}, s_{j}\right)=2 \gamma(h)=E\left\{\left[Z\left(s_{i}\right)-Z\left(s_{j}\right)\right]^{2}\right\}
$$

onde os pontos $s_{i}$ e $s_{j}$ estão separados por uma distância $h$. Além disto, como:

$E\left\{\left[Z\left(s_{i}\right)-Z\left(s_{j}\right)\right]^{2}\right\}=E\left\{\left[Z\left(s_{i}\right)\right]^{2}\right\}+E\left\{\left[Z\left(s_{i}\right)\right]^{2}\right\}-2 E\left[Z\left(s_{i}\right) Z\left(s_{j}\right)\right]$

tem-se que:

$$
E\left[Z\left(s_{i}\right) Z\left(s_{j}\right)\right]=\frac{1}{2}\left\{E\left\{\left[Z\left(s_{i}\right)\right]^{2}\right\}+E\left\{\left[Z\left(s_{j}\right)\right]^{2}\right\}\right\}-\gamma\left(s_{i}, s_{j}\right)
$$

Substituindo então este resultado na expressão da variância de estimação e prosseguindo sua expansão obtem-se:

$$
\begin{aligned}
& \ldots=\sum_{i} \sum_{j} \lambda_{i} \lambda_{j}\left\{\frac{1}{2}\left\{E\left\{\left[Z\left(s_{i}\right)\right]^{2}\right\}+E\left\{\left[Z\left(s_{j}\right)\right]^{2}\right\}\right\}-\gamma\left(s_{i}, s_{j}\right)\right\}- \\
& -2 \sum_{i} \lambda_{i}\left\{\frac{1}{2}\left\{E\left\{\left[Z\left(s_{i}\right)\right]^{2}\right\}+E\left\{\left[Z\left(s_{0}\right)\right]^{2}\right\}\right\}-\gamma\left(s_{i}, s_{0}\right)\right\}+E\left\{\left[Z\left(s_{0}\right)\right]^{2}\right\}= \\
& =\frac{1}{2} \sum_{i} \lambda_{i} E\left\{\left[Z\left(s_{i}\right)\right]^{2}\right\}\left(\sum_{j} \lambda_{j}\right)+\frac{1}{2} \sum_{j} \lambda_{j} E\left\{\left[Z\left(s_{j}\right)\right]^{2}\right\}\left(\sum_{i} \lambda_{i}\right)- \\
& -\sum_{i} \sum_{j} \lambda_{i} \lambda_{j} \gamma\left(s_{i}, s_{j}\right)-\sum_{i} \lambda_{i} E\left\{\left[Z\left(s_{i}\right)\right]^{2}\right\}-E\left\{\left[Z\left(s_{0}\right)\right]^{2}\right\}\left(\sum_{j} \lambda_{j}\right)+ \\
& +2 \sum_{i} \lambda_{i} \gamma\left(s_{i}, s_{j}\right)+E\left\{\left[Z\left(s_{0}\right)\right]^{2}\right\}
\end{aligned}
$$


60.

$\left(\sum_{i} \lambda_{i}\right)=\left(\sum_{j} \lambda_{\jmath}\right)=1$, os dois primeiros termos se equivalem e após a simplificação chega-se a:

$\operatorname{Var}\left\{\hat{Z}\left(s_{0}\right)-Z\left(s_{0}\right)\right\}=-\sum_{i} \sum_{j} \lambda_{i} \lambda_{j} \gamma\left(s_{i}, s_{j}\right)+2 \sum_{i} \lambda_{i} \gamma\left(s_{1}, s_{0}\right)$

Esta expressão deve ser minimizada sujeita a restrição de que a soma dos pesos seja 1. Desta forma, incluindo o lagrangeano, a função a ser minimizada fica:

$$
\operatorname{Var}\left\{\hat{z}\left(s_{0}\right)-Z\left(s_{0}\right)\right\}=-\sum_{i} \sum_{j} \lambda_{i} \lambda_{j} \gamma\left(s_{i}, s_{j}\right)+2 \sum_{i} \lambda_{i} \gamma\left(s_{i}, s_{0}\right)-2 \nu\left(\sum_{i} \lambda_{i}\right)
$$

As derivadas parciais fornecem:

$$
\begin{aligned}
& \frac{\partial M}{\partial \lambda_{l}}=-2 k \sum_{l} \lambda_{i} \gamma\left(s_{i}, s_{j}\right)+2 k \gamma\left(s_{l}, s_{j}\right)-2 k \eta \\
& \frac{\partial M}{\partial \eta}=-2 \sum_{l} \lambda_{l}+2
\end{aligned}
$$

Igualadas a zero formam um sistema $(k+1) x(k+1)$ com equações do tipo:

$$
\left\{\begin{array}{l}
\sum_{i} \hat{\lambda}_{i} \gamma\left(s_{i}, s_{j}\right)+\hat{\eta}=\gamma\left(s_{i}, s_{0}\right) \\
\sum_{i} \hat{\lambda}_{i}=1
\end{array}\right.
$$


Sob a notação matricial assume a forma:

$$
\left[\begin{array}{ccccc}
\gamma\left(s_{1}, s_{1}\right) & \gamma\left(s_{1}, s_{2}\right) & \ldots & \gamma\left(s_{1}, s_{k}\right) & 1 \\
\gamma\left(s_{2}, s_{1}\right) & \gamma\left(s_{2}, s_{2}\right) & \ldots & \gamma\left(s_{2}, s_{k}\right) & 1 \\
\ldots & \ldots & \ldots & \ldots & 1 \\
\gamma\left(s_{k}, s_{1}\right) & \gamma\left(s_{k}, s_{2}\right) & \ldots & \gamma\left(s_{k}, s_{k}\right) & 1 \\
1 & 1 & 1 & 1 & 0
\end{array}\right]\left[\begin{array}{c}
\hat{\lambda}_{1} \\
\hat{\lambda}_{2} \\
\ldots \\
\hat{\lambda}_{k} \\
\hat{\eta}
\end{array}\right]=\left[\begin{array}{c}
\gamma\left(s_{1}, s_{0}\right) \\
\gamma\left(s_{2}, s_{0}\right) \\
\ldots \\
\gamma\left(s_{k}, s_{0}\right) \\
1
\end{array}\right]
$$

Escrito resumidamente,

$$
A\left[\begin{array}{l}
\hat{\lambda} \\
\hat{\eta}
\end{array}\right]=b
$$

Tem como solução:

$$
\left[\begin{array}{l}
\hat{\lambda} \\
\hat{\eta}
\end{array}\right]=A^{-1} b
$$

Para obtenção dos coeficientes $\gamma\left(s_{i}, s_{j}\right)$ da matriz $A$, verifica-se a distância $h_{i j}$ entre os vizinhos localizados em $s_{i}$ e $s_{j}$ e substituise este valor na expressão do modelo adotado para o semivariograma. $O$ mesmo é feito para os termos do vetor $b$, onde são medidas distâncias entre os vizinhos e o ponto a ser estimado.

Este desenvolvimento mostra claramente a importância da hipótese intrínseca e do modelo escolhido na obtenção do preditor de Krigagem, que assume que os passos anteriores da análise estão livres de erro.

Usando raciocínio semelhante mostra-se ainda que variância da estimativa independe dos valores dos vizinhos, usando apenas informações da geometria relativa destes: 


$$
\operatorname{Var}\left[\hat{Z}\left(s_{0}\right)\right]=b^{r}\left[\begin{array}{l}
\hat{\lambda} \\
\hat{\eta}
\end{array}\right]
$$

A obtenção dos pesos é portanto consequência do se atender a critérios de qualidade do estimador.

Uma forma de obter estimativas ainda mais precisas é a Krigagem por blocos onde estimạn-se não um único ponto, mas diversos, a fim de se obter uma estimativa média. As deduções constituem uma ampliação das anteriormente vistas e não serão apresentadas neste trabalho.

\subsubsection{Mapas e superfícies que descrevem o fenômeno}

Quando o interesse é ter uma idéia visual do comportamento do atributo na área é utilizada alguma representação gráfica onde as coordenadas dos pontos e os valores da variável são representados em um sistema.

Este mapa é construído a partir de uma malha obtida por aplicações sucessivas da Krigagem. Esta malha é bem mais fina do que a de amostragem. A representação pode ser tridimensional, através do desenho de uma superficie onde o eixo $\mathrm{Z}$ corresponde ao valor do atributo em cada ponto identificado nos eixos $\mathrm{X}$ e $\mathrm{Y}$. Outra opção é uma representação bidimensional através da confecção de mapas de isolinhas.

Este trabalho não aborda aspectos ligados ao traçado destes mapas. O programa utilizado (Geo-EAS) desenha mapas de isolinhas a partir de um arquivo gerado pela Krigagem. Este arquivo pode ser utilizado em outros programas para obtenção de gráficos de melhor qualidade visual. 


\section{RESULTADOS E DISCUSSÃO}

Uma síntese das análise efetuadas nos dois conjuntos de dados é apresentada a seguir. Os dados dos dois conjuntos são discutidos separadamente. $O$ objetivo é mostrar como alguns recursos estatísticos podem ser empregados na análise de dados espacialmente distribuídos. Uma grande ênfase é dada na análise descritiva (geral e espacial) devido a grande importância que recai sobre a decisão de estacionaridade do fenômèno. As estratégias de análise seguidas não são únicas e por isto mesmo são questionáveis. Apesar da forma sequencial de apresentação dos resultados, chama-se a atenção ao fato de que no decorrer das análises são necessárias várias "idas e vindas" antes de se chegar aos resultados definitivos.

Para a densidade do solo, discutida em 4.1., são mostrados resultados desde a análise descritiva até a confeç̧ão de mapa de isolinhas. Com isto pretende-se dar uma visão geral do mapeamento de um atributo em uma área, utilizando a geoestatística.

Os dados de umidade do solo são discutidos em 4.2. A intenção com este conjunto é mostrar como a falta de estacionaridade pode ser detectada e corrigida utilizando o refinamento pela mediana. Neste caso são apresentados simplesmente os resultados da análise descritiva e a obtenção do variograma amostral.

Em nenhuma das duas situações pretende-se discutir os resultados em relação à interpretação física dos fenômenos. O objetivo é tão somente ilustrar as possibilidades de aplicação da teoria geoestatística em conjuntos de dados reais. 


\subsection{Dados de densidade do solo}

A partir das informações fornecidas pela amostra foi construído um gráfico (figura 3) a fim de se visualizar, de forma geral e inicial, o comportamento da densidade do solo na região.

Valores notadamente distintos dos demais e regiões anômalas já podem começar a ser identificados. É o caso da região situada à esquerda na parte de trás do gráfico, que mostra os maiores valores de densidade encontrados na região. A explicação para o fato é que, devido a conformação do relevo, houve remoção de camadas superficiais do solo nesta parte do terreno. Com isto, horizontes mais profundos e compactados ficaram expostos, provocando elevadas leituras de densidade (atingem até $\left.1,727 \mathrm{~g} / \mathrm{cm}^{3}\right)^{1}$.

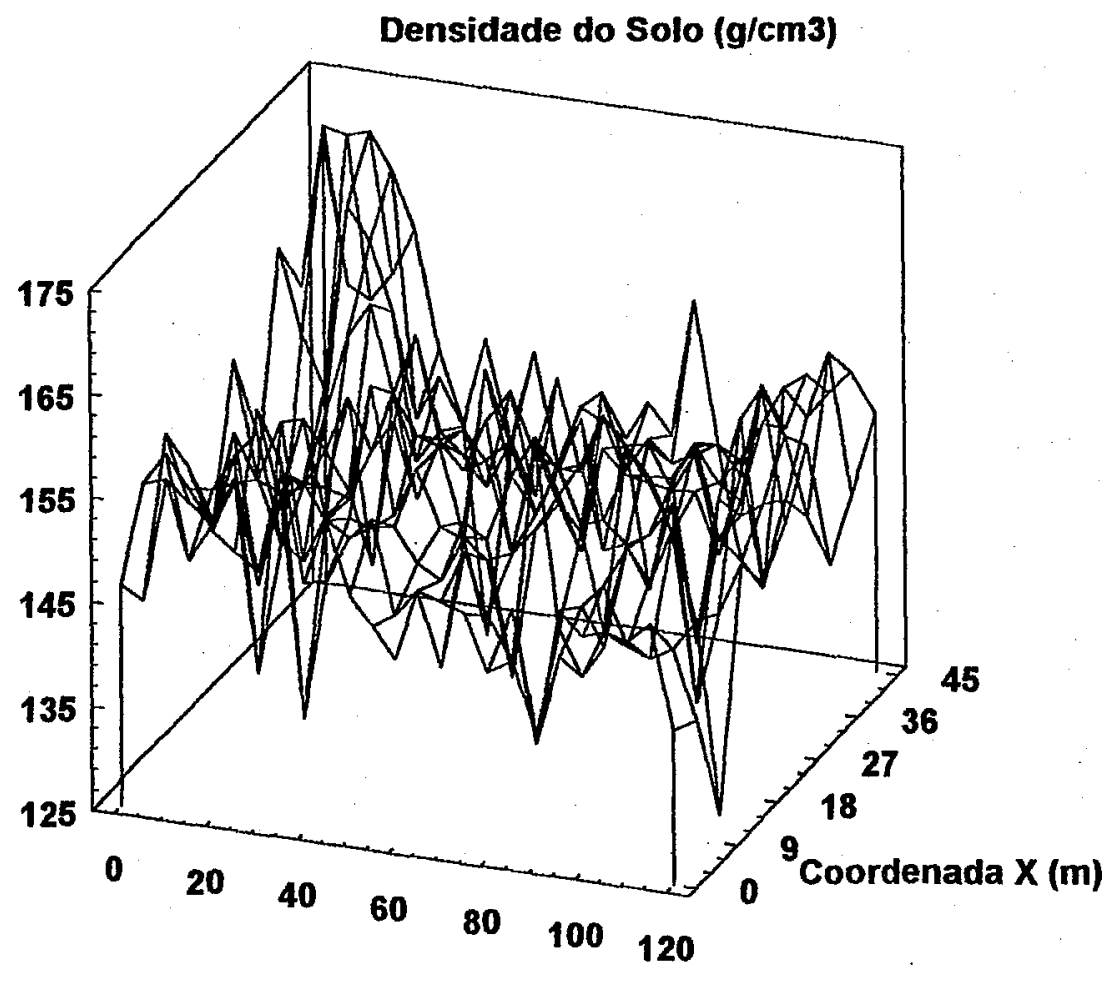

Coordenada $Y(\mathbf{m})$

Figura 3 - Superficie mostrando os valores amostrados e suas posições.

'MORAES, S.O. (Escola Superior de Agricultura "Luiz de Quiroz" / USP, SP) Comunicação Pessoal. 1994. 


\subsubsection{Análise descritiva}

Iniciou-se a análise descritiva com o cálculo dos valores de estatísticas que resumem o comportamento dos dados (tabela 1).

Tabela 1 - Estatísticas da densidade do solo.

\begin{tabular}{|l|l|l|l|l|l|}
\hline $\begin{array}{l}\text { Número de } \\
\text { dados }\end{array}$ & Mínimo & $\begin{array}{l}\text { Quartil } \\
\text { Inferior }\end{array}$ & Mediana & $\begin{array}{l}\text { Quartil } \\
\text { Superior }\end{array}$ & Máximo \\
\hline 250 & 1.272 & 1.449 & 1.490 & 1.520 & 1.727 \\
\hline \hline Média & Variância & $\begin{array}{l}\text { Desvio } \\
\text { Padrão }\end{array}$ & $\begin{array}{l}\text { Coeficiente } \\
\text { de Variação }\end{array}$ & $\begin{array}{l}\text { Coef. de Assimetria } \\
\text { Asín }\end{array}$ & $\begin{array}{l}\text { Coeficiente } \\
\text { de Curtose }\end{array}$ \\
\hline 1.490 & 0.005 & 0.071 & 4.791 & 0.354 & 4.215 \\
\hline
\end{tabular}

Os dados possuem um comportamento próximo distribuição normal conforme pode ser notado através da figura 4 . Os coeficientes de assimetria e curtose afastam-se um pouco de 0 e 3 , respectivamente, principalmente devido aos três valores acima de 1.7, todos situados na área atípica, já discutida. Retirando-se estes valores e recalculando os coeficientes obtém-se assimetria de 0.150 e curtose de 3.524 .
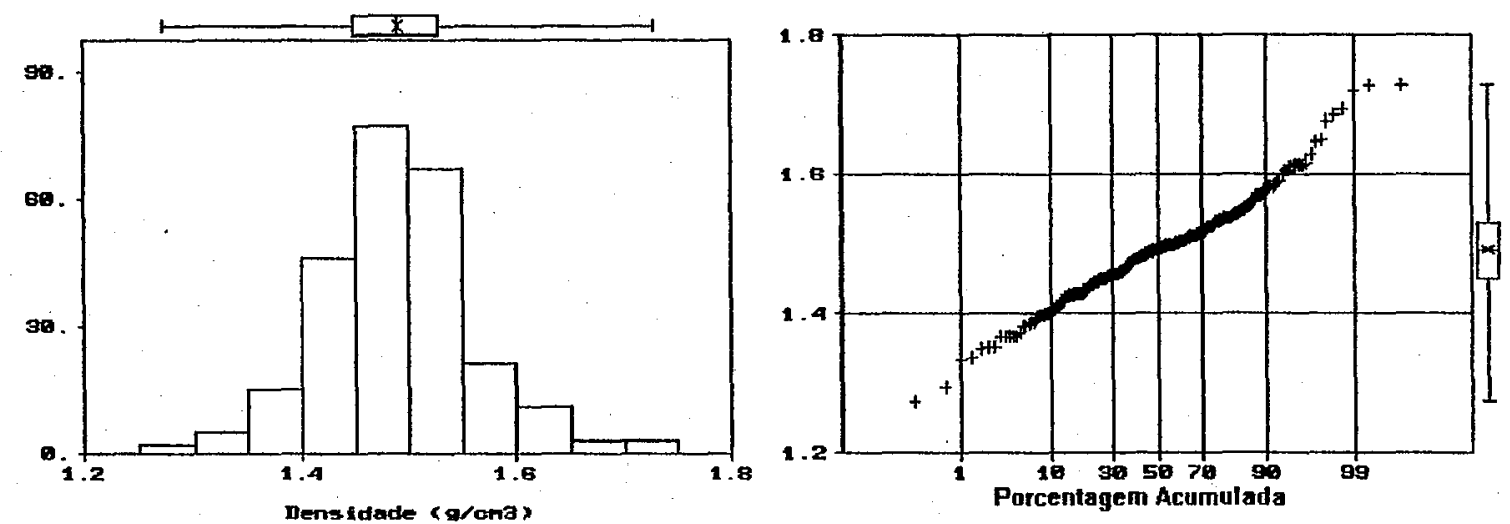

Figura 4 - Histograma e gráfico de probabilidade normal dos dados de densidade do solo. 
Os valores atípicos de forma geral podem ser identificados pelo gráfico da figura 5. São definidos limites subtraindo o primeiro quartil e somando ao terceiro uma vez e meia o valor da amplitude interquartilica. Os dados situados fora destes limites são destacados. Oito pontos mostraram este comportamento e seus efeitos nas análises foram avaliados. Verificou-se que apenas os valores superiores a 1.7 causam maiores perturbações nas estimativas.

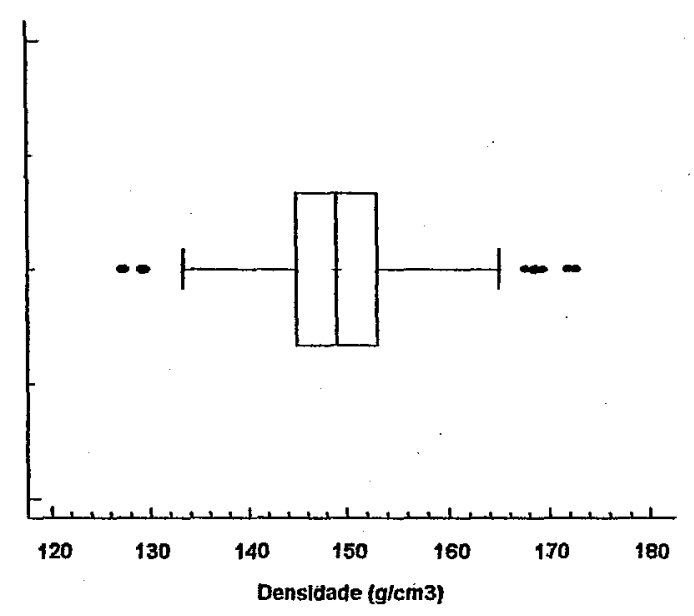

Figura 5 - "Box-Plot" dos dados de densidade do solo.

As figuras 6 a 11 ilustram alguns recursos da análise descritiva espacial. A principal preocupação é verificar se existem tendências associadas às posições espaciais.

pela figura 3 .

O "postplot" gerado pelo Geo-EAS (figura 6) associa símbolos a cada valor, indicando a qual quartil ele pertence. Concentrações de símbolos iguais podem indicar sub-regiões. Variações gradativas ao longo de alguma direção indicam existência de tendências. Portanto, para atender à hipótese intrínseca não deve ser possível identificar padrões neste gráfico. Os dados de densidade parecem estar de acordo com tal hipótese, exceto pela concentração que ocorre no alto a esquerda do gráfico, detectada também pela figura 3 . 


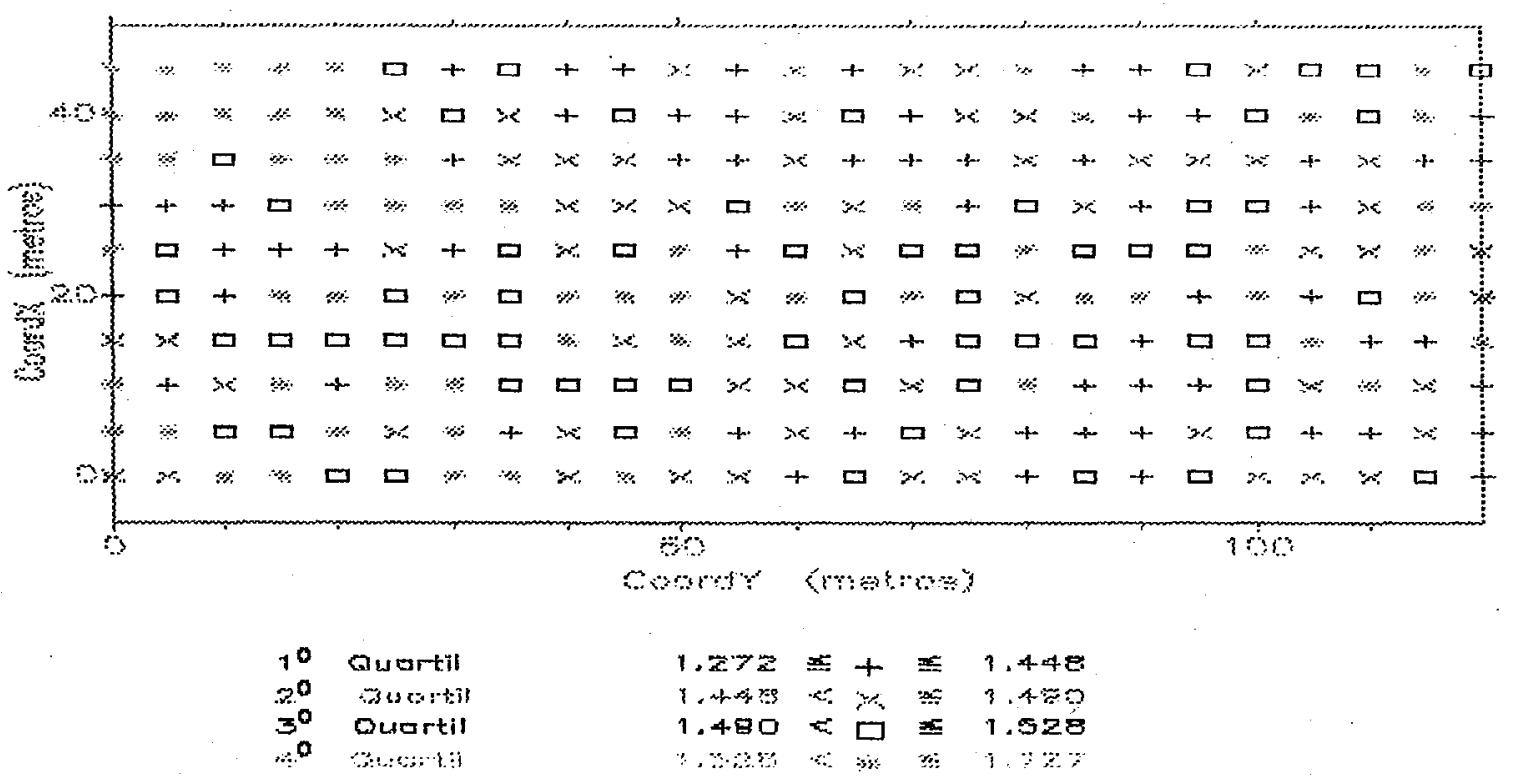

Figura 6 - "Postplot" dos dados de densidade do solo.

A fim de detectar o comportamento dos dados em relação às direções da malha amostrada foram construídos os gráficos da figura 7. Para cada linha e cada coluna foram assinalados os valores encontrados. Tendências $\mathrm{e}$ heterogeneidades de variâncias que coincidam com as coordenadas da malha podem ser identificadas desta forma. Em relação a coordenada $X$ não há qualquer tipo de problema uma vez que as linhas mostram valores médios próximos e dispersões semelhantes. Nas colunas há pequenas flutuações nos valores médios porém sem definir claramente qualquer tendência. As dispersões não são tão homogêneas quanto nas linhas. A explicação pode ser dada pelo fato de que o gráfico da esquerda (a) foi construído com 25 pontos para cada linha enquanto que o da direita (b) possui apenas 10 pontos por coluna. Isto faz com que nesta segunda situação os dados atípicos anteriormente mencionados causem maiores perturbações. 

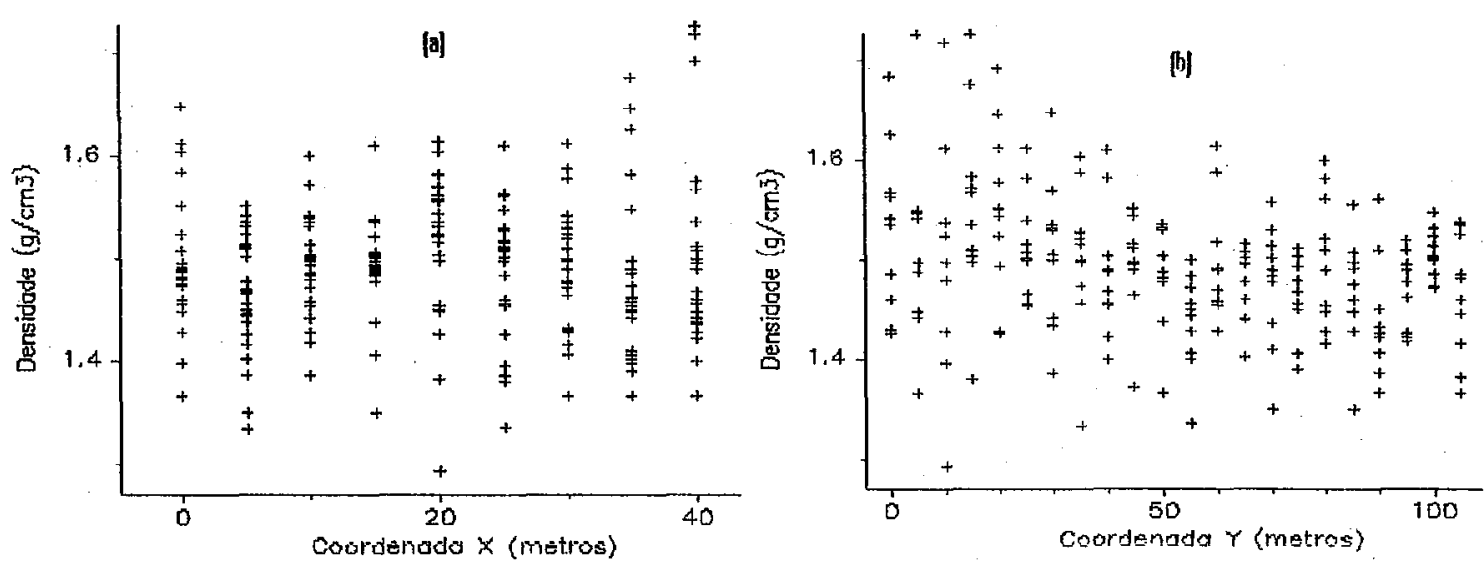

Figura 7 - Valores da densidade por linhas(a) e colunas(b) da malha amostrada.

O comportamento do atributo pode ser verificado também em janelas móveis. Neste estudo englobavam 2 (duas) linhas e 5 (cinco) colunas, totalizando $10(\mathrm{dez})$ dados cada uma. Não foi feita sobreposição entre as janelas. As figuras 8,9 e 10 são três alternativas para resumir as informações das janelas (gráfico mais à direita de cada figura) além das linhas e colunas da malha. O objetivo é o mesmo da figura 7: verificar a existência de tendências, heterogeneidades de variâncias e comportamentos isolados. A figura 8 mostra médias e desvios padrões de linhas, colunas e janelas móveis. A figura 9 usa medidas resistentes (medianas e amplitudes interquartilicas) para esta representação. Gráficos com un apelo visual maior são traçados na figura 10 que se utiliza de múltiplos "box-plot".
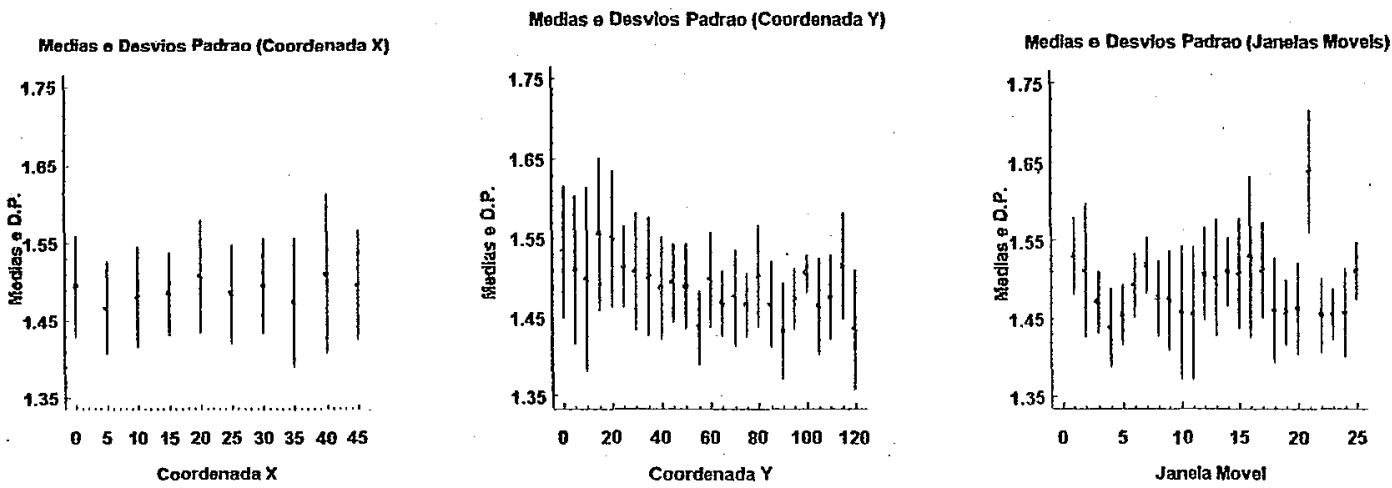

Figura 8 - Médias e desvios padrão da densidade para cada coluna (à esquerda), linha (ao centro) e janela móvel (à direita). 

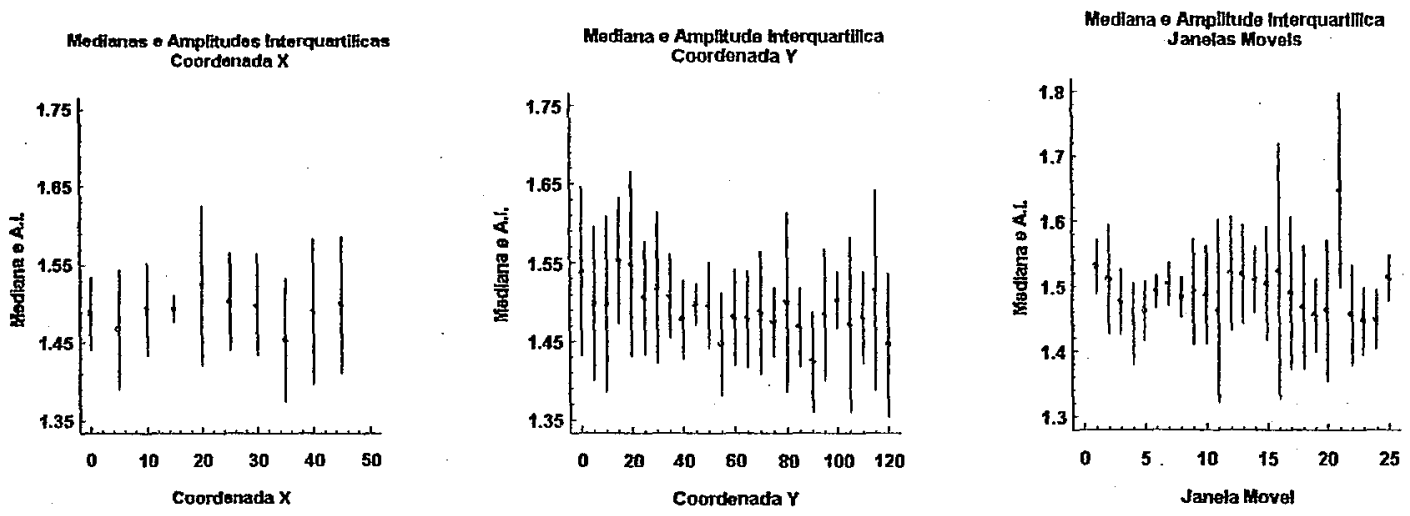

Figura 9 - Medianas e amplitudes interquartilicas da densidade para cada coluna (à esquerda), linha (ao centro) e janela móvel (à direita).
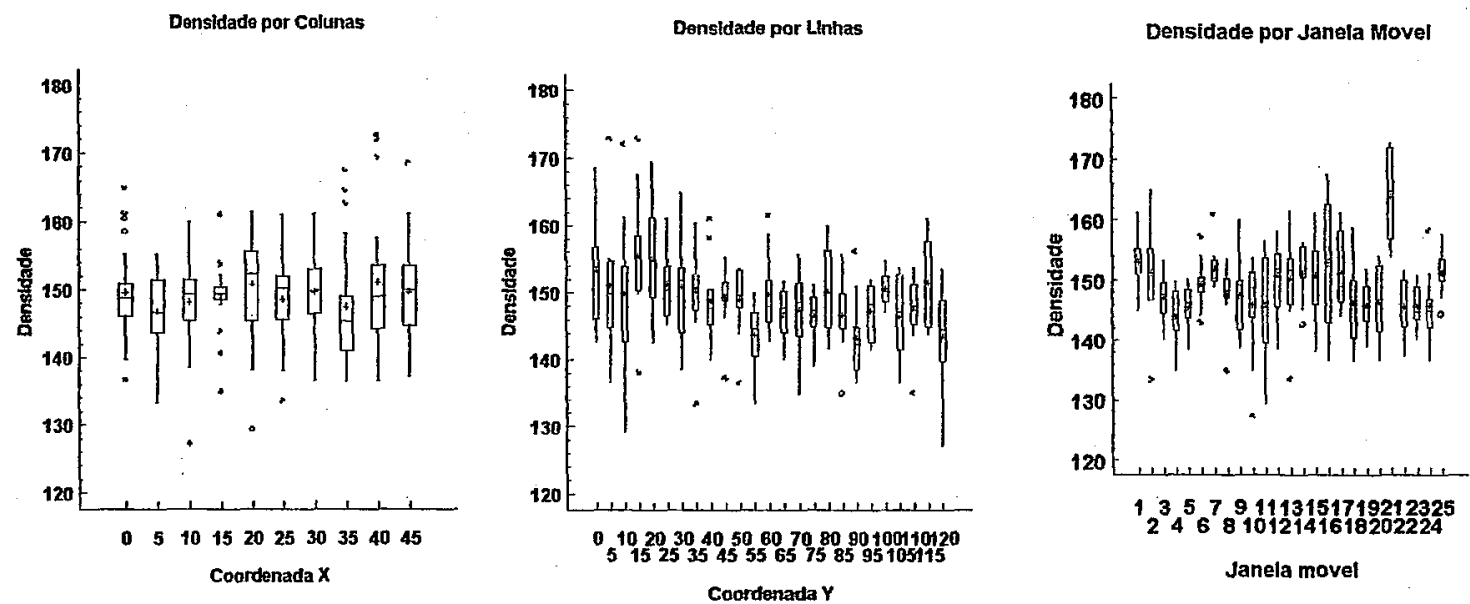

Figura 10 - "Box-Plot" da densidade para cada coluna (à esquerda), linha (ao centro) e janela móvel (à direita).

A região de valores elevados de densidade fica bem evidenciada especialmente nos gráficos das janelas móveis. Além disto, causa perturbações nos gráficos de linhas e colunas conforme discutido na análise da figura 7 .

A fim de verificar se há ocorrência de efeito proporcional (relação entre medidas de posição e dispersão), as médias e desvios padrão 
de linhas, colunas e janelas móveis; assim como medianas e amplitudes interquartílicas foram dispostas em gráficos da figura 11. A existência do efeito proporcional é incompatível com a hipótese intrínseca e geralmente exige alguma transformação dos dados. Novamente os pontos mais isolados do gráfico se devem à região de altos valores de densidade. Nesta situação não há evidências da ocorrência do efeito proporcional.
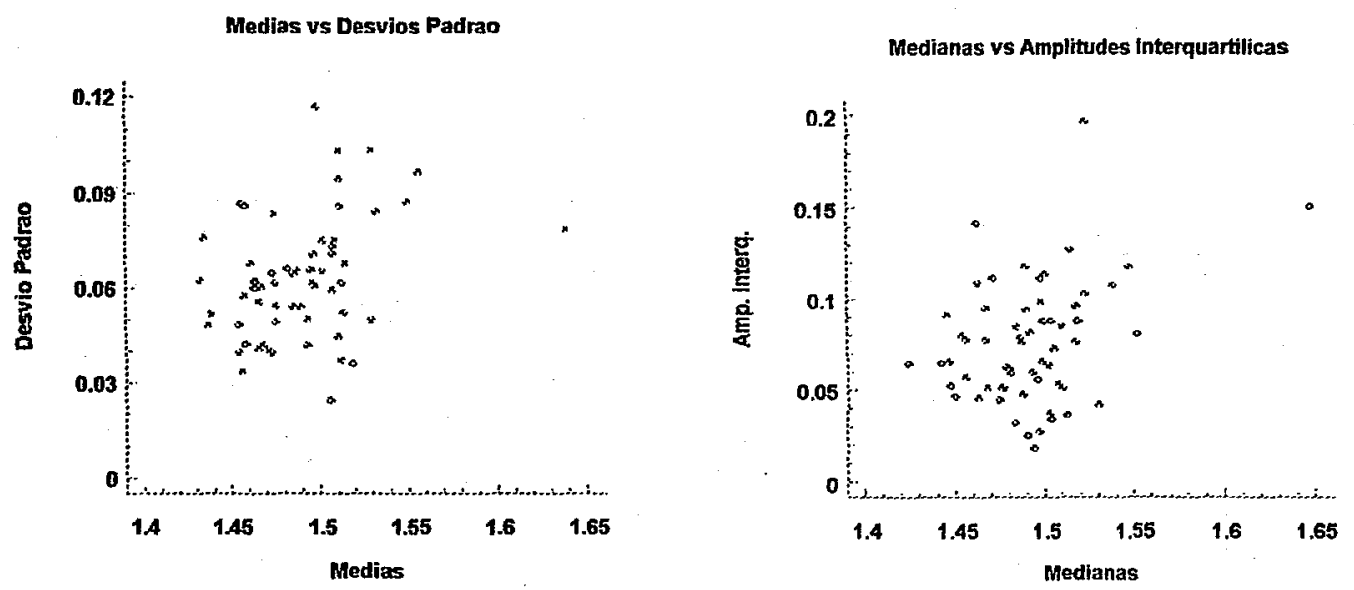

Figura 11 - Gráficos para verificar existência de efeito proporcional.

Todas estas análises indicam efeitos nitidamente perturbadores dos dados atípicos (valores acima de 1.7) que devem portanto ser cuidadosamente avaliados nos passos subseqüentes. Afora este fato, o comportamento do conjunto de dados não mostra problemas que afrontem as hipóteses de estacionaridade.

\subsubsection{Variograma}

O próximo passo, assumida a hipótese intrínseca, é a estimação da estrutura de dependência espacial através do semivariograma. Este é um passo crítico e trabalhoso da análise. Requer paciência, várias tentativas e avaliações uma vez que o modelo de variabilidade espacial escolhido será tomado como livre de erro e utilizado nas predições a serem feitas. 
A partir das indicações da análise descritiva, foi verificado o efeito causado pelas observações atípicas na estimação do variograma. Retirando-se tais observações as semivariâncias estimadas se reduzem (cerca de $10 \%$ ) embora o aspecto do gráfico não se altere. Basicamente, provocam alteração apenas no efeito pepita, pemanecendo inalterados os demais parâmetros do variograma.

Modelos isotrópicos e anisotrópicos foram considerados e avaliados pela validação cruzada. Baseando-se neste critério e buscando a parcimônia, decidiu-se pelo modelo isotrópico que, se por um lado detalha menos a estrutura espacial de correlações, por outro é mais simples uma vez que possui menor número de parâmetros.

Após a estimação de vários semivariogramas, decidiu-se não considerar distâncias superiores a $45 \mathrm{~m}$. Como o alcance está situado abaixo deste valor (por volta de $20 \mathrm{~m}$ ), o que se busca é um melhor ajuste especialmente para os primeiros pontos.

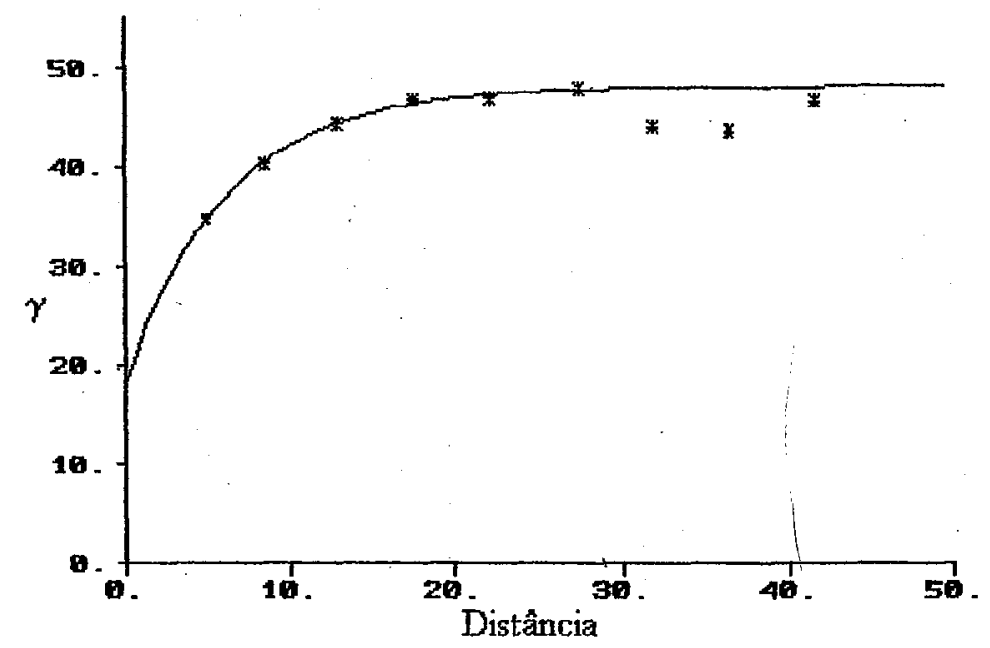

Figura 11 - Variograma ajustado para densidade do solo.

O modelo que se mostrou mais adequado foi o exponencial. Alguns ajustes a sentimento foram tentados e comparados e chegou-se aos parâmetros estimados: efeito pepita $19\left(\mathrm{~g} / \mathrm{cm}^{3}\right)^{2}$, patamar $28\left(\mathrm{~g} / \mathrm{cm}^{3}\right)^{2}$ e alcance de $17 \mathrm{~m}$. A seguir, uma sintonia mais fina das estimativas dos parâmetros foi obtida por mínimos quadrados ponderados, utilizando as 
indicações do ajuste a sentimento como valores iniciais do processo iterativo. $O$ resultado após avaliadas diversas alternativas foi: efeito pepita 18,10 ; patamar 30.15 e alcance de $18.58 \mathrm{~m}$. A ponderação buscou um ajuste que fosse mais adequado aos pontos iniciais do semivariograma, uma vez que eles representam as depêndencias espaciais de interesse. $O$ modelo de semivariância adotado, sobreposto ao variograma amostral é mostrado na figura 12.

\subsubsection{Validação cruzada}

A validação cruzada foi feita por diversas vezes ao longo da análise. Verificando a influência dos pontos atípicos, avaliando a isotropia, comparando modelos de semivariograma e seus parâmetros além de avaliar diferentes estratégias para a krigagem (como por exemplo, tamanho e configuração de vizinhança), a validação cruzada constitui-se em um importante auxilio nas diversas decisões tomadas ao longo de uma análise geoestatística.

A fim de ilustrar seus recursos e mostrar o uso de suas informações, serão apresentados aqui os resultados da validação associados às decisões definitivas tomadas na análise.

O primeiro passo é a obtenção das estatísticas geradas pela validação cruzada, que estão na tabela 2 .

A comparação das duas primeiras colunas mostra que os valores estimados têm menor variabilidade do que os observados. É esperado que isto ocorra uma vez que na validação cruzada os valores estimados são médias dos vizinhos e portanto as oscilações são atenuadas. As diferenças ou erros padronizados devem ter, ao menos idealmente, média nula e variância unitária. Além disto é desejável que tenham distribuição normal. As estatísticas assinalam valores muito próximos ao ideal para este estudo. Os gráficos mostrados na figura 13 ilustram através de histogramas o comportamento da diferenças e diferenças padronizadas. A padronização é 
feita a partir do desvio padrão de Krigagem obtido para cada um dos pontos da malha.

Tabela 2 - Estatísticas da validação cruzada.

\begin{tabular}{||l|l|l|l|l|l||}
\hline Estatísticas & $\begin{array}{l}\text { Valores } \\
\text { Observados }\end{array}$ & $\begin{array}{l}\text { Valores } \\
\text { Estimados }\end{array}$ & $\begin{array}{l}\text { Diferença } \\
\text { obs. - est. }\end{array}$ & $\begin{array}{l}\text { Desvio padrão } \\
\text { de Estimação }\end{array}$ & $\begin{array}{l}\text { Diferenças } \\
\text { Padronizadas }\end{array}$ \\
\hline $\mathrm{N}^{\circ}$ dados & 250 & 250 & 250 & 250 & 250 \\
\hline Média & 1.490 & 1.490 & -0.00005 & 0.062 & -0.001 \\
\hline Desvio Padrão & 0.071 & 0.038 & 0.062 & 0.001 & 1.006 \\
\hline Mínimo & 1.272 & 1.415 & -0.140 & 0.061 & -2.288 \\
\hline $1^{\circ}$ Quartil & 1.448 & 1.462 & -0.041 & 0.061 & -0.674 \\
\hline Mediana & 1.490 & 1.485 & -0.003 & 0.061 & -0.045 \\
\hline $3^{\circ}$ Quartil & 1.528 & 1.506 & 0.037 & 0.063 & 0.582 \\
\hline Máximo & 1.727 & 1.623 & 0.198 & 0.066 & 3.225 \\
\hline
\end{tabular}
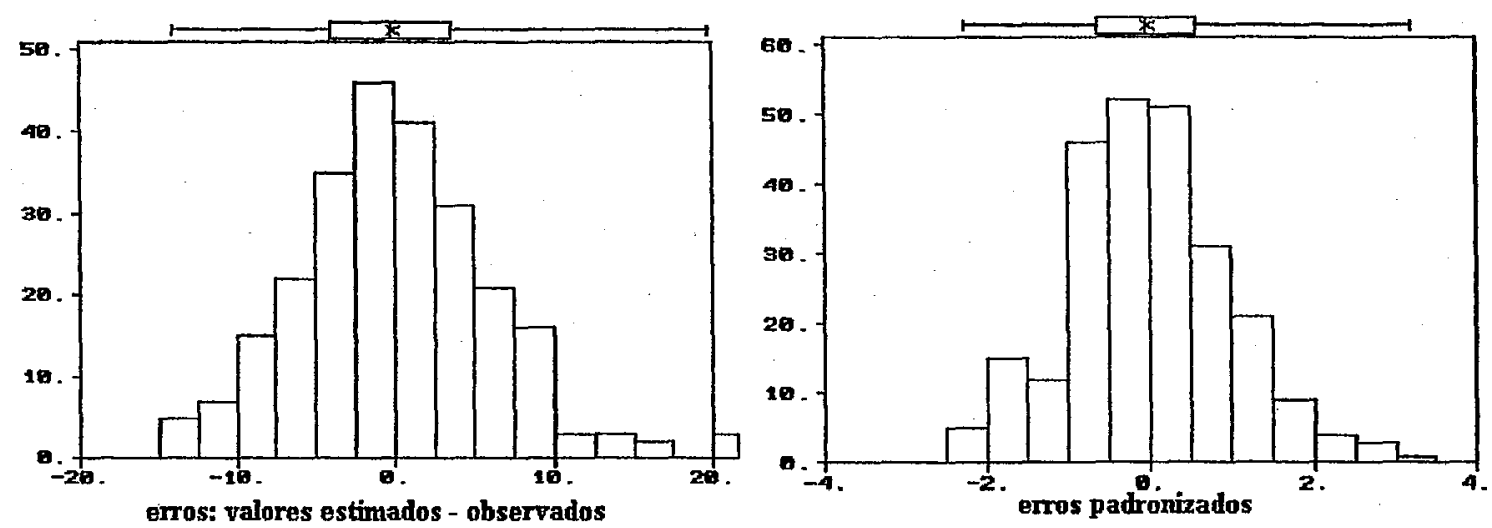

Figura 13 - Resultados da validação cruzada: diferenças (esquerda) e diferenças padronizados (direita).

Nas figuras 14 e 15 o símbolo "+" representa erros positivos e " $\mathrm{x}$ " representa erros negativos.

No gráfico da esquerda da figura 14 são representados valores observados e estimados por krigagem. Eles devem estar 
acompanhando, o mais próximo possível, a diagonal traçada. Os dois lados da diagonal devem estar equilibrados. $\mathrm{O}$ mesmo equilíbrio deve ser notado no gráfico da direita que apresenta os erros em relação aos valores estimados. Neste caso além de ser desejável que os erros estejam concentrados em torno de zero, também se espera que nenhuma relação entre a magnitude dos erros e dos valores estimados seja perceptível.
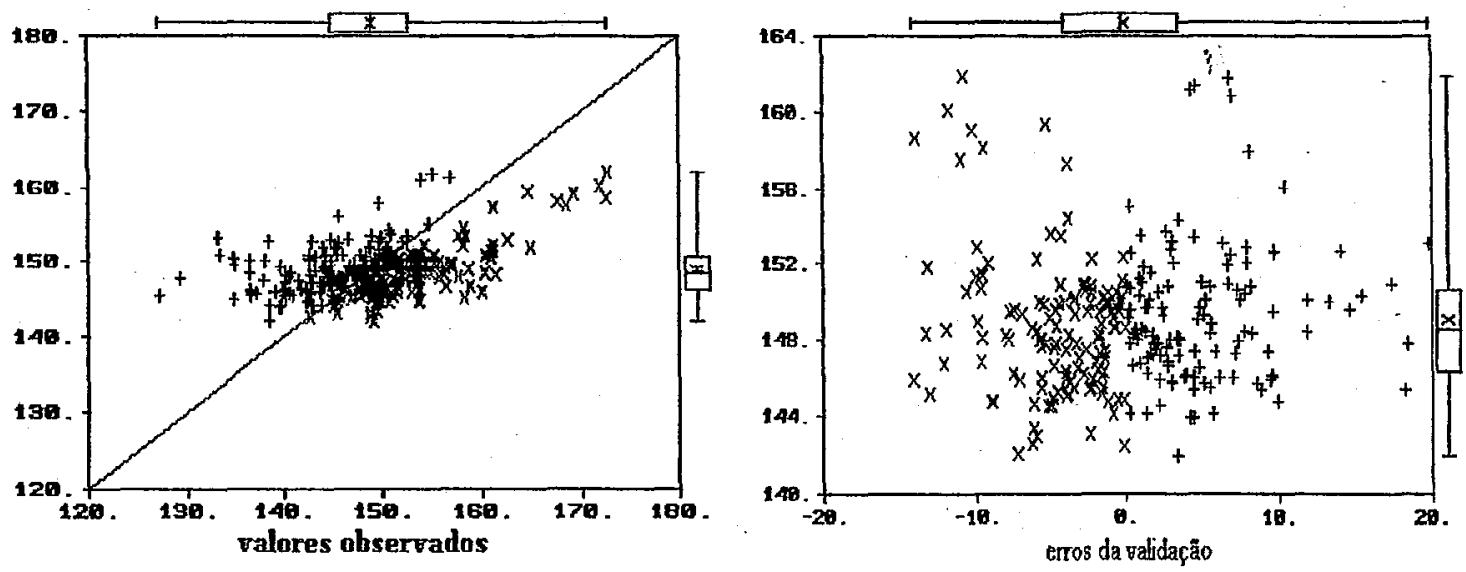

Figura 14 - Valores observados (direita) e resíduos da validação cruzada (esquerda) vs valores estimados por Krigagem (+ positivos; negativos).

Assim como os dados, os erros da validação devem ser considerados em relação à sua posição no espaço. Não deve haver associações entre eles nem qualquer tipo de tendência relacionada com posições. Portanto, todas as técnicas de análise descritiva espacial podem ser utilizadas para avaliar o comportamento destes erros.

Aqui será apresentado, na figura 15 , apenas um mapa dos erros onde os tamanhos dos símbolos é proporcional a seu valor. O desejável é que não ocorram concentrações de erros de mesmo sinal e/ou de tamanho semelhante. Eles devem estar distribuídos aleatoriamente, sem mostrar qualquer tipo de padrão. 


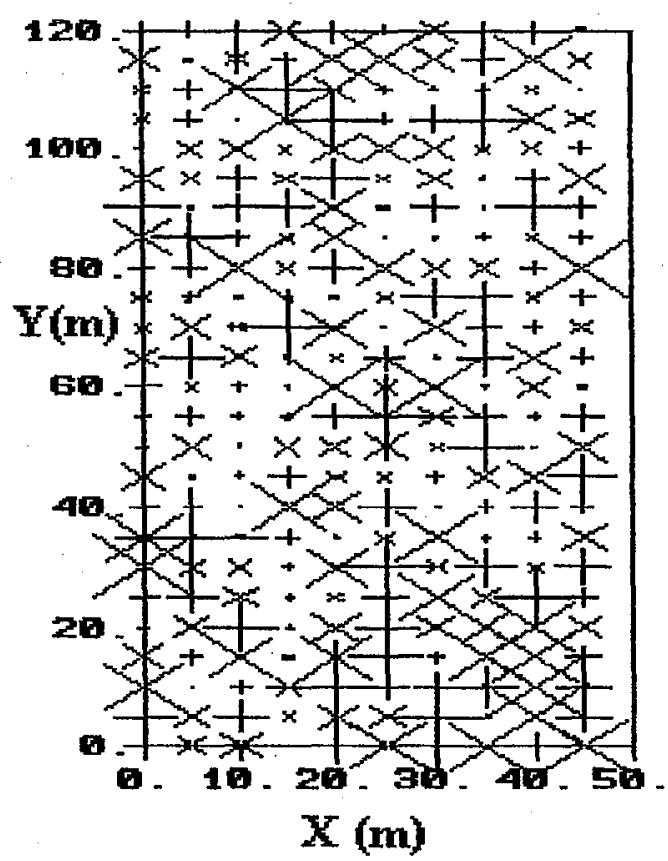

Figura 15 - Mapa dos erros da validação cruzada $(+$ positivos; $\mathrm{x}$ negativos), com tamanho dos símbolos proporcionais aos valores.

\subsubsection{Krigagem e mapa de isolinhas}

Após as avaliações pela validação cruzada, foi efetuada a krigagem ordinária tomando-se até um máximo de 20 vizinhos em um raio de 20 metros ao redor do ponto a ser estimado. Foi utilizada a opção "Bloco $4 \times 4$ " do programa Geo-EAS a fim de obter estimativas mais suaves e com menor variância de estimação.

Através da krigagem foi obtida uma malha interpolada de 45 linhas separadas por $1 \mathrm{~m}$ e 80 colunas separadas por $1,5 \mathrm{~m}$, totalizando 3.600 pontos. A partir desta malha foi construído com o mesmo programa um mapa de isolinhas (figura 16) que descreve o comportamento da variável na região.

$O$ programa utilizado não mostrou capacidade de construir um mapa de boa qualidade visual. A ideia é simplesmente dar um exemplo do resultado gerado pela análise uma vez que não é interesse deste trabalho 
discutir especificamente a densidade do solo a partir deste mapa. O programa fornece um arquivo com os valores estimados e suas coordenadas. Em estudos detalhados e específicos este arquivo pode ser utilizado em outros programas computacionais para confecção de mapas de isolinhas ou traçado de superficies mais detalhados e de melhor qualidade visual.

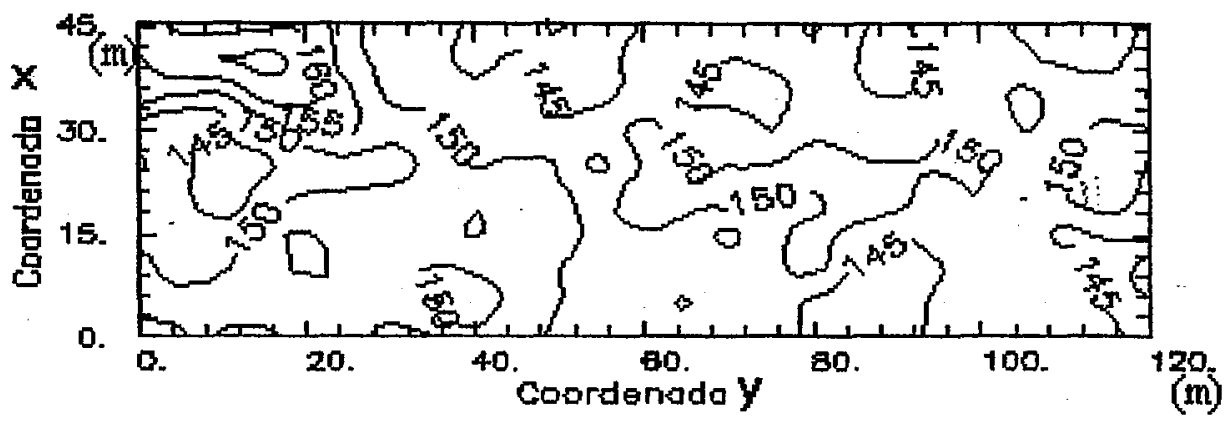

Figura 16- Mapa de isolinhas da densidade do solo.

\subsection{Dados de umidade do solo}

O primeiro conjunto de dados discutido neste trabalho, exceto por alguns valores atípicos concentrados em uma pequena parte da área, não apresentava maiores problemas em relação às hipóteses de estacionaridade. Nenhuma tendência nítida que comprometesse a análise invalidando os pressupostos pôde ser percebida.

Este fato motivou o uso deste segundo conjunto da dados para ilustrar como as ferramentas descritivas podem captar tendências, apresentar uma forma de contornar o problema (no caso o refinamento pela mediana), analisar os resíduos do refinamento a fim de verificar se a tendência foi removida de fato e se estes podem ser assumidos como intrinsicamente estacionários. Desta forma, a análise deste conjunto enfoca apenas as técnicas descritivas e mostra como as estimativas dos variogramas amostrais são afetadas pela presença da tendência, modificando a forma do gráfico. 
Gráficos da mesma natureza daqueles confeccionados para os dados de densidade do solo são aqui novamente utilizados. As funções e padrões a serem identificados permanecem os mesmos. Porém, os resultados obtidos para os dados deste conjunto levam a conclusões e decisões diferentes daquelas tomadas na situação anterior.

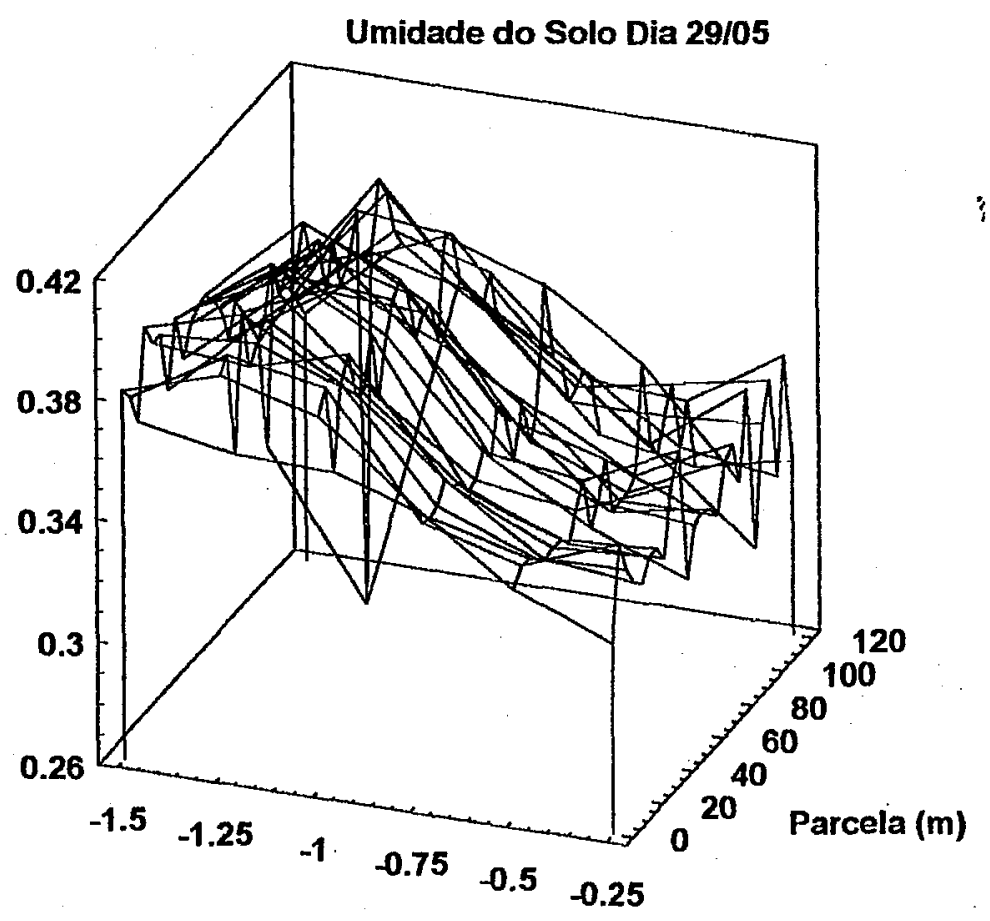

Profundidade (m)

Figura 17 - Dados de umidade do solo provenientes das amostras.

A superficie inicialmente obtida (figura 17) mostrou problemas com os dados da parcela 20. As leituras desta parcela foram sistematicamente baixas ao longo dos estudos realizados nesta área. Isto foi atribuído ao fato de que a estrutura do solo foi deformada no local do tubo de acesso da sonda de nêutrons de forma a manter um espaço poroso, prejudicando a precisão das medições de umidade ${ }^{2}$.

2REICHARDT, K. (Escola Superior de Agricultura "Luiz de Quiroz" / USP, Piracicaba, SP) Comunicação pessoal. 1994. 
Como se tratava de um erro associado ao processo de medida que não tinha como ser corrigido, decidiu-se retirar das análises os dados referentes a esta parcela.

Conforme será notado nas figuras seguintes (17 a 31$)$, os dados indicam claramente que o tipo de estacionaridade desejada (hipótese intrínseca) não pode ser assumida. Procedeu-se então o refinamento pela mediana. Diferentes números de iterações foram utilizados no processo. De forma geral obteve-se bons resultados com duas iterações. Com quatro iterações as estimativas foram estáveis para todas as datas de coleta. A tabela 3 mostra as estimativas dos efeitos geral (valor tipico), linhas (profundidades), colunas (parcelas) para os dados do dia 29/05. Estas estimativas compoêm a variação de larga escala do fenômeno.

Tabela 3 - Resultados do refinamento pela mediana. Efeitos de parcelas multiplicados por 1000 .

\begin{tabular}{|c|c|c|c|c|c|c|c|c|c|c|c|}
\hline \multicolumn{2}{|c|}{ Valor típico: } & 0.35711 & & & & & & & & & \\
\hline \multicolumn{2}{|c|}{ Prof. 0,25} & Prof. 0,50 & \multicolumn{2}{|c|}{ Prof. 0,75} & \multicolumn{2}{|c|}{ Prof. 1,00} & \multicolumn{2}{|c|}{ Prof. 1,25} & \multicolumn{2}{|l|}{ Prof. 1,50} & \\
\hline \multicolumn{2}{|c|}{0.01081} & 0.03291 & \multicolumn{2}{|c|}{0.02009} & \multicolumn{2}{|c|}{-0.01258} & \multicolumn{2}{|c|}{-0.02366} & \multicolumn{3}{|l|}{-0.02166} \\
\hline $\begin{array}{l}\text { Parc. } \\
01\end{array}$ & $\begin{array}{l}\text { Parc. } \\
02\end{array}$ & $\begin{array}{l}\text { Parc. } \\
03\end{array}$ & $\begin{array}{l}\text { Parc } \\
.04 \\
\end{array}$ & $\begin{array}{l}\text { Parc. } \\
05\end{array}$ & $\begin{array}{c}\text { Parc } \\
.06\end{array}$ & $\begin{array}{l}\text { Parc. } \\
07\end{array}$ & $\begin{array}{l}\text { Parc. } \\
08\end{array}$ & $\begin{array}{c}\text { Parc } \\
.09 \\
\end{array}$ & $\begin{array}{l}\text { Parc. } \\
10 \\
\end{array}$ & $\begin{array}{l}\text { Parc. } \\
11\end{array}$ & $\begin{array}{l}\text { Parc. } \\
12\end{array}$ \\
\hline 3.20 & 7.25 & 0.22 & 6.17 & 5.51 & 1.55 & 1.55 & 6.17 & 3.75 & 11.75 & 4.11 & 15.72 \\
\hline $\begin{array}{l}\text { Parc. } \\
13 \\
\end{array}$ & $\begin{array}{l}\text { Parc. } \\
14\end{array}$ & $\begin{array}{l}\text { Parc. } \\
15\end{array}$ & $\begin{array}{c}\text { Parc } \\
.16 \\
\end{array}$ & $\begin{array}{l}\text { Parc. } \\
17 \\
\end{array}$ & $\begin{array}{c}\text { Parc } \\
.18 \\
\end{array}$ & $\begin{array}{l}\text { Parc. } \\
19 \\
\end{array}$ & $\begin{array}{l}\text { Parc. } \\
21\end{array}$ & $\begin{array}{l}\text { Parc } \\
.22 \\
\end{array}$ & $\begin{array}{l}\text { Parc. } \\
23 \\
\end{array}$ & $\begin{array}{l}\text { Parc. } \\
24 \\
\end{array}$ & $\begin{array}{l}\text { Parc. } \\
25 \\
\end{array}$ \\
\hline 10.22 & -4.29 & -7.75 & 1.91 & -4.25 & 6.20 & 10.10 & -4.28 & 2.11 & -11.75 & -8.32 & -24.75 \\
\hline
\end{tabular}

A fim de facilitar a apresentação e permitir uma comparação visual imediata dos comportamentos, os gráficos apresentados a seguir colocam sempre a representação dos dados originais junto à dos resíduos do refinamento pela mediana (daqui por diante tratados simplesmente por resíduos).

$\mathrm{Na}$ figura 18 a superficie da figura 17 é redesenhada agora já sem os dados da parcela 20. Fica mais nítida, no gráfico da esquerda, a tendência de se ter valores menores de umidade nas maiores profundidades. 
Por outro lado nos resíduos (gráfico da direita) não é notado tal comportamento.

\subsubsection{Análise descritiva}

As estatísticas dos dados e dos resíduos são mostradas na tabela 4. Os valores não são imediatamente comparáveis, exceto para os coeficientes. Por estes é possivel notar um maior agrupamento dos resíduos e um comportamento mais próximo da distribuição normal. As figuras 19, 20 e 21 ilustram e reforçam tais observações. Por outro lado, nota-se nos resíduos observações discrepantes, o que não ocorre com os dados originais. Isto se explica pelo fato destes últimos conterem os efeitos de larga escala que mascaram os dados atípicos.

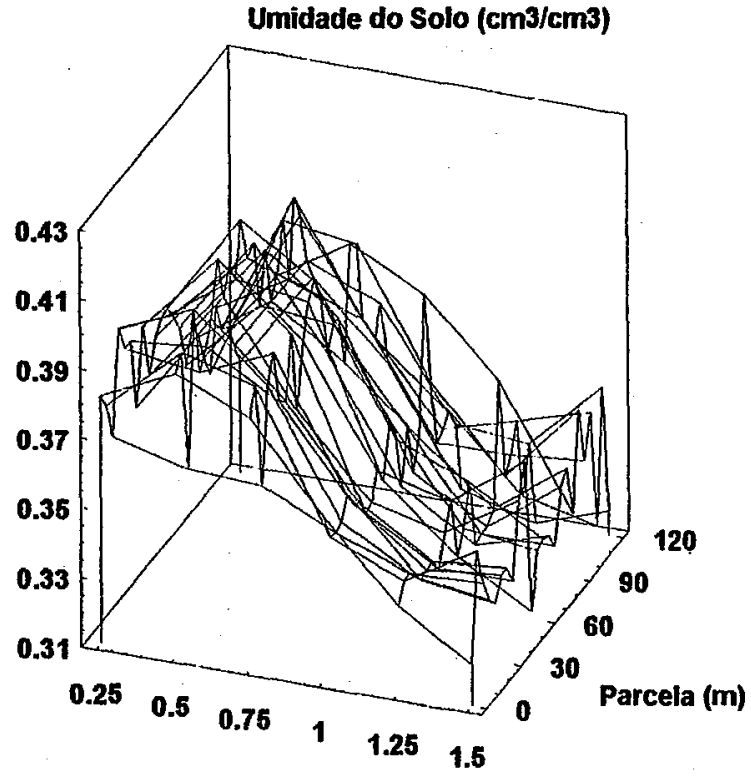

Profundidade (m)

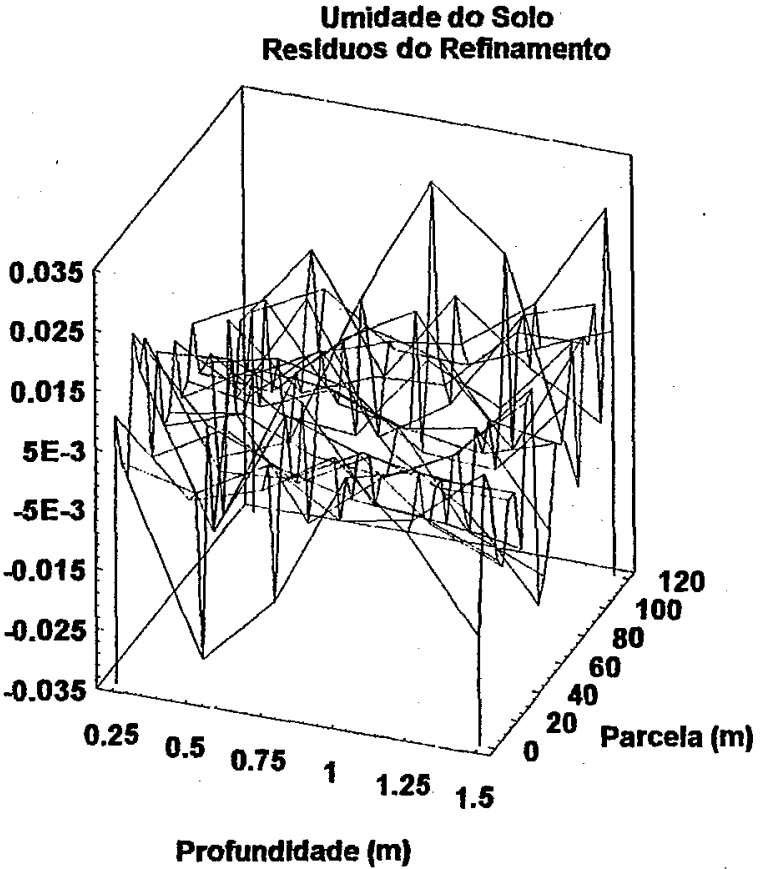

Profundldade (m)

Figura 18 - Superficies com valores de umidade e sua localização. Dados originais (esquerda) e resíduos do refinamento pela mediana (direita). 
80.

Tabela 4 - Estatísticas dos dados originais e resíduos (multiplicados por 1000).

\begin{tabular}{||l|l|l|l|l|l|l||}
\hline & $\begin{array}{l}\text { Número } \\
\text { de dados }\end{array}$ & Mínimo & $\begin{array}{l}\text { Quartil } \\
\text { Inferior }\end{array}$ & Mediana & $\begin{array}{l}\text { Quartil } \\
\text { Superior }\end{array}$ & Máximo \\
\hline Dados & 144 & 0.310 & 0.338 & 0.357 & 0.381 & 0.412 \\
\hline Resíduos & 144 & -31.2344 & -4.4688 & 0.0000 & 6.2656 & 34.2656 \\
\hline & Média & Variância & $\begin{array}{l}\text { Desvio } \\
\text { Padrão }\end{array}$ & $\begin{array}{l}\text { Coef. de } \\
\text { Variação }\end{array}$ & $\begin{array}{l}\text { Coef. de } \\
\text { Assimetria }\end{array}$ & $\begin{array}{l}\text { Coeficient } \\
\text { e de } \\
\text { Curtose }\end{array}$ \\
\hline Dados & 0.3697 & 0.0006 & 0.0246 & 6.8509 & 0.1487 & 1.9346 \\
\hline Resíduos & 0.2969 & 97.2929 & 9.8637 & 3322.5380 & -0.0273 & 4.4261 \\
\hline
\end{tabular}
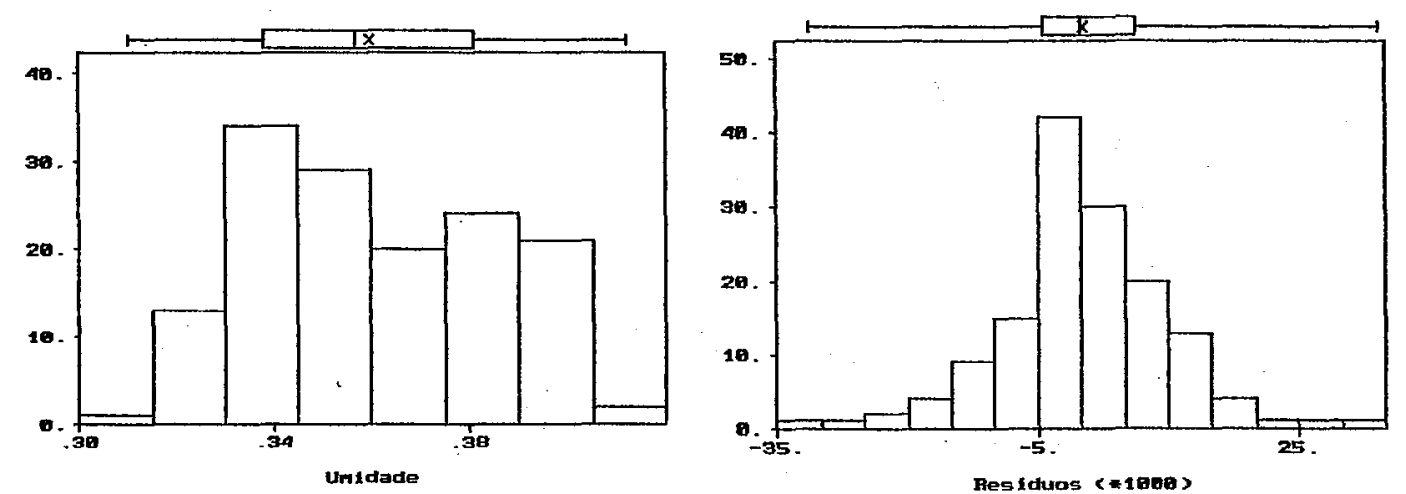

Figura 19 - Histogramas do dados de umidade do solo (esquerda) e resíduos do refinamento (direita).
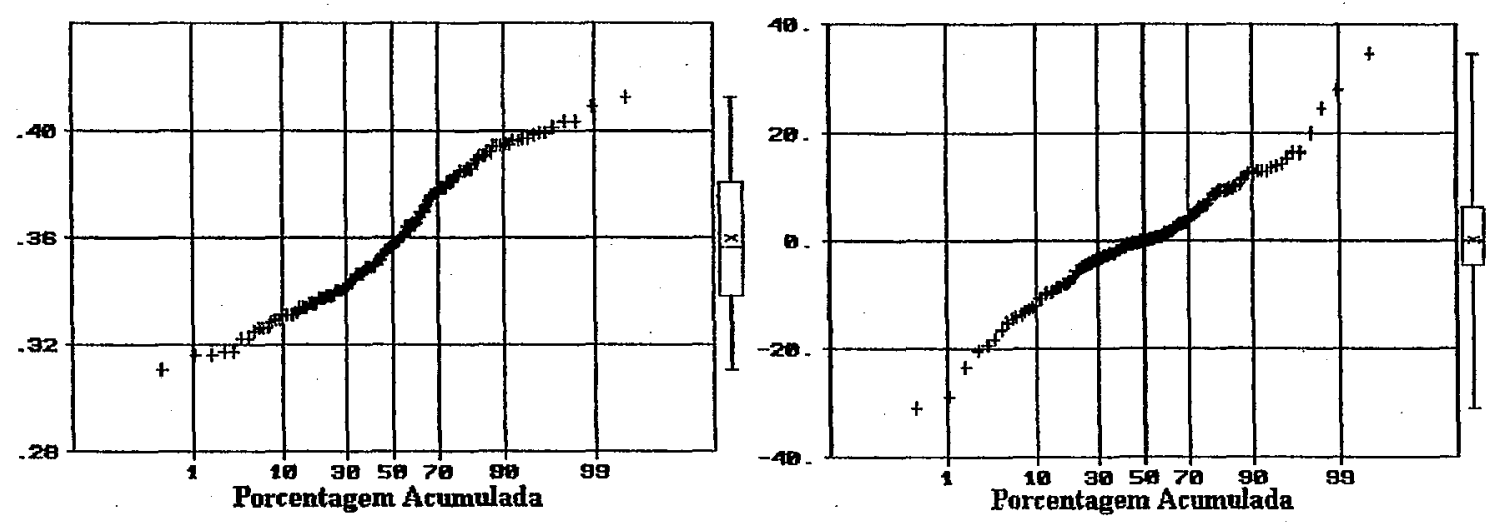

Figura 20 - Gráficos de probabilidade normal. Dados originais de umidade (esquerda) e resíduos do refinamento (direita). 
Na figura 21, o "box-plot" dos resíduos aponta dados atípicos que são responsáveis pelo alto coeficiente de variação encontrado. São nítidos os efeitos deste dados na construção de variogramas.
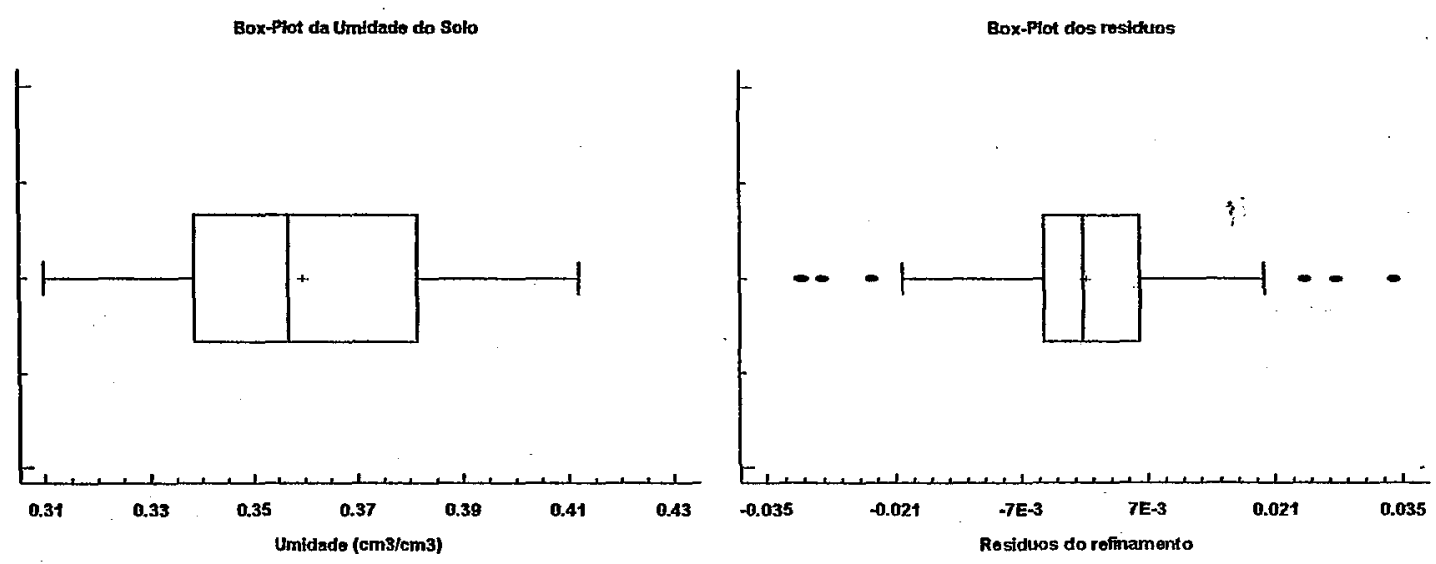

Figura 21 - Gráficos "box-plot" dos dados originais (esquerda) e resíduos do refinamento pela mediana (direita).

$\mathrm{O}$ "postplot" inicia as técnicas descritivas espaciais. No caso dos dados originais (figura 22), é nítida a tendência no sentido da profundidade uma vez que os símbolos que indicam quartis de valores mais elevados estão, em sua quase totalidade, nas camadas mais próximas à superficie, enquanto aqueles que indicam os quartis inferiores concentram-se nas camadas mais profundas. Já para os resíduos (figura 23), este padrão não é notado e a distribuição não mostra conflito com os pressupostos definidos na hipótese intrínseca. 


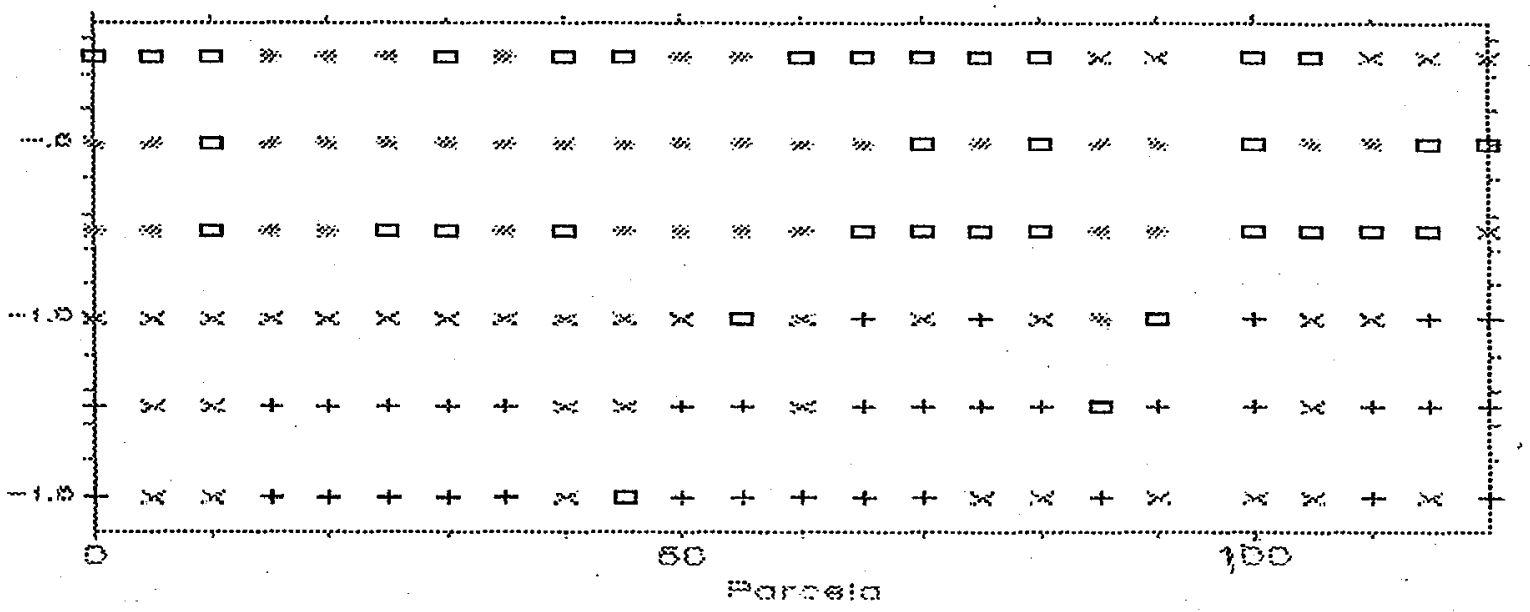

\begin{tabular}{|c|c|c|c|c|c|c|}
\hline 1 & Guartil. & .310 & 도 & + & $\equiv$ & .338 \\
\hline$x^{0}$ & Sils: $=5$. & 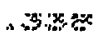 & $\approx$ & $m$ & 垟 & $\sqrt{3} ; 8 \%$ \\
\hline 30 & Dugrtil & .357 & $\approx$ & $\square$ & $\equiv$ & .381 \\
\hline$\Leftrightarrow$ & 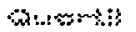 & $\therefore \%:$ & $\because$ & 3 & : & $\because 3$ \\
\hline
\end{tabular}

Figura 22 - "Postplot" dos dados originais de umidade $\left(\mathrm{cm}^{3} / \mathrm{cm}^{3}\right)$.

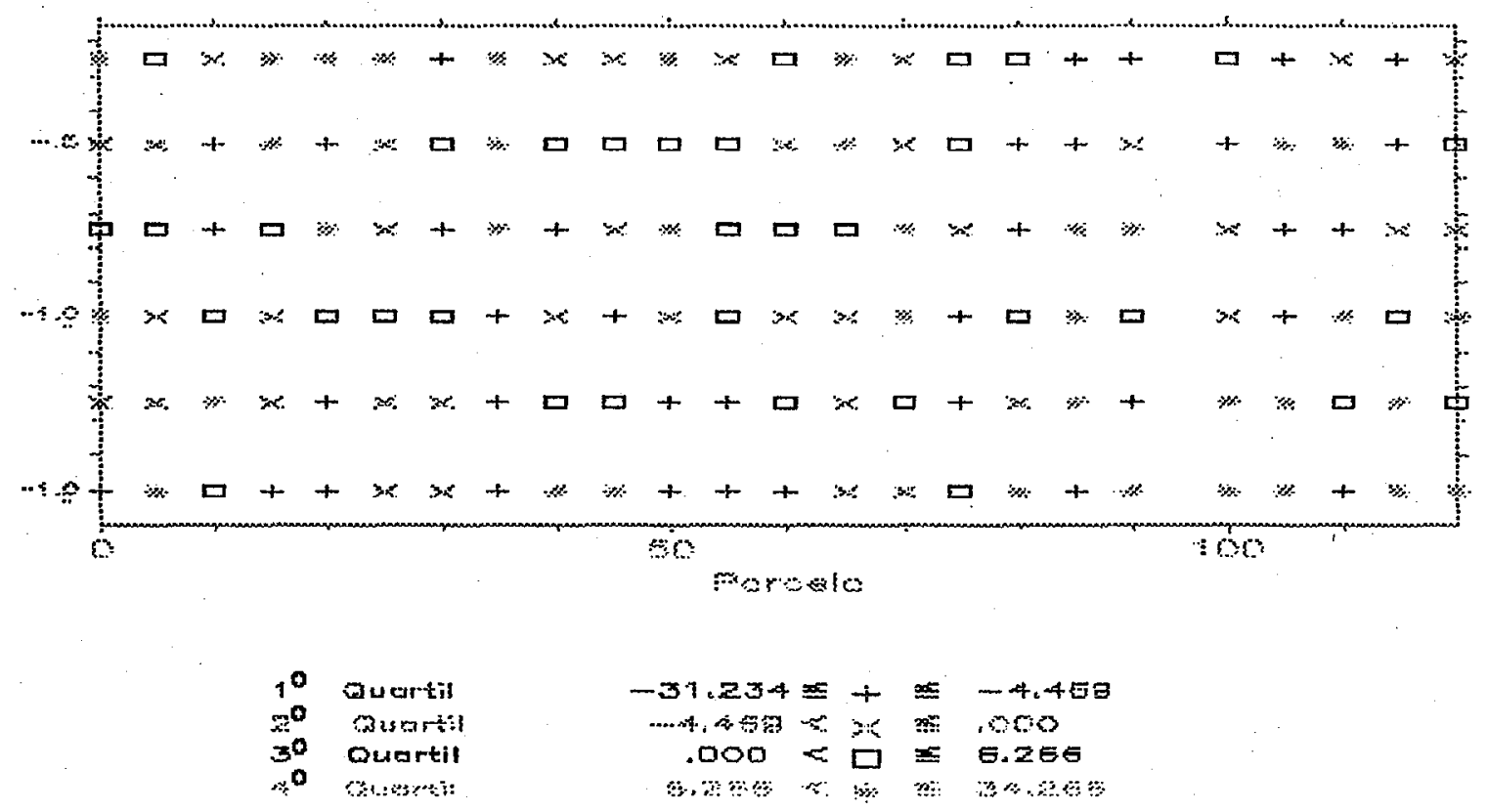

Figura 23 - "Postplot" dos resíduos do refinamento. 
Os dados mostram um comportamento semelhante entre as parcelas. As variabilidades são muito parecidas, embora com apenas seis informações por parcela, conforme o gráfico da esquerda da figura 24 . No gráfico da direita os resíduos exibem possuem o mesmo padrão, exceto por uma das parcelas que possui valores atípicos e que mostra uma maior variabilidade.
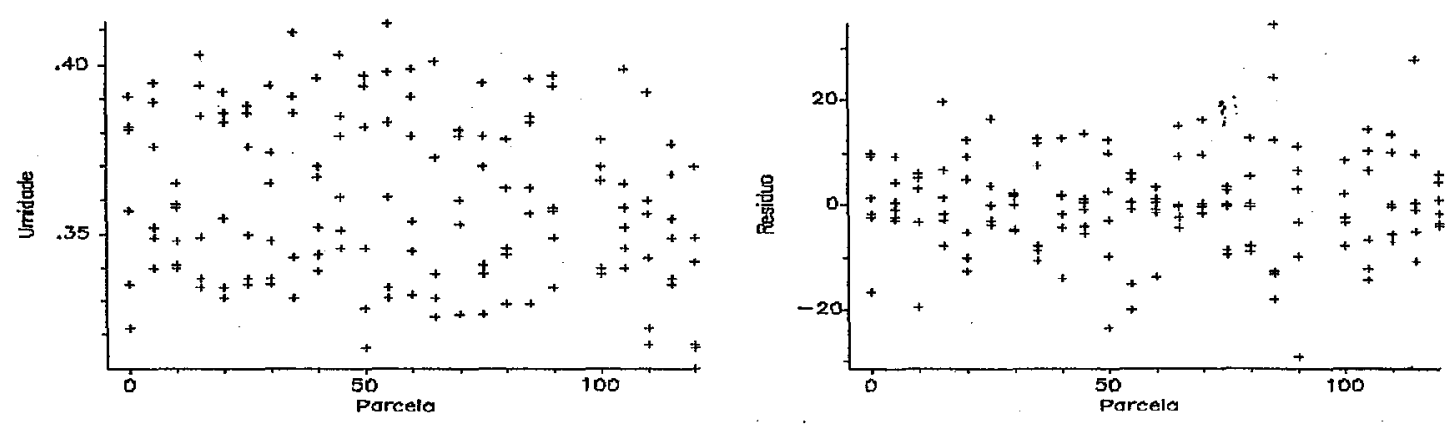

Figura 24 - Gráficos de dispersão dos valores observados nas parcelas.
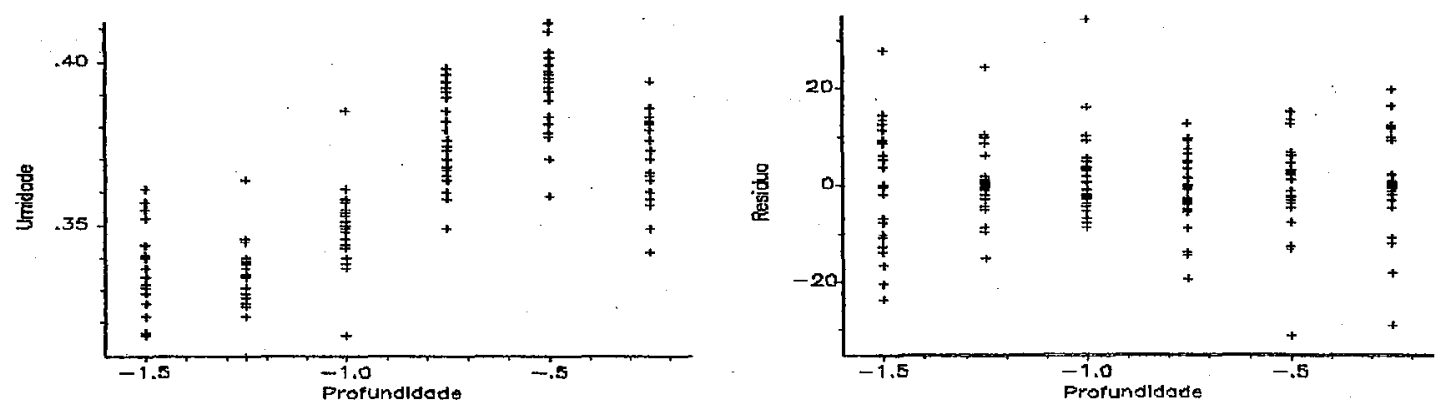

Figura 25 - Gráfico de dispersão dos valores observados nas profundidades.

A figura 25 compara o comportamento nas diferentes profundidades. Os valores observados são claramente distintos. Por outro lado, as dispersões são novamente muito parecidas. Isto indica que os valores de umidade estão relacionados com a profundidade mas as variabilidades não acompanham esta tendência. Os gráficos seguintes examinam com mais detalhes estes fatos.

As médias e desvios padrões das parcelas são mostrados nos gráficos à esquerda na figura 26 . As médias são próximas em todas as 
parcelas, excetuando-se a última que se mostra um pouco inferior. Já os desvios padrões são apresentam pouca variação. Nos residuos as médias são todas próximas e existe uma parcela com desvio padrão nitidamente maior do que as demais, que é atribuído aos dados atípicos já comentados.

O mesmo comportamento é evidenciado pelas nas medianas e amplitudes interquartílicas dos gráficos da esquerda da figura 27.
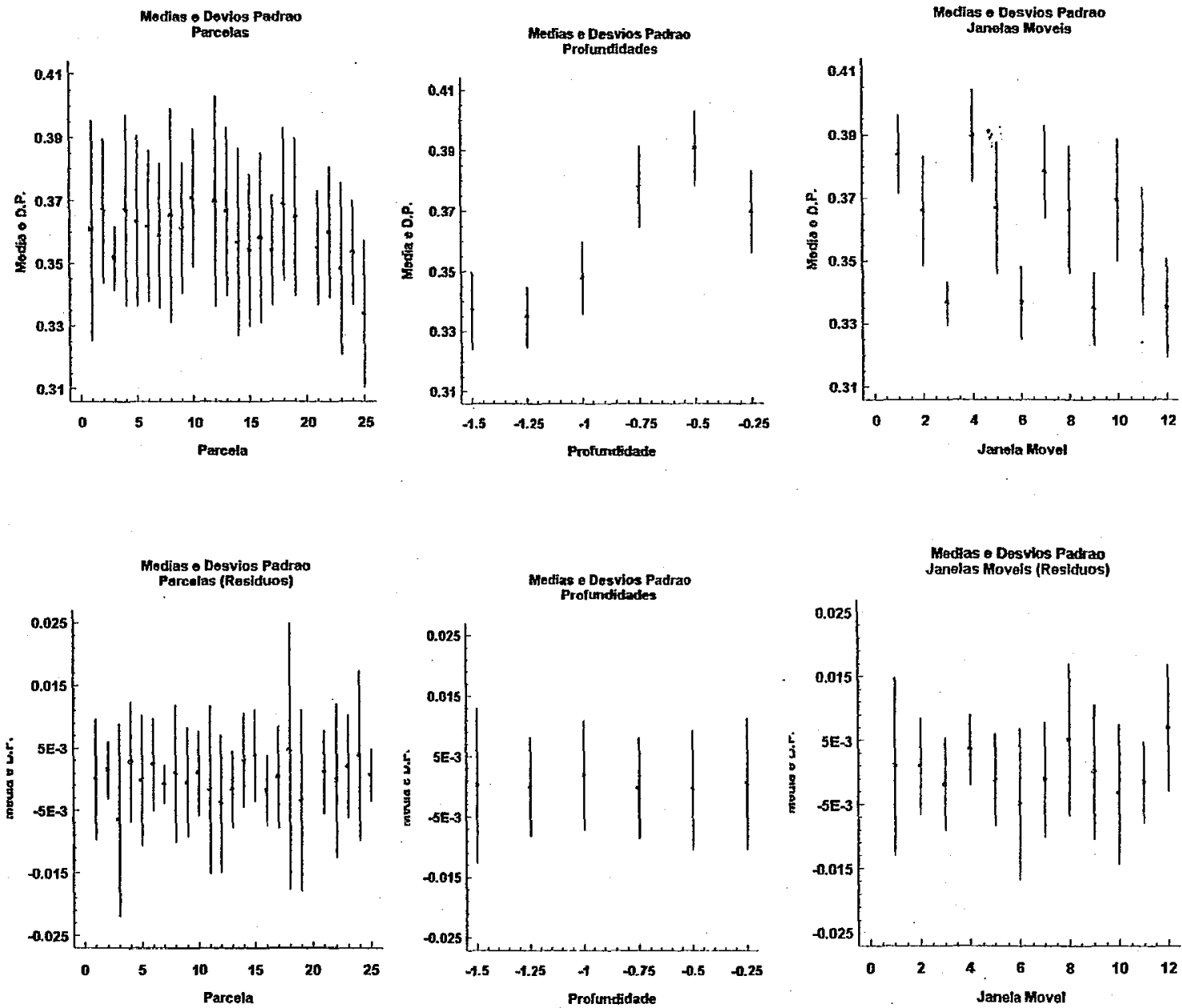

Figura 26 - Médias e desvios padrões dos dados de parcelas (esquerda), profundidades (centro) e janelas móveis (direita). Dados originais nos gráficos superiores e resíduos nos inferiores.

Para as profundidades é clara a tendência de decréscimo da umidade entre as camadas de 0,50 até $1,25 \mathrm{~m}$. O refinamento pela mediana mostrou-se eficiente na retirada desta tendência uma vez que ela desaparece 
nos resíduos. Os gráficos do centro mostram isto tanto para médias (figura 26) quanto para medianas (figura 27). Já os desvios padrão mostram-se praticamente iguais, enquanto as amplitudes interquartílicas (medidas mais resistentes) indicam, embora não nitidamente, uma variabilidade um pouco maior nas camadas superiores.

As janelas móveis construídas com duas linhas e seis colunas sem sobreposição, cada uma portanto com 12 dados, têm suas estatísticas representadas nos gráficos da direita das figuras 26 e 27 . Elas confirmam os achados dos gráficos referentes a parcelas e profundidades, mostrando também variabilidades menores para camadas inferiores, exceto pela última janela.
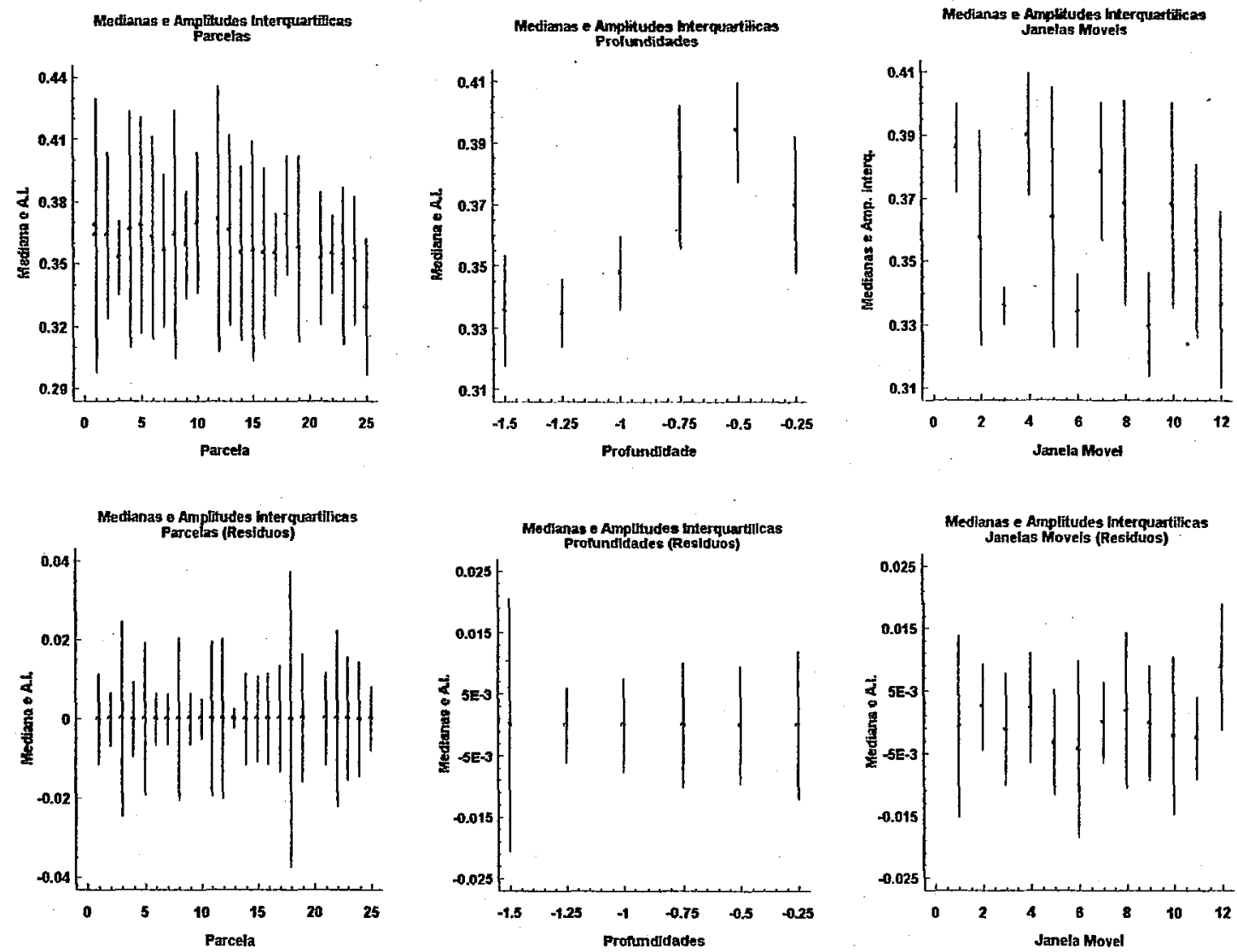

Figura 27 - Medianas e amplitudes interquartilicas de parcelas (esquerda), profundidades. (centro) e janelas móveis (direita). Dados originais nos gráficos superiores e resíduos nos inferiores. 
A figura 28 faz representação semelhante às figuras 26 e 27 , porém utilizando os "box-plot". Neste caso valores localmente atípicos ficam evidenciados. Além disto, esta representação não faz qualquer tipo de cálculo o que é um aspecto interessante considerando que as observações não são independentes. Sob este ponto de vista é o gráfico mais indicado para detectar comportamentos associados com posições na malha de amostragem. Todas as considerações feitas com base nos gráficos anteriores (figuras 24 a 27) podem ser identificadas na figura 28 .
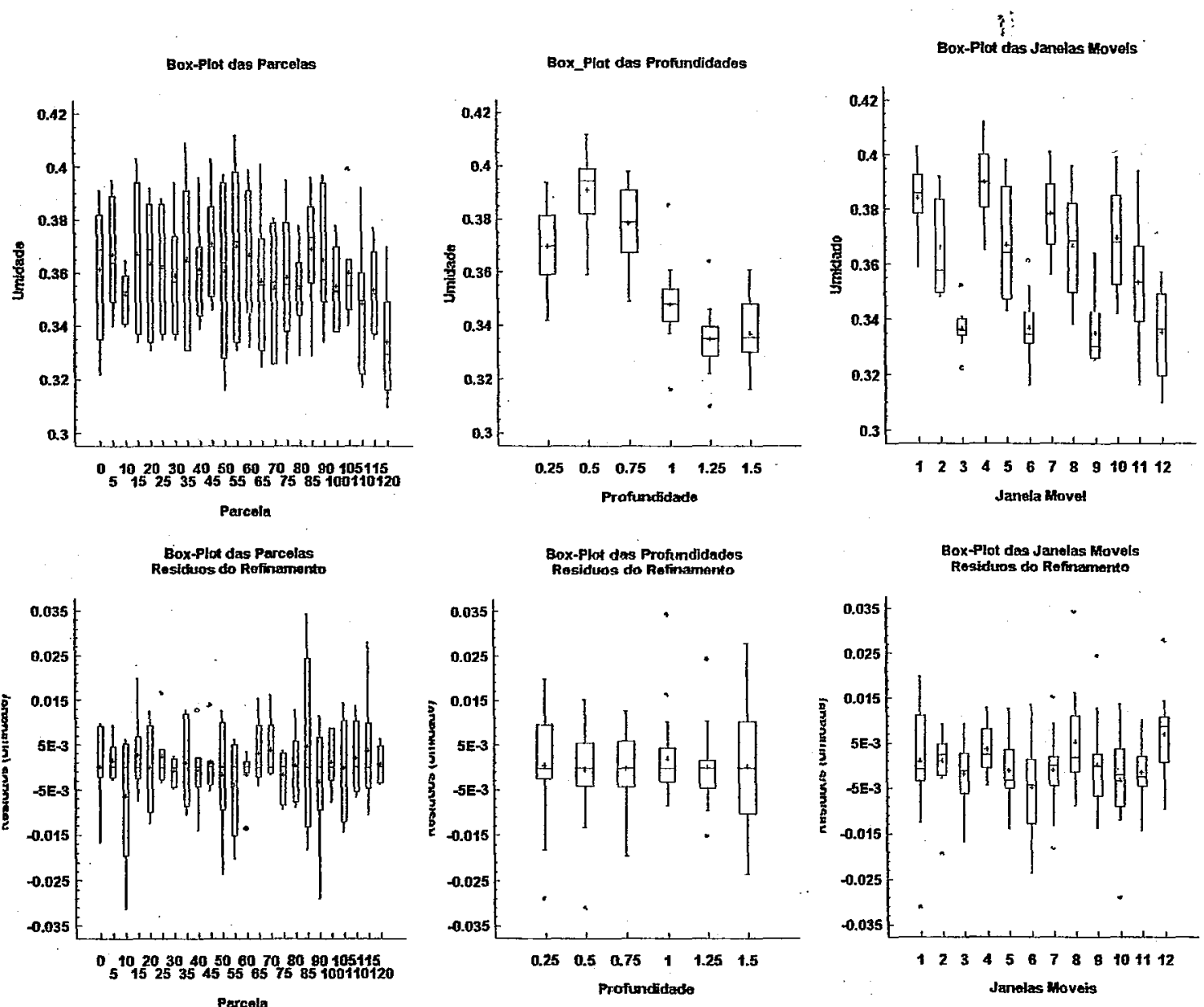

Figura 28 - "Box-plot" múltiplos para os dados de parcelas (esquerda), profundidades (centro) e janelas móveis (direita). Dados originais nos gráficos superiores e resíduos nos inferiores. 
A existência do efeito proporcional é investigada na figura 29 (médias e desvios padrões) e 30 (medianas e amplitudes interquartílicas). Medidas de posição mais altas corresponderam, ainda que fracamente, a medidas de dispersão mais elevadas para os dados originais. Tal relação não foi percebida nos resíduos. A refinamento mostrou-se portanto eficiente também para retirar este outro tipo de tendência.

De forma geral, a análise descritiva mostrou que os dados originais são incompatíveis com a hipótese intrínseca. Por outro lado, os "novos dados", que são os resíduos produzidos pelo refinamento pela mediana, mostram comportamento compatível com tal tipo de hípótese.
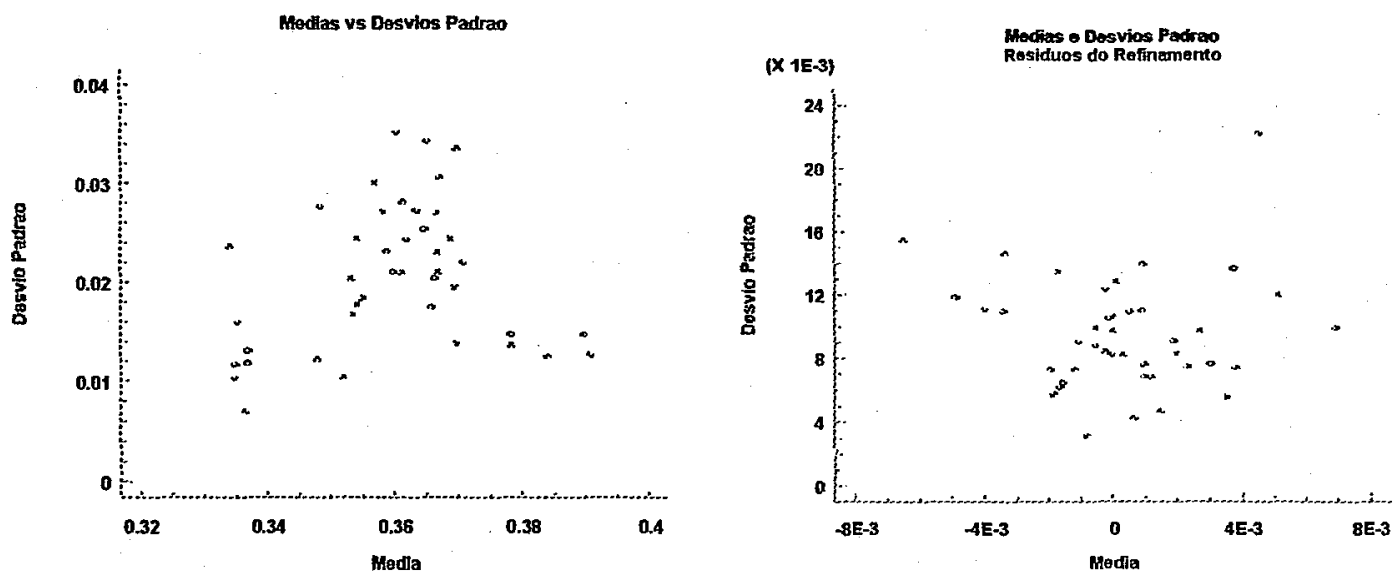

Figura 31 - Médias e desvios padrões de parcelas, profundidades e janelas móveis.
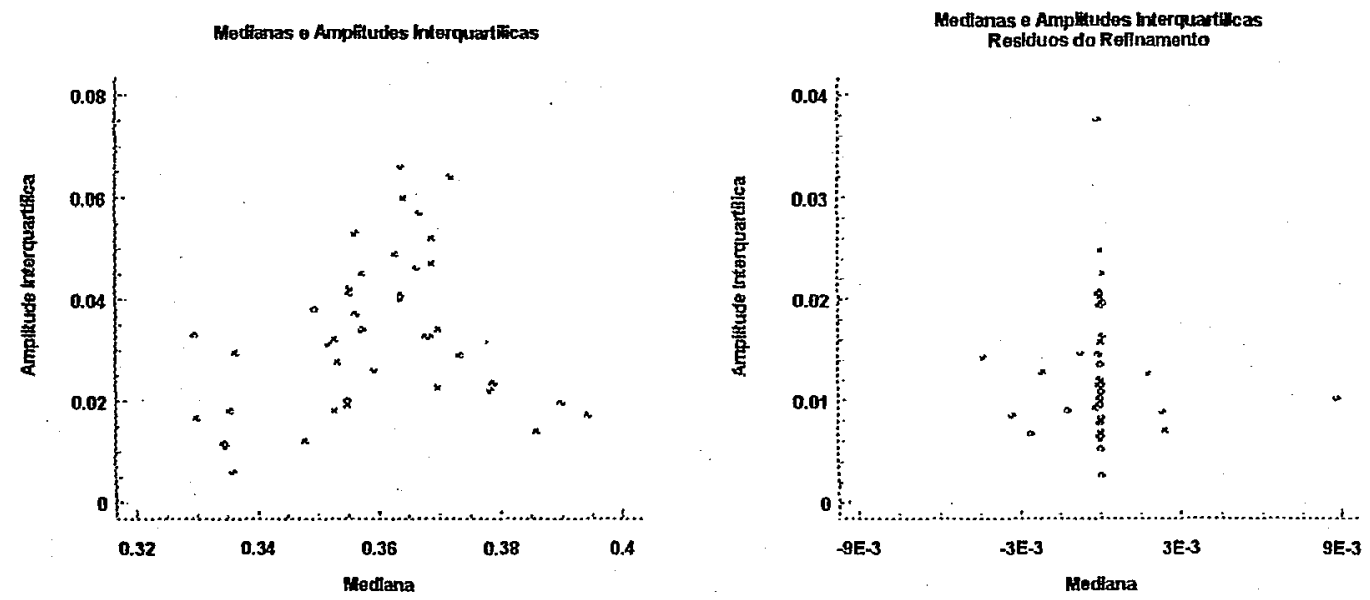

Figura 30 - Medianas e amplitudes interquartílicas de parcelas, profundidades e janelas móveis. 
Os recursos descritivos exibem aqui toda sua potencialidade para detectar problemas, identificar padrões e auxiliar a tomada de decisões; além de proporcionar um contato inicial com o conjunto de dados.

\subsubsection{Variogramas}

Sob o enfoque deste trabalho, os variogramas só são válidos para representar a estrutura de dependência espacial se a hipótese intrínseca for assumida. Portanto, para o problema em discussão, somente há sentido em estimar o variograma, utilizando as 144 informações disponíveis, a partir dos resíduos do refinamento pela mediana. Uma outra alternativa seria dividir os dados em subregiões e reiniciar as análise em cada uma delas separadamente.

A fim de mostrar como o efeito da variação de larga escala pode afetar a estimação de estrutura de dependência foram estimados variogramas para os dados originais e para os resíduos do refinamento. Os gráficos estão na figura 31 .

Após diversas avaliações concluiu-se que a exclusão de valores dos resíduos menores que $-20 \times 10^{-3}$ e maiores que $20 \times 10^{-3}$ nos cálculos das semivariâncias proporciona uma melhor estimativa do semivariograma amostral.
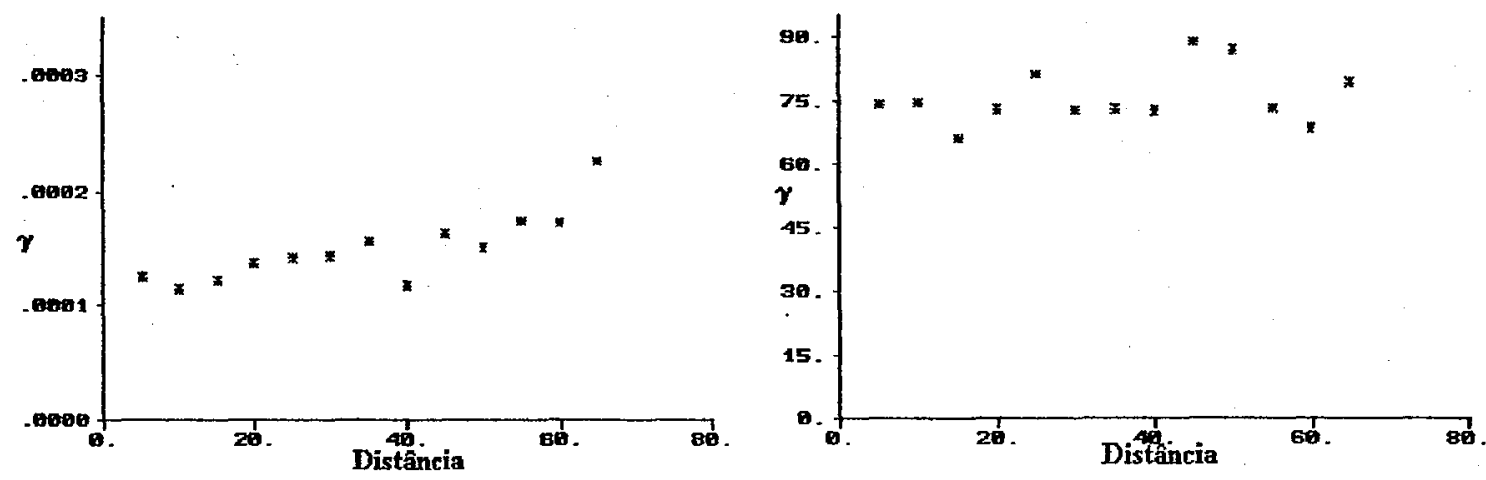

Figura 31 - Semivariogramas dos dados originais (esquerda) e resíduos do refinamento (direita). 
Fica claro que se a hipótese intrínseca for inadequadamente assumida, como no caso dos dados originais, o variograma estimado leva a interpretações inadequadas que comprometem e talvez invalidem toda a análise. Enquanto para os resíduos (gráfico da direita) o variograma indica o efeito pepita puro, nos dados originais suge um "falso" comportamento linear devido a influência da variação de larga escala.

A análise do semivariograma dos resíduos mostra que a umidade do solo estudado não apresenta estrutura de dependência espacial. Isto pode ser atribuído ao fato de que o espaçamento entre as parcelas é largo demais para detectar tal estrutura. No sentido da profundidade o número de pontos (apenas 6) é insuficiente para estimar qualquer estrutura de dependência. 


\section{CONCLUSÕES}

O ferramental geoestatístico foi capaz de detectar e descrever a variabilidade espacial dos parâmetros do solo estudados, em especial para os dados densidade do solo onde a análise foi mais completa. Aspectos desta técnica, em especial a suposição de estacionaridade que é feita, recomendam cuidados em seu uso uma vez que as estimativas' são afetadas por esta decisão.

Dados atípicos afetam os resultados, em especial quando se usa o estimador do método dos momentos para o semivariograma. Portanto, a qualidade dos dados e conhecimentos sobre problema em questão são fundamentais para decidir como agir diante de observações discrepantes. Os instrumentos de medida devem ser cuidadosamente avaliados.

A decisão de estacionaridade deve ser reconhecida como um decisivo passo da análise. Só deve ser tomada após uma extensa análise descritiva que leve em conta a posição das amostras. As técnicas da análise exploratória utilizadas neste trabalho cumprem bem este papel, embora não sejam as únicos disponíveis. Foram portanto, fundamentais para orientar a escolha de estratégias de estudo e modelagem. Elas não garantem a qualidade da análise, mas é inconcebível que uma análise de qualidade prescinda do uso de técnicas desta natureza.

A capacidade de detectar a variabilidade é determinada em grande parte pelo plano amostral, que precisa ser definido tendo em mente as estruturas que deseja-se detectar. Malhas regulares, embora muito úteis, podem ser modificadas a fim de captar as estruturas a pequenas distâncias, como no caso da densidade do solo onde não se tem informação do que acontece a distâncias inferiores a $5 \mathrm{~m}$. $O$ plano amostral adequado pode variar para cada propriedade em estudo. 
Sendo o interesse descrever a dependência, é preciso que se busque estimação e modelagem mais cuidadosa do variograma. Existem alternativas ao uso do estimador de momentos e o método de ajuste de modelos a sentimento pode ser incrementado por um ajuste mais criterioso, como o de mínimos quadrados ponderados.

Por outro lado, se o interesse se concentra no mapa de isolinhas baseado em uma malha interpolada, há que se considerar a robustez da Krigagem em relação ao modelo variográfico. Nos dados de densidade, que apresentavam distribuição simétrica e a hipótese intrínseca se mostrou plausível, foi possível notar tal qualidade do procedimento de, interpolação. Mesmo alterações nos parâmetros do modelo, mantida a consistência a nuvem de pontos estimada do variograma não mostraram diferenças marcantes nos resultados da validação cruzada, caracterizando a robustez citada.

Uma vez que a dependência espacial se mostra presente e pode ser detectada de alguma forma, há que se reavaliar as análises que supõe dados georeferenciados como independentes. Este é o caso, por exemplo, de experimentos de campo. Estimativas baseadas em mínimos quadrados ordinários podem ser substituídas pelas de mínimos quadrados generalizados onde a matriz de covariância incorpora a informação da dependência espacial. 


\section{REFERÊNCIAS BIBLIOGRÁFICAS}

AKAIKE, H. A new look at the statistical model identification. IEEE Transactions on Automatic Control, New York, 19(6): 716-23, 1974.

BARDOSSY, A. Notes on the robustness of the kriging system. Mathematical Geology, New York, 20(3): 189-204, 1988.

BARNES, R.J. The variogram sill and the sample variance. Mathematical Geology, New York, 23(4): 673-8, 1991.

BISHOP, T.; PETERSEN, B.; TRAYSER, D. Another look at the Statistician role in experimental planning and design. The American Statistician, Alexandria, 36(4): 387-9, 1982.

BOX, G.E.P. The importance of pratice in the development of statistics. Technometrics, Washington, 26(1): 1-8, 1984.

BOX, G.E.P.; HUNTER, W.G.; HUNTER, J.S. Statistics for Experimenters. New York, John Wiley, 1978. 653p.

BRAGA, L.P.V. Geoestatística e aplicações. São Paulo, IME-USP, 1990. $35 \mathrm{p}$. 
BREGT, A.K.; McBRATNEY, A.B.; WOPEREIS, M.C.S. Construction of isolinear maps of soil attributes with empirical confidence limits. Soil Science Society of American Journal, Madison, 55 (1): 14-9, 1991.

CAHN, M.D.; HUMMEL, J.W.; BROUER, B.H. Spatial analysis of soil fertility for site-specific crop management. Soil Science_Society of American Journal, Madison, 58: 1240-8, 1994.

CLARK, I. Pratical geostatistics. Essex, Applied Science Publ., 1979. $129 \mathrm{p}$.

CRESSIE, N. Fitting variogram model by weighted least squares. Mathematical Geology, New York, 17(5): 563-86, 1984.

CRESSIE, N. Kriging nonstationary data. Journal of American Statistical Association, Alexandria, 81: 625-34, 1986.

CRESSIE, N. Spatial prediction and ordinary kriging. Mathematical Geology, New York, 20(4): 405-21, 1988. [Erratum, Mathematical Geology, New York, 21(4):493-4, 1989.]

CRESSIE, N. Geostatistics. The American Statistician, Alexandria, 43(4): 197-202, 1989.

CRESSIE, N. Statistics for spatial data. New York, John Wiley, 1991. 900 p.

CRESSIE, N. \& HAWKINS, D.M. Robust estimation of the variogram. Mathematical Geology, New York, 12(2): 115-25, 1980.

DAVIS, B.M. Uses and abuses of cross-validation in geostatistics. Mathematical Geology, New York, 19(3): 241-8, 1987. 
DOURADO NETO, D. Variabilidade espacial das alturas de chuva e irrigação e potenciais da solução do solo. Piracicaba, 1979. 180p. (Mestrado -.Escola Superior de Agricultura "Luiz de Queiroz"/USP).

ENGLUND, E. \& SPARKS, A. Geo-EAS geostatistical enviromental assessment software. U.S. Environmental Protency Agency, Las Vegas, 1988. (EPA/600/4-88/033a).

GATES, C.E. A user's guide to misanalyzing planned experiments. Hortscience, New York, 26(10): 1262-5, 1991.

GRONDONA, M.O. \& CRESSIE, N. Using spatial considerations in the analysis of experiments. Technometrics, Washington, 33(4): 381-92, 1991.

GUERRA, P.A.G. Geoestatística operacional. Brasília, Ministério das Minas e Energia, 1988. 145p.

GUIMARÃES, E.C. Variabilidade espacial da umidade e densidade do solo em um latossolo roxo. Campinas, 1994. (Mestrado - Engenharia Agrícola/Unicamp).

HAHN, G.J. Experimental design in the complex world. Technometrics, Washington, 26 (1): 19-31, 1984.

HAMAKAWA, P.J. Variabilidade espacial de alguns componentes de produção de uma cultura de feijoeiro. Piracicaba, $1988.114 \mathrm{p}$. (Mestrado - Escola Superior de Agricultura "Luiz de Quiroz"/USP).

HAMLET, J.M.; HORTON, R.; CRESSIE, N. Resistant and exploratory techniques for use in semivariogram analysis. Soil Science Society of American Journal, Madison, 50: 868-75, 1986. 
HAWKINS, D.M. \& CRESSIE, N. Robust kriging - a proposal. Mathematical Geology, New York, 16(1): 3-19, 1984.

HIPEL, K.W. Geophysical model discrimination using the Akaike informaton criterion. IEEE Transactions on Automatic Control, New York, 26(2): 358-78, 1981.

HOAGLIN, D.C.; MOSTELLER, F; TUKEY, J.W. Uderstanding robust and exploratory data analysis. New York, John Wiley, 1983. 446p.

HOOKE, R. Getting people to use statistics properly. The American Statistician, Alexandria, 34: 39-42, 1980.

HOROWITZ, J. \& HILLEL, D. A critic of some recents attempts to characterize spatial variability. Soil Science Society of American Journal, Madison, 47: 614-5, 1983.

ISAAKS, E.H. \& SRISVASTAVA, R.M. An introduction to applied geostatistics. New York, Oxford University Press, 1989. 560p.

JOURNEL, A.G. Geostatistics for Enviromental Sciences. Las Vegas, Enviromental Protection Agency, 1988.

JOURNEL, A.G. Fundamentals of geostatistics in five lessons. Washington, American Geophysical Union, 1989. 40p.

KEMPTORNE, O. \& ALLMARAS, R.R. Erros and variability of observations. In: BLACK,C.A., ed. Methods of soil analysis. Madison, American Society of Agronomy, Soil Science Society American, 1986. p.1-31.

LANDIM, P.M.B. Introdução à geoestatística. Rio Claro, Unesp, 1988. 144p. (Publicação Didática, 3). 
LASLETT, G.M. Kriging and splines: an empirical comparation of their predictive performance in some applications. Journal of American Statistical Association, Alexandria, 89(426): 391-400, 1994.

LASLETT, G.M. \& McBRATNEY, A.B. Estimations and implications of instrumental drift, random measurement error and nugget variance of soil attributes - a case study for soil pH. Journal of Soil Science, Oxford, 41: 451-71, 1990.

LEGENDRE, P. Spatial autocorrelation: Trouble or new paradigm? Ecology, New York, 74(6):1659-73, 1993.

LI, D. \& LAKE, L.W. A moving window semivariance estimator. Water Resources Research, Washington, 30(5): 1479-89, 1994.

McBRATNEY, A.B. \& WEBSTER, R. Choosing functions for semivariograms of soil properties and fitting them to sample estimates. Journal of Soil Science, Oxford, 37: 617-39, 1986.

MORAES, S.O. Heterogeneidade hidráulica de uma terra roxa estruturada. Piracicaba, 1991. 141p. (Doutorado - Escola Superior de Agricultura "Luiz de Queiroz"/USP).

OLIVEIRA, M.S. Planos amostrais para variáveis espaciais utilizando geoestatística. Campinas, 1990. 100p. (Mestrado - Instituto de Matemática, Estatística e Ciência da Computação/Unicamp).

OLIVER, M.A. \& WEBSTER, R. Kriging: a method of interpolation for geographical information systems. International Journal of Geographical Information Systems, Hants, 4(3): 313-32, 1990.

PAPOULIS, A. Probability, randon variables and stochastic processes. New York, McGraw-Hill, 1991. 666p. 
ROBINSON, G.K. A role for variograms. Australian Journal of Statistics, Canberra, 32(3): 327-35, 1990.

SAMPER, F.J. \& RAMIREZ, J.C. Geoestadística - aplicationes a la hidrogeología subterránea. Barcelona, Universitat Politècnica de Catalunya, Centro International de Métodos Numéricos en Ingeniería, 1990. 484p.

SAMSA, G \& ODDONE, E.Z. Integrating scientific writing into a statistics curriculum: a course in statistically based scientific writing. The American Statistician, Alexandria, 48 (2): 117-9, 1994.

SEARLE, S.R. Linear Models. New York, John Wiley, 1971. 532p.

SILVA, A.P. Variabilidade espacial de atributos físicos do solo. Piracicaba, 1988. 98p. (Doutorado - Escola Superior de Agricultura "Luiz de Queiroz"/USP).

STARKS, T.H. \& FANG, J.H. The effect of drift on the experimental semivariogram. Mathematical Geology, New York, 14(4): 309-19, 1982.

STATGRAPHICS. Statistical graphics system. v:6.0. Statistical Graphics Corporation, 1987.

TABOR, J.A.; WARRICK, A.W.; PENNINGTON, D.A.; MYERS, D.E. Spatial variability of nitrate in irrigated cotton: I. Petioles. Soil Science Society of American Journal, Madison, 48: 602-7, 1984.

ÜNLU, K.; NIELSEN, D.R.; BIGGAR, J.W.; MORKOC, F. Statistical parameters characterizing the spatial variability of selected soil hydraulic properties. Soil Science Society of American Journal, Madison, 54(6): 1537-47, 1990. 
VALENTE, J.M.G.P. Geomatemática - lições de geoestatística. Ouro Preto, Fundação Gorceix, 1982. 8v.

Van ES, H.M. \& Van ES, C.L. Spatial nature of randomization and its effect on the outcome of field experiments. Agronomy Journal, Madison, 85: 420-8, 1993.

VIEIRA, S.R.; CASTRO,O.M.; TOPP, G.C. Spatial variability of some soil physical properties in tree soils of São Paulo, Brazil. Pesquisa Agropecuária Brasileira, Brasilia, 27(2): 333-341, 1992."

VIEIRA, S.R.; NIELSEN, D.R.; BIGGAR, J.W. Spatial varialility of fieldmeasured infiltration rate. Soil Science Society of American Journal, Madison, 45(2): 1040-8, 1981.

VIEIRA, S.R.; HATFIELD, J.L.; NIELSEN, D.R.; BIGGAR, J.W. Geostatistical theory and applications to variability of some agronomical properties. Hilgardia. Berkeley, 51(3): 1-75, 1983.

WEBSTER, R. Quantitative spatial analysis of soil in the field. Advances in Soil Science. New York, 3:1-70, 1985.

WEBSTER, R. \& McBRATNEY, A.B. On the Akaike Information Criterion for choosing models for variograms of soil properties. Journal of Soil Science, Oxford, 40(3): 493-6, 1989.

WEBSTER, R. \& NORTCLIFF, S. Improved estimation of micro nutrients in hectare plots of the Sonning series. Journal of Soil Science, Oxford, 35: $667-72,1984$.

WEBSTER, R. \& OLIVER, M.A. Sample adequately to estimate variograms of soil properties. Journal of Soil Science, Oxford, 43: 177-92, 1992. 
WILD, C. J. Embracing the "wider view"of statistics. The American Statistician, Alexandria, 48(2): 163-71, 1994.

$\wedge$ YOST, R.S.; UEHARA, G.; FOX, R.L. Geostatistical analysis of soil chemical properties of large land areas. II. Kriging. Soil Science Seciety of American Journal, Madison, 46: 1033-7, 1982. 